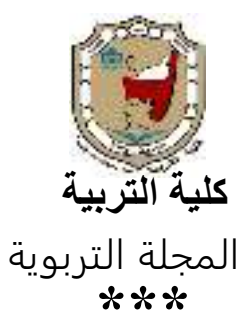

\title{
ماخص بحن
}

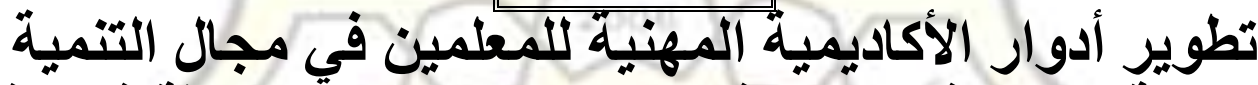

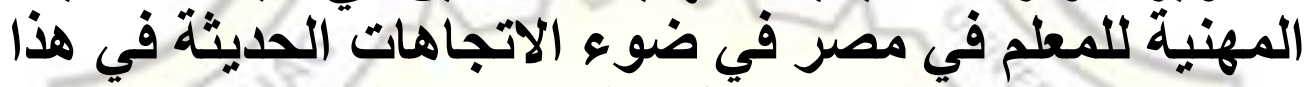

$$
\text { دراسة مبدانية فئية }
$$

$$
\text { إعداد }
$$

دكتور/ عماد صموئيل وهبه

أستاذ مساعد بقسم أصول التربية

$$
\text { كلية التربية - جامعة سوهاج }
$$

المجلة التربوية ـالعدد الثالث والثلاثون - يناير 2013م

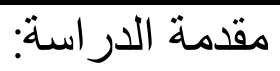

لقد بدأت الدول جميعها في مراجعة نظمها التعليمية وإعادة تخطيطها وتنظيمها ومن ثم

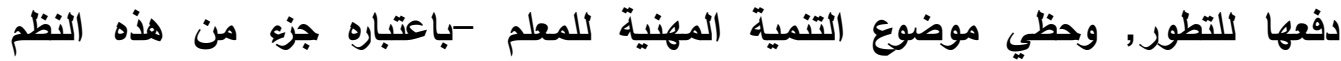


التعليمية- باهتمام خاص, حيث أصبحت هذه الدول تخطط للنهوض حاضراً ومستقبلاً بالتنمية المهنية للمعلم, وتخصص لها ميزانيات كبيرة باعتبارها أرقي أنواع التنمية وأكثرها

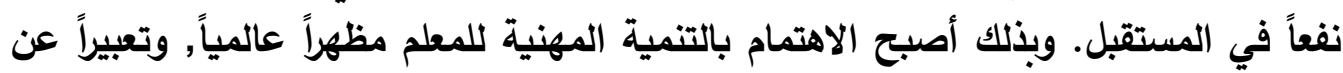

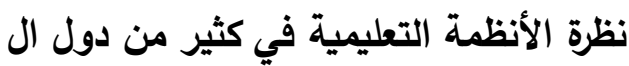
عالم إلي المعلم بوصفه أحد العناصر الفاعلة في تحقيق أي إصلي إصلاح أو تطوير في العملية التعليمية بأكملها, فمهما بلفت درجة كفاءة العناصر التعليمية الأخري ودرجة تطورها فإنها تبقي محدودة التأثير إذا لم يوجد المعلم الكفه الذي يسيه يسعي للتنمية المهنية المستمرة ولديه مهارات وقدرات مهنية متجددة.

كما أن الارجة الجامعية الأولي ومجموعة المعلومات والخبرات التي يحصل عليها المعلم في مؤسسات وكليات الإعداد الجامعي أصبحت غير كافية لممارسة المعلم للمهنة والأستمرار فيها, ولابد وأن يتبعها تنمية مهنية مستمرة, تجدد من خبراته والهات وتنمي من قدراته, فئه

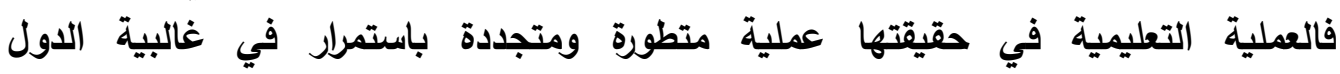
والمجتمعات في الوقت الراهن, وتحتاج إلي معلم من نوع خاص, معلم متطور ومتجدد في مئه مختلف جوانب عمله وشخصيته.

ومن هذا المنطلق فقد أنشئت الأكاديميات المهنية للمعلمين في كثير من دول العالم في

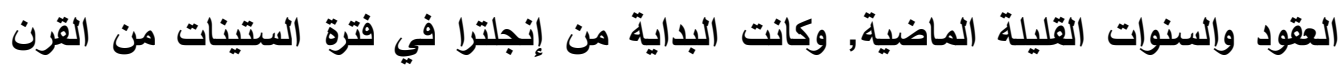

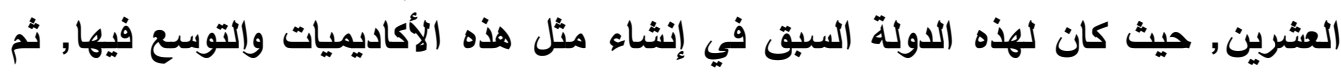

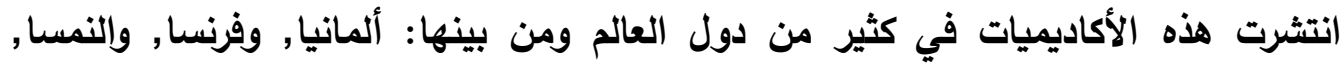

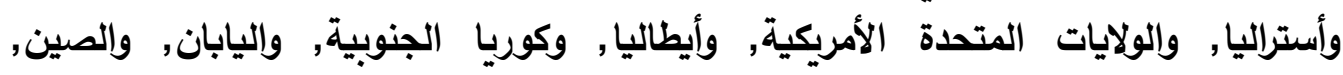

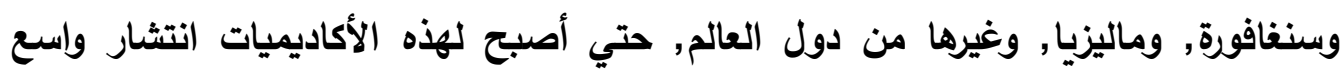
ووجود مؤثر في كثير من الدول, وتسهم بفاعلية في تطوير أنظمتها التعليمية التعليمية. وبناء علي ذلك فقد شكلت الأكاديميات المهنية للمعلمين أحد المظاهر البارزة للاهتمام

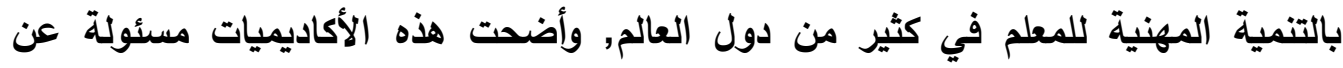

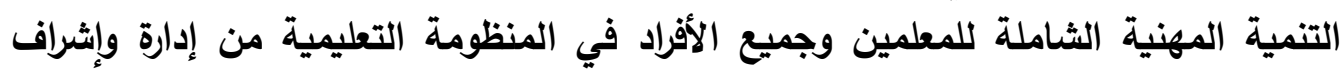
تربوي وغير ذلك, ومقابلة احتياجاتهم المهنية وتمكينهم من متابعة كل جديد في مجال التعليم .(American Academy for Teacher Excellence, 2012: 5)

وتقوم فلسفة إنثـاء الأكاديمية المهنية للمعلمين علي أسـاس أن تحسين أداء المعلم

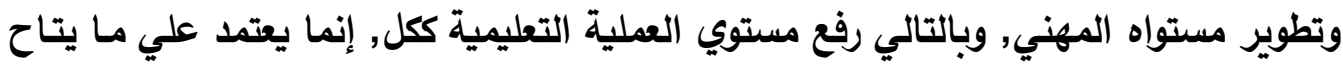


للمعلم من فرص للتنمية المهنية المستمرة, وكذلك تكوين علاقة بين المعلم ومؤسسات التنمية

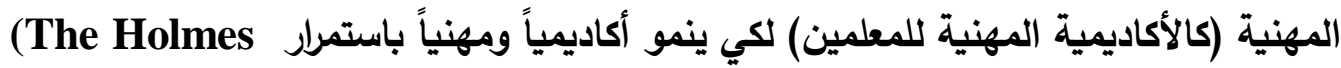
.Group, 2008: 11)

كمـا أن فلسفة عمل الأكاديمية المهنية للمعلم تجمـع عدة اتجاهـات تربويـة وفلسـفية

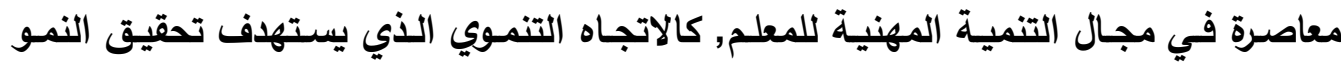

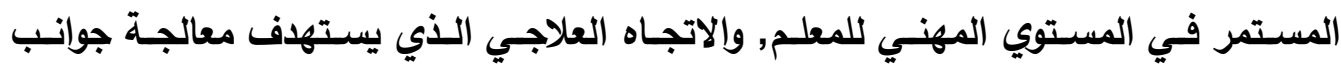
القصور والضعف لاي المعلم, والاتجاه التجديدي الذي يعتمد علي استخدام الأساليب الحديثة

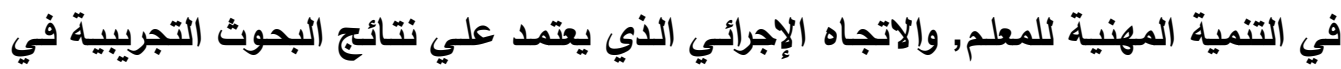
الاهتمـام بـالمعلم وتنميتهـه مهنيـاً (نبيل سـعد خليـل, 2009م, 445, و و

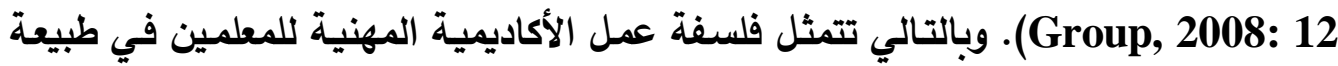
الجمع بين الاتجاهات الأربعة: التنموي, والعلاجي, والتجديدي, والإجرائي في التنمية المهنية للمعلم.

كما تمثل فلسفة إنشاء الأكاديمية المهنية للمعلمين أحد جوانب التطور في فلسفة التعليم عامةً, وترتكز في عملها علي المعلم نفسه واحتياجاته المهنية الحاضرة والمستقبلية, وإعطاء المعلم دور أكبر في تقرير ما يريده من تدريب وتنمية مهنية, مما يزيد من واقعية

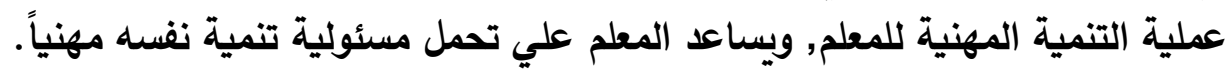
وقد برزت عديد من النماذج والخبرات الناجحة عالمياً في مجال عمل الأكاديمية المهنية

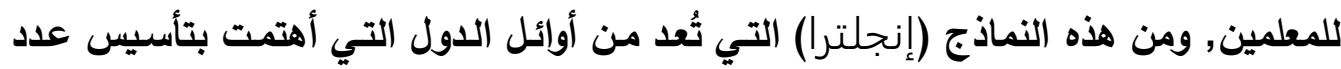

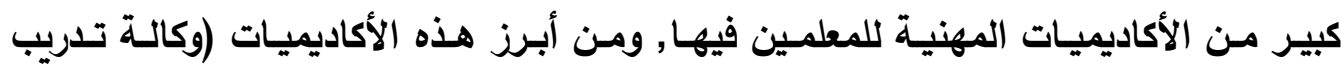

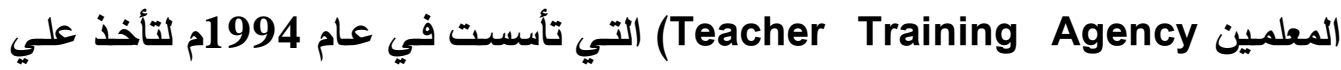
عاتقها مسئولية التنمية المهنية للمعلم في جميع المراحل الدراسية. وقد حققت الأكاديميات

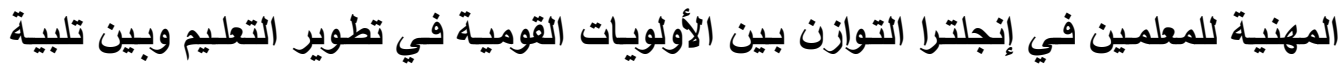

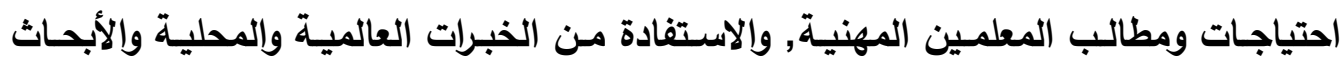

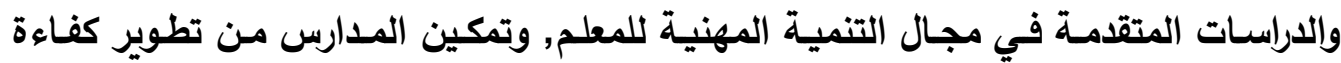

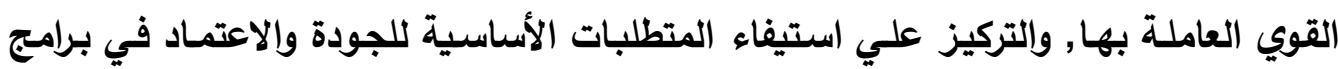

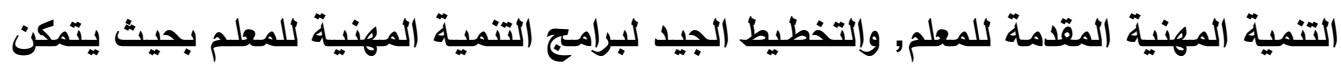
المجتمع مـن الحصـول علي درجـة المعلم الكفـ المؤهل, وإعداد خطط مستقبلية للتنميـة 
العدد (33) يناير 2013م

(Training and Development Agency for المهنية للمعلم في المملكة المتحدة .Schools (TDA), 2009: 1, Stella, V., 2012: 7-12)

وفي (اليابان) يعد نموذج التنمية المهنية للمعلم الياباني مثالاً يحتذي به من جميع

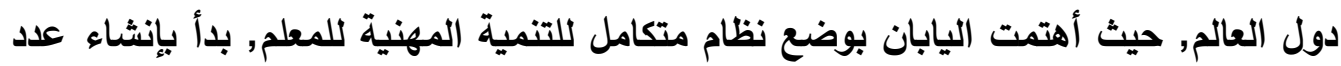

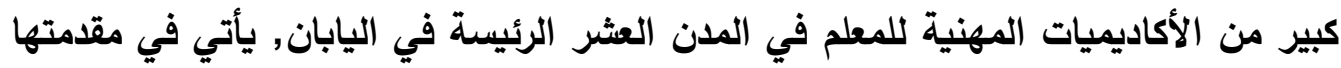

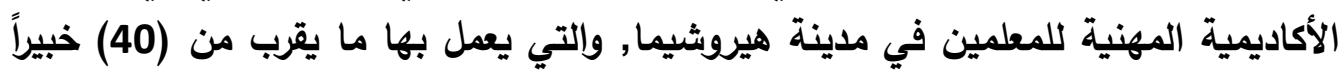

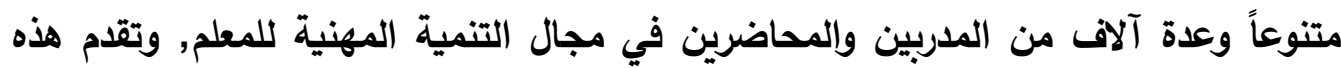
الأكاديمية ما يقرب من (160) برنامج مختلف ومتنوع للتنمية المهنية للمعلمين, هذه والهين البرامج

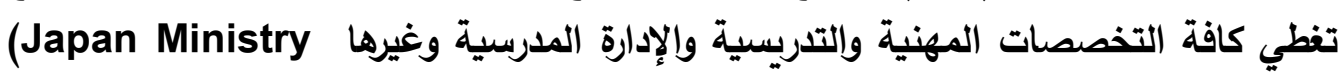
.of Education, 2010: 5)

أما في (الولايات المتحدة الأمريكية) فأسلوب عمل الأكاديمية المهنية للمعلمين

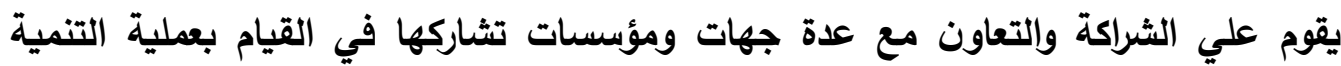

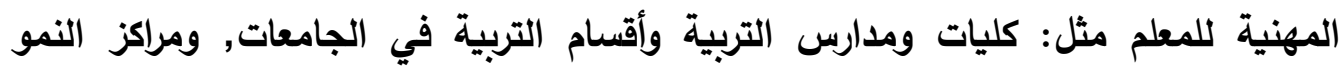
المهني للمعلم (كمركز ديترويت للنمو المهني للمعلمين), واللجنة القومية للتنمية المهنية للمعلمين بفروعها في مختلف الولايات, ومراكز التخطيط والسياسات التربوية, والاتحاد التئه

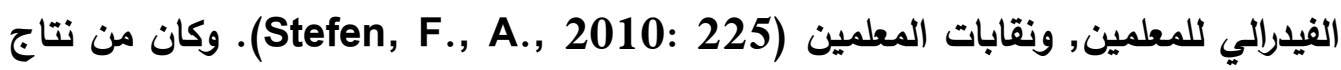
هذا التعاون والثراكة مع هذا العدد الكبير من المؤسسات هو أن جهود الأكاديميات المهنية

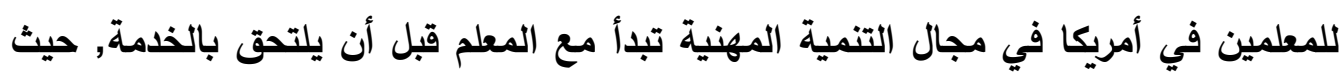
تثارك الأكاديميات المهنية في وضع الخطط والسياسات التي تسير عليها كليات إعداد

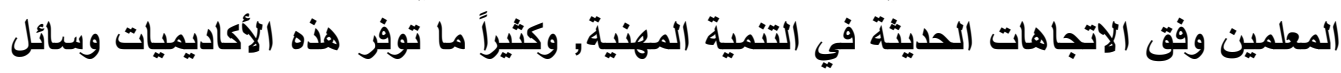
الدعم والمتابعة لطلاب كليات إعداد المعلمين ومساعدتهم في التعرف علي الجديد في في مجال

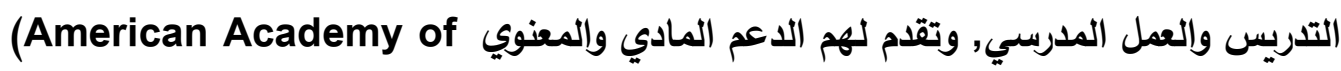
.Teachers of Singing: 2012: 1)

وفي (الصين) جاء إنشاء الأكاديميات المهنية للمعلمين لتعالج كثير من المشكلات التعليمية, ومثكلة نقص أعداد المعلمين في كثير من المدن الصينية وخاصة الصناعية

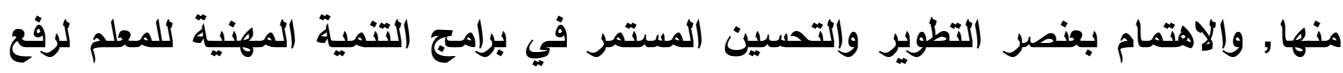

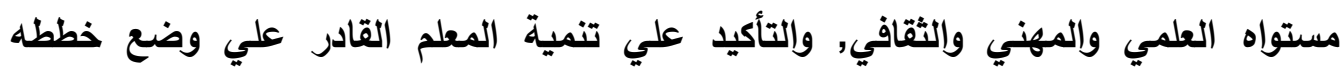
المستقبلية في مهنته, فلا قيام لعملية التعليم وتحقيق أهدافها المنشودة إلا بوجود المعلم 
الذي تتجسد فيه الخبرة والكفاءة وأساليب التفكير والعمل المطلوب (نبيل سعد خليل, 2005م:

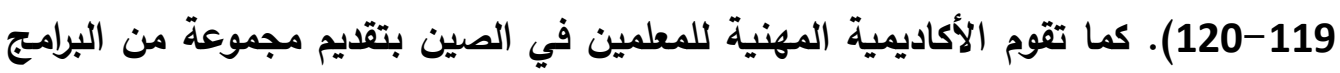

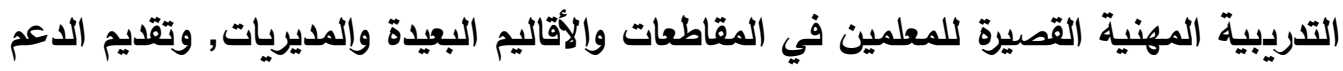

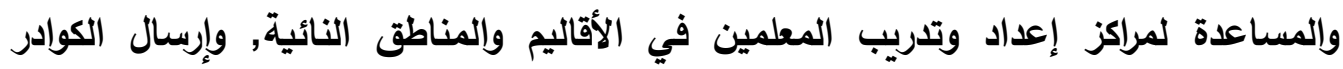
التدريبية إلي مدارس الأقاليم البعيدة لتدريب معلمي هذه المدارس وذلك في في بداية كل عام العام

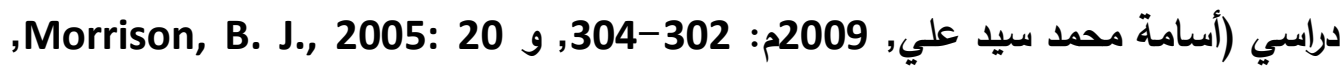

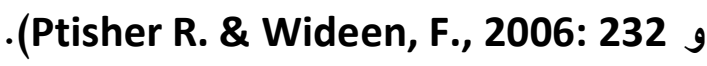
وفي (أستراليا) تم التوسع في إنشاء الأكاديميات المهنية للمعمين في السنوات الأخيرة حتي أصبح لديها ما يقارب (72) فرعاً ومقراً رئيساً موزعة علئ علي جميع الولايات الأيات الأسترالية

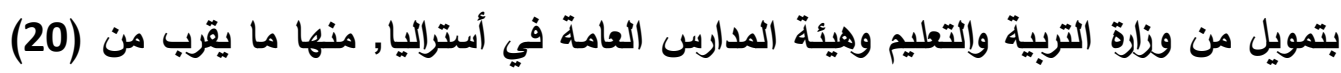

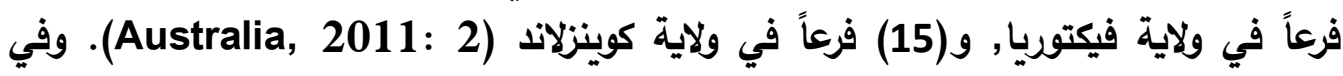

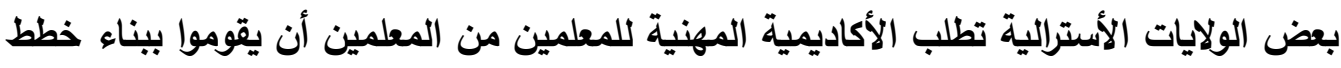

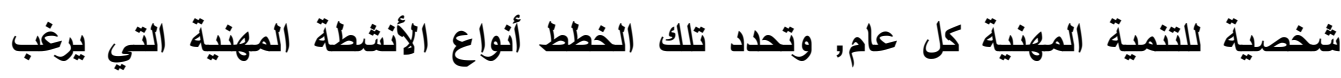

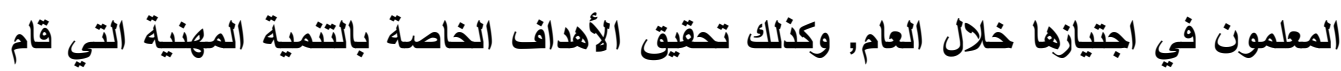

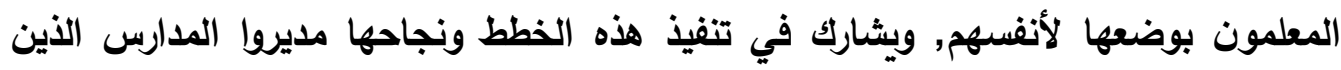

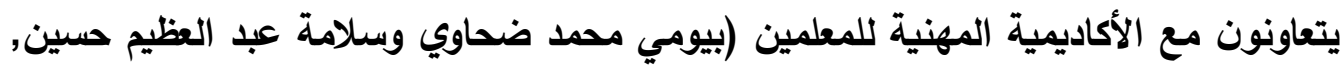
2009م: 304 وفي (كوريا الجنوبية) تميز أسلوب عمل الأكاديمية المهنية للمعلمين بكثير من

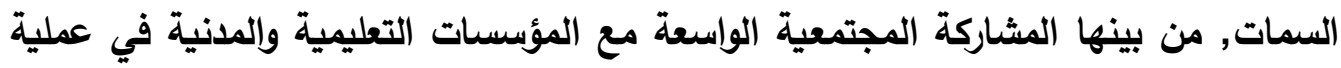

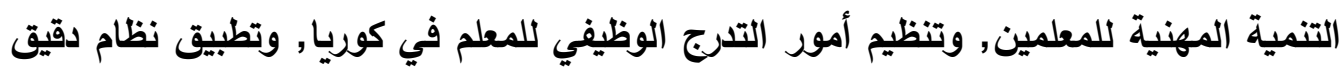

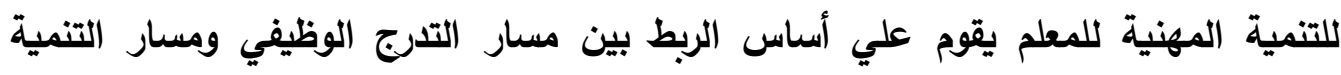
المهنية للمعلم, وتنظيم أمور منح المعلم رخصة للتربس, وتطبيق مجموعة من الاتجاهات

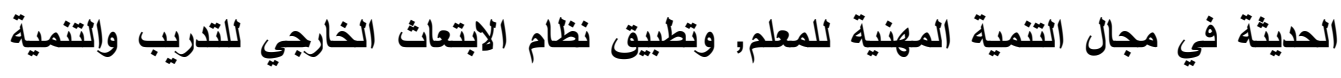

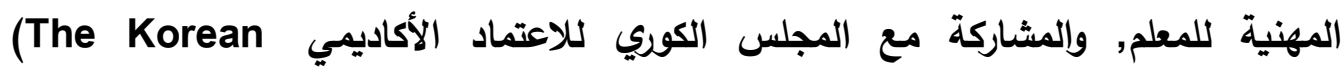
وذلك لتقييم واعتماد برامج التنمية المهنية للمعلم, Council for Accreditation) والمساعدة في اعتماد كليات ومؤسسات إعداد المعلم, ومن ثم القيام باعتماد المعلم مهنياً قبل

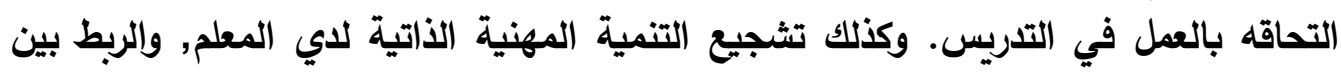

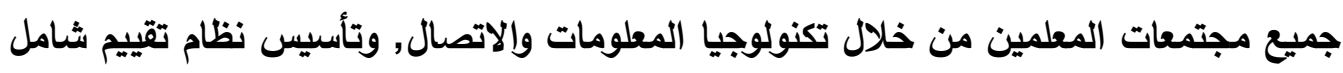


(Ministry of Education in Korea, 2011 : لبرامج التنمية المهنية وتحقيق جودتها .2, The Korean Federation of Teachers' Associations(KFTA), 2012: 1)

وفي (سنغافورة) يتركز عمل الأكاديمية المهنية للمعلمين علي إعادة النظر في تطوير دور المعلمين إزاء التلاميذ, وكذلك دور المؤسسات التعليمية ككل من خلال الإرتقاء بكلة الإكاءة

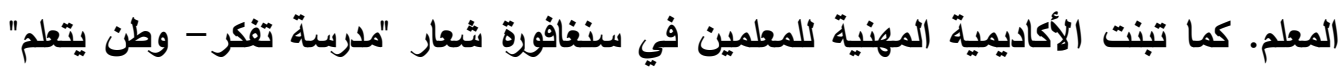
كثعار لتطوير التعليم في سنفافورة, وكان التركيز علي ضرورة أن ينتقل المعلمون بمفهوم التعليم

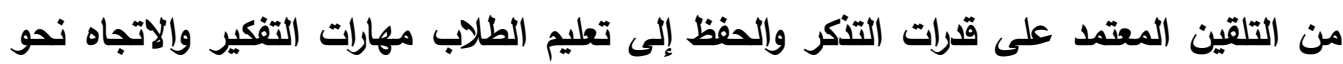
التعلم والتقصي الذاتي, وقد كان لهذا الاتجاه وقعه وصداه، حيث أبدات الأوساط التفان التربوية في

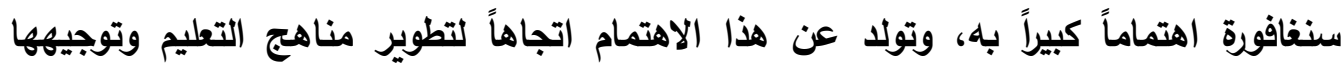

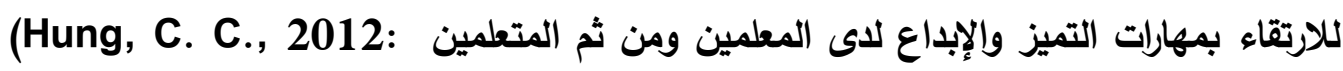

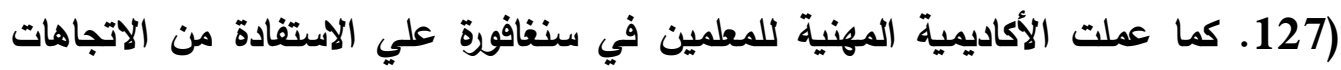

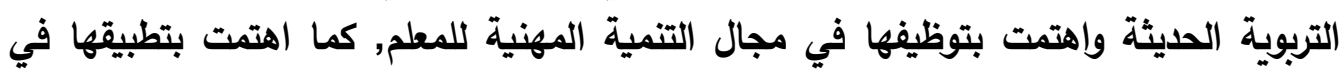
تعاملها مع المعلم وكيفية تنميته مهنياً.

ويتضح من خلال كل هذه النماذج والخبرات العالمية الرائدة مدي حرص الأكاديميات

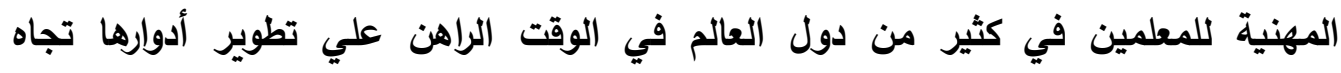

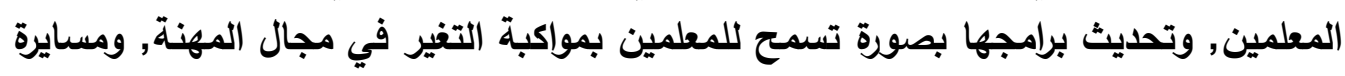

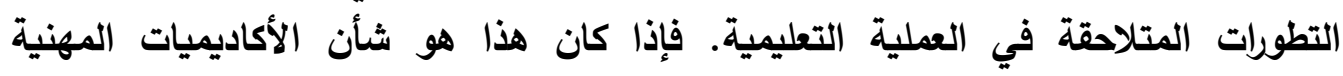

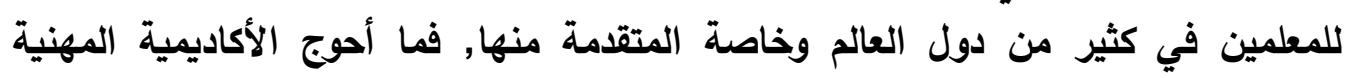

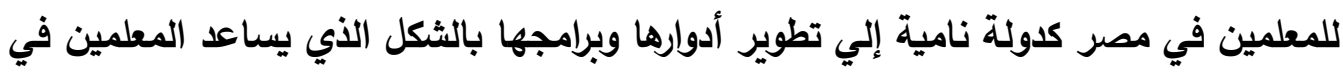

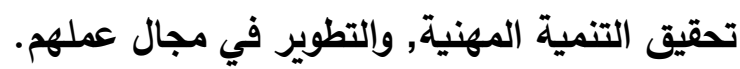
أما عن (مصر) فتعتبر من الاول التي تأخرت في الاهتمام بالتنمية المهنية للمعلم, حيث العاء

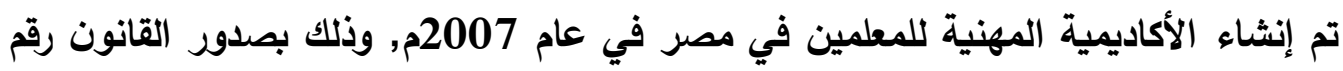

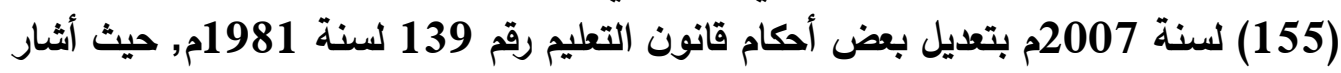
هذا القانون في مادته رقم (75) علي أن: تنشأ أكاديمية للمعلمين تسمى "الأكاديمية المهنية

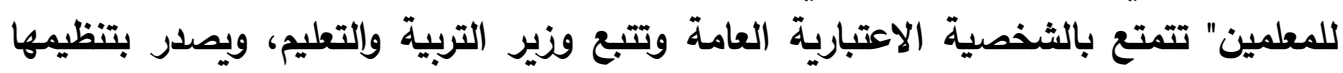

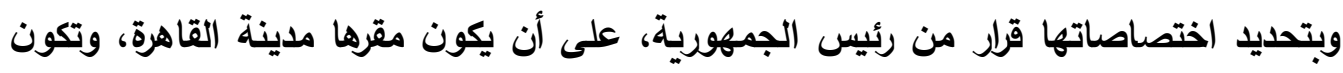

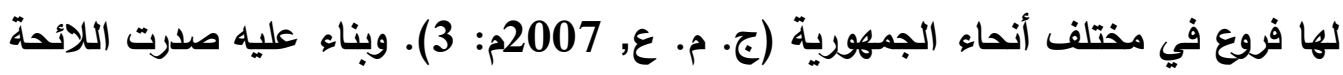
التنفيذية للقانون رقم (155) لسنة 2007م بقرار رئيس مجلس الوزراء رقم (2840) لسنة 
العدد (33) يناير 2013م

2007م (رئاسة مجلس الوزراء بمصر, 2007م), كما صدر القرار الجمهوري رقم (129)

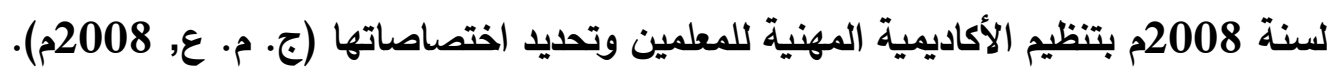
ومن هذا المنطلق تم إنثاء الأكاديمية المهنية للمعلمين بمقرها الرئيس بالمدينة التعليمية

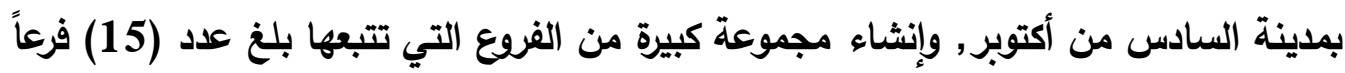
في محافظات: القاهرة, والإسكندرية, والثرقية, والغزبية, وبورسبعيد, ودمياط, والثينة والبحيرة, وكفر

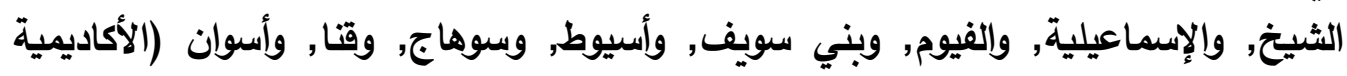

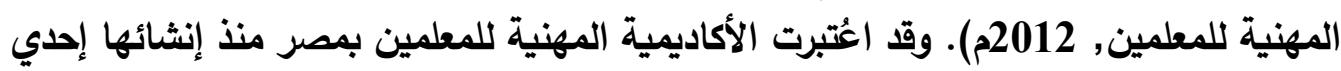

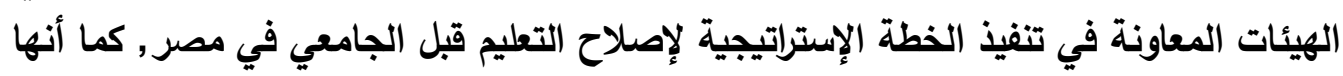

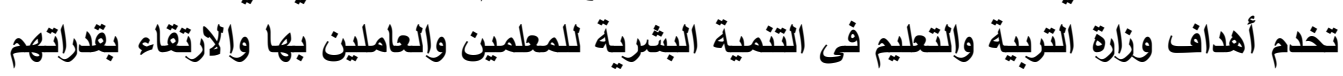

ومهاراتهم.

وعلي الرغم من إنثاء هذا العدد الكبير من الفروع للأكاديمية المهنية للمعلمين في

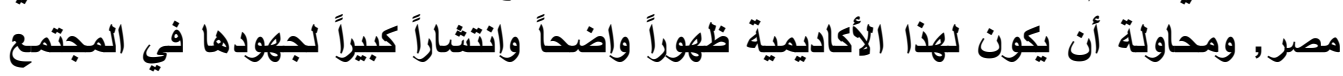

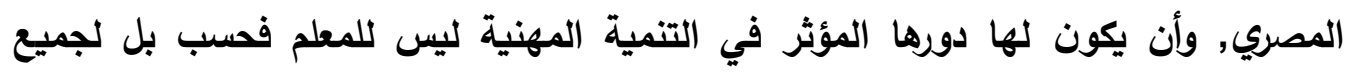

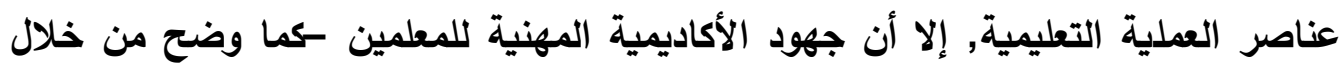

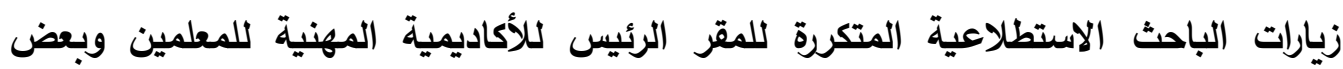

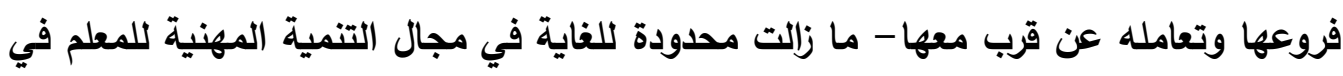

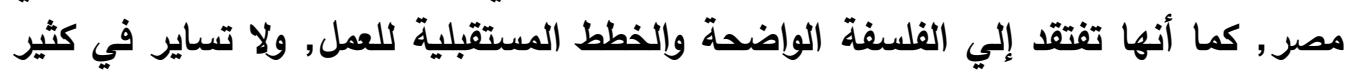
من الأحيان الاتجاهات الحديثة والمعاصرة في مجال التنمية المهنية للمعلم. وقد ظهرت في السنوات القليلة الماضية مجموعة كبيرة من الاتجاهات الحديثة في مجال التنمية المهنية في كثير من دول العالم, حيث تمثلت أهم هذه الاتجاهات في: الاتجاه

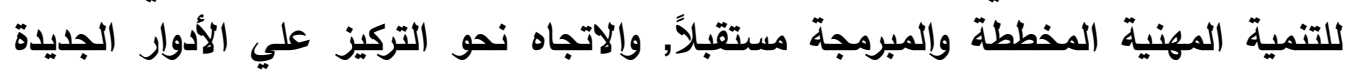

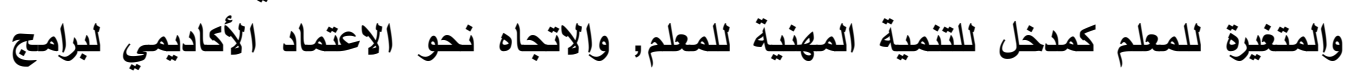

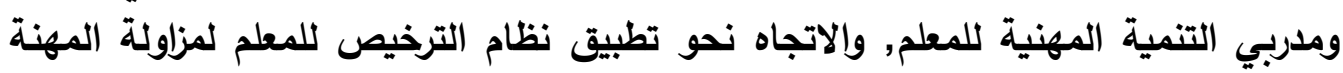

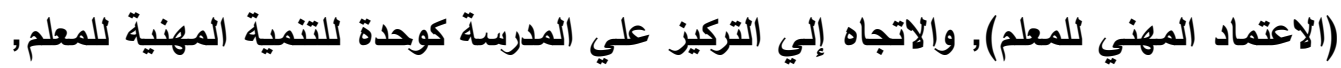
والاتجاه لاستخدام نماذج جديدة وأساليب وطرق حديثة في التنمية المهنية للمعلم, والاتجاه

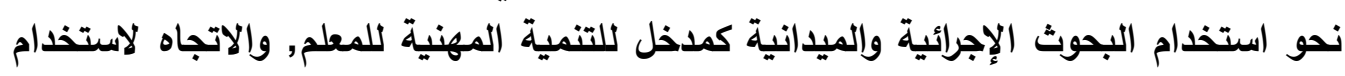
نظم التدريب من بُعد والتدريب الإكتروني في تلبية الاحتياجات المهنية للمعلم, والاتجاه إلبئي التركيز علي القدرات الإبداعية وتحقيق التميز كمدخل للتنمية المهنية للمعلم (وسوف تعرض الإنيل 
الداسة هذه الاتجاهات الحديثة للتنمية المهنية للمعلم بالتفصيل في القسم الثالث من الدراسة (الحالية).

وبذلك يتضح أن علي الأكاديمية المهنية للمعلمين في مصر ضرورة إعادة النظر فيما

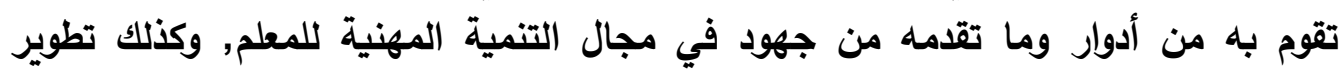

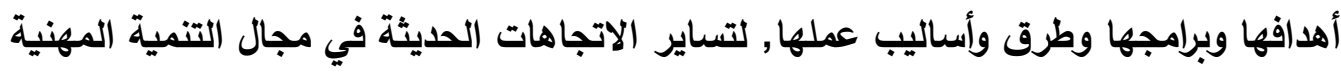

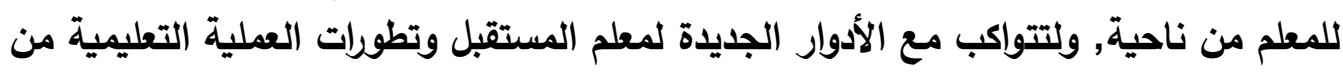
ناحية أخري.

ولكل ما سبق تتضح ضرورة ومبررات الاراسة الحالية في التوجه بالتطوير إلي

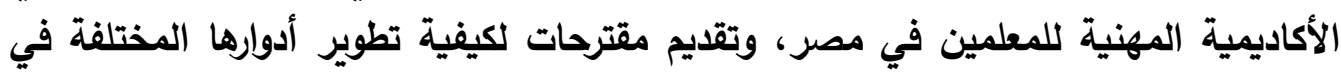

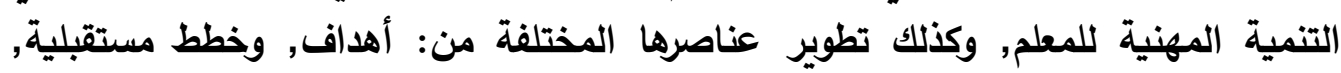

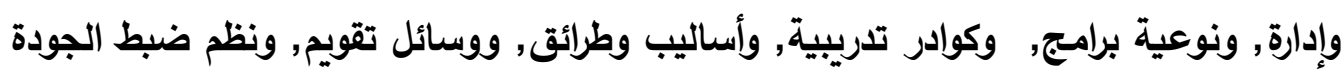

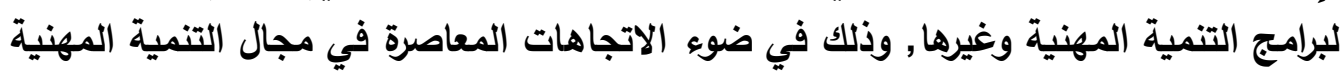
للمعلم.

مشكلة الدر اسة: تنطلق مشكلة الدراسة الحالية من أن الأكاديميات المهنية للمعلمين في كثير من دول

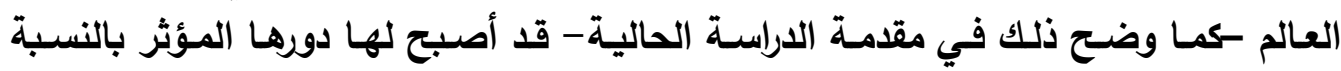
للمعلمين في جميع المراحل الدراسية في هذه الدول, كما اتجهت هذه الأكاديميات إلي التطوير

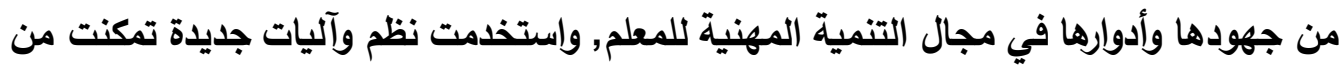

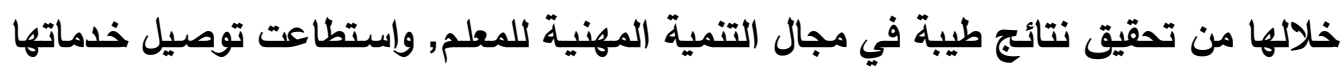
المهنية إلي المعلمين بأيسر الطرق وأكثرها فاعلية وأعمقها تأثيراً في المعلم.

وعلي الرغم من ذلك فأن الأكاديمية المهنية للمعلمين في مصر مـا تزال تعمل بفكر

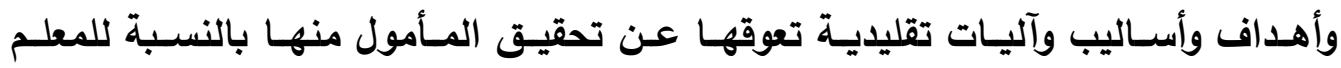

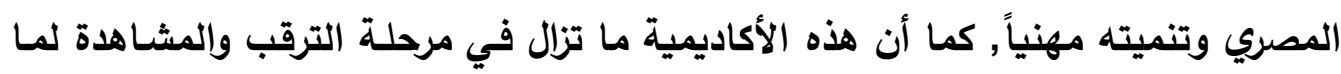

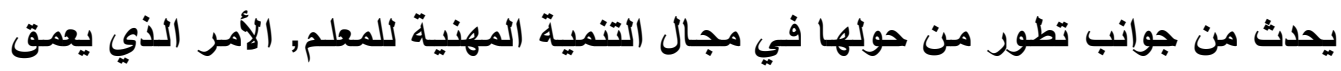

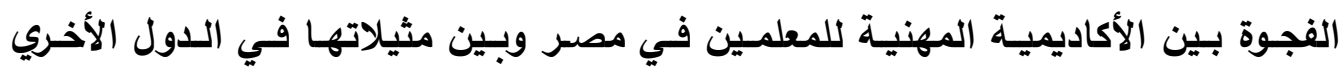
وخاصة المتقدمة منها.

ومن خلال تعامل الباحث عن قرب مع بعض فروع الأكاديمية المهنية للمعلمين (خاصة

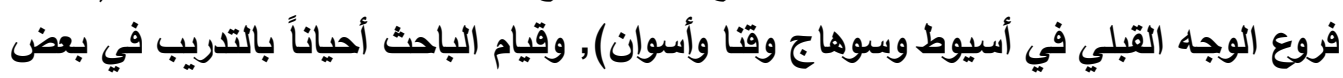


هذه الفروع, وكذلك من خلال المقابلات الثخصية مع بعض المسئولين في الأكاديمية المهنية للمعلمين وفروعها, وما دار معهم من أحاديث ومناقثات وحوارات حول مشكات مشكلات

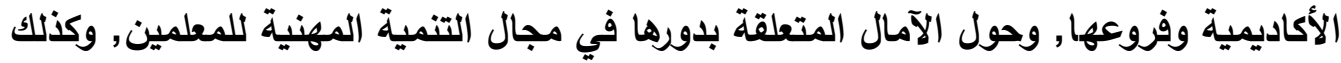
من خلال إطلاع الباحث علي بعض الدراسات والبحوث السابقة في مجال التنمية المهنية

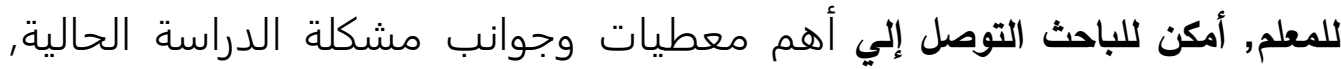
والتي تمثلت فيما يلي:

1- لم يحدث أي تطوير ملموس في أهداف وخطط وبرامج وأساليب التنمية المهنية داخل الأكاديمية المهنية للمعلمين في مصر علي الرغم من مرور 6 سنوات منذ في إنشاء هاء ها في عام 2007م. الأمر الأي يتطلب ضرورة إعادة النظر في كل هذه الجوانب, مما يساعد في في مرودي

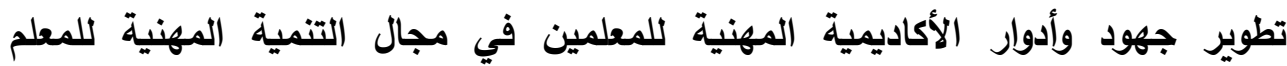
المصري. بالإضافة إلي عدم وضوح الفلسفة والسياسة التي تستند إليها الأكاديمية

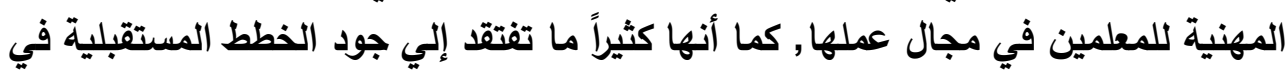

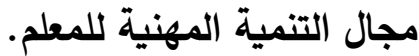

2- علي الرغم من إعلان المسئولين عن التعليم في مصر, وكذلك التربويين في أكثر من

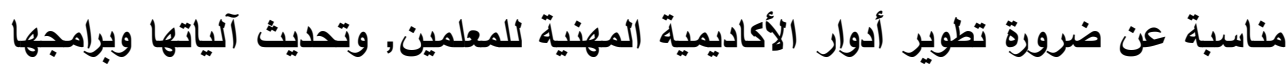

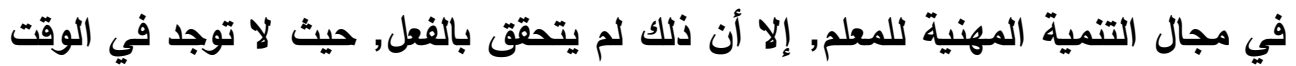

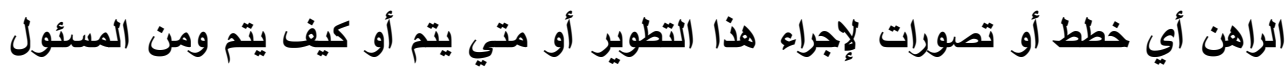
عنه والمشارك فيه.

3- أن موضوعات برامج التنمية المهنية المقدمة للمعلمين من خلال الأكاديمية المهنية لا يتم

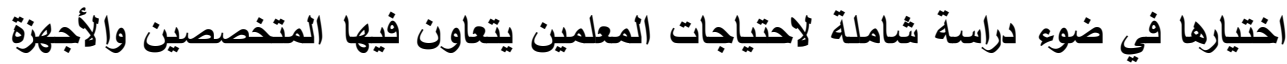

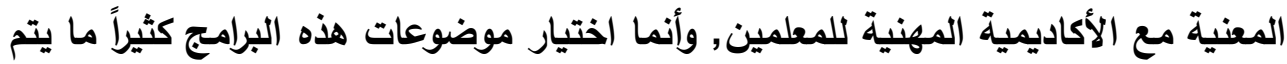
بثكل عشوائي ينتج عنه تكرار كثير من موضوعات هذه البرامج وسطحيتها وعدم الدقة في بناء ها.

4- اعتماد أغلب برامج التنمية المهنية المقدمة داخل الأكاديمية المهنية للمعلمين علي

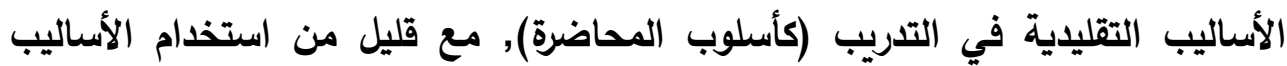

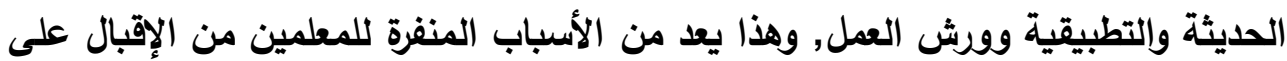
برامج التنمية المهنية. 
5- ضعف اهتمام الأكاديمية المهنية للمعلمين بتحقيق استمرارية برامج التنمية المهنية التي

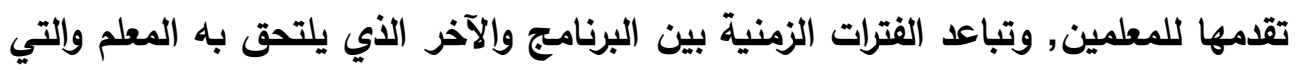
قد تصل عدة سنوات, مما يضعف ترسيخ مفهوم التنمية المهنية المستدامة لدي المعلمين. 6- رغم إنشاء (15) فرعاً للأكاديمية المهنية للمعلمين في مصر , إلا أن هذه الفروع لا تكفي

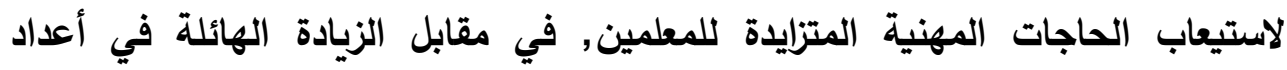
المعلمين وتخصصاتهم, وزيادة طلبهم علي التنمية المهنية.

7- سيادة المركزية الإدارية والمالية والتحكم المركزي من جانب المقر الرئيس للأكاديمية المهنية للمعلمين في كل ما يخص الفروع المختلفة للأكاديمية, وعدم توفر مساحة من من الأبه الحرية للفروع فيما يخص التمويل وتخطيط برامج التنمية المهنية المقدمة للمعلمين. 8- رغم أن قانون إنثاء الأكاديمية المهنية للمعلمين في مصر رقم (155) لسنة 2007م ينص علي تعاون الأكاديمية مع كليات التربية في كل خططها وأنثطتها وبرامجها وتنفيذها (ج. م. ع, 2007م: 3), إلا أن هذا التعاون لا يتحقق في كثير من الأحيان نتيجة أن أن فئل

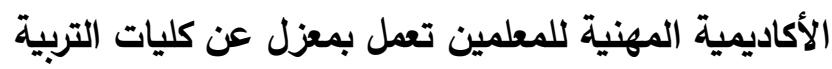

9- المعلمون في مصر كثرة تفوق في عددها أصحاب المهن الأخري, وهي كثرة مجردة في غالبيتها من قوة الكيف, وبالتالي فهذه الكثرة تحتاج إلي التنمية المهنية المستمرة , وهذا المها ما يدعو إلي الاهتمام بدراسة الأكاديمية المهنية للمعلمين في مصر وكيفية تطوير أدوارها تجاه المعلمين.

10- أظهرت الزيارات الاستطلاعية المتكرة التي قام بها الباحث للمقر الرئيس للأكاديمية

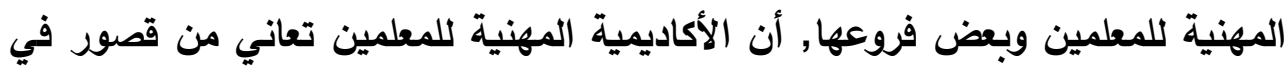

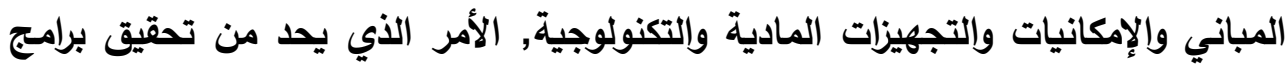

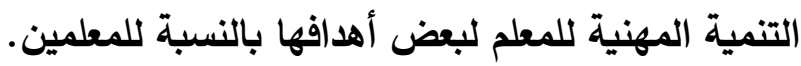
11- أن كثير من برامج التنمية المهنية التي تقدمها الأكاديمية المهنية للمعلمين لا تساير إلي حد

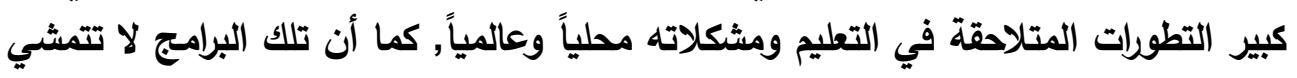
مع الاتجاهات التربوية المعاصرة في مجال التنمية المهنية للمعلم. 12- توجد عديد من الخبرات والنماذج والتجارب الدولية المتميزة والناجحة سكما وضح ذلك في

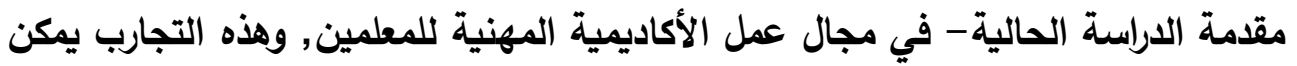


الإفادة منها في تطوير الأكاديمية المهنية للمعلمين في مصر, وتحديث أدوارها تجاه المعلمين وتنميتهم مهنياً.

كما تبرز مشكلة الدراسة الحالية من خلال ما أشارت إليه نتائج بعض الاراسات (مثل:

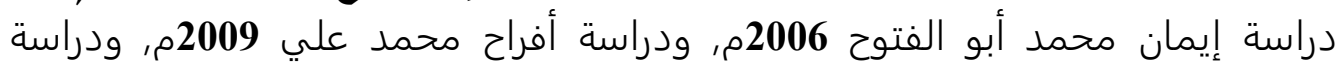

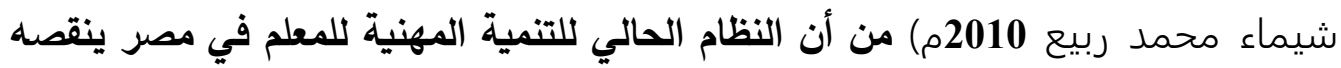

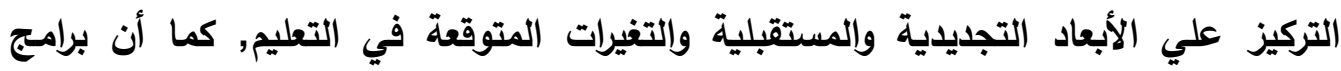

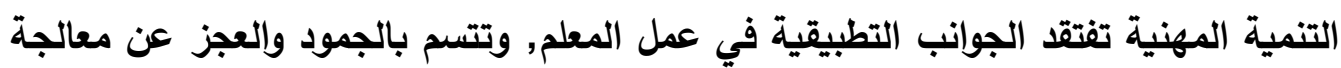

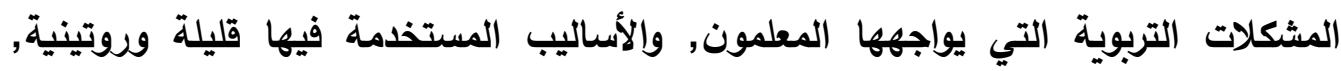
والمدربون غير مؤهلين, وعدم كفاية التقويم.

كما يوجد ضعف في التنسيق والتعاون بين المؤسسات والجهات المعنية بالتنمية المهنية للمعلم في مصر, وفي مقدمتها مراكز وإدارات وأقسام التدريب في وزارة التربية والتعليم

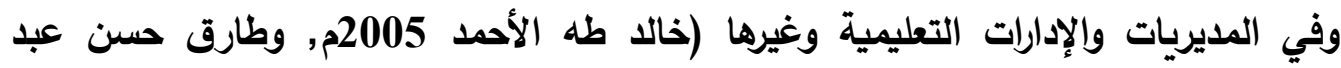

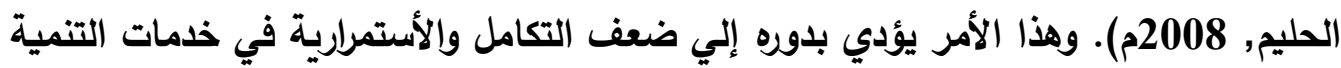

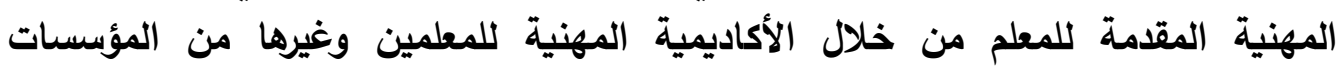

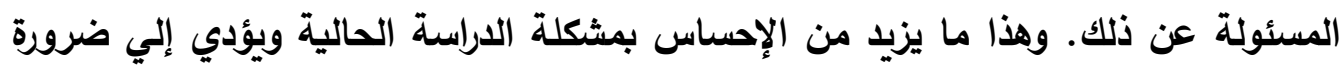
إجرائها.

كما تتضح مشكلة الدراسة الحالية من خلال ما توصلت إليه "دراسة إيهاب مصطفي

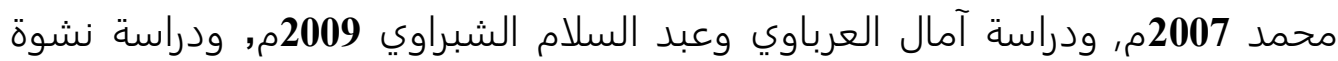

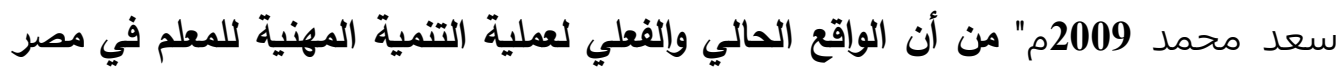
يعاني كثير من جوانب القصور والضعف, بجانب تقليدية وجمود برامج التنمية المهنية المقدمة

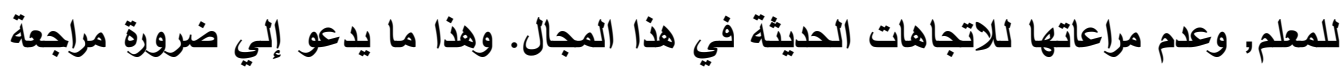

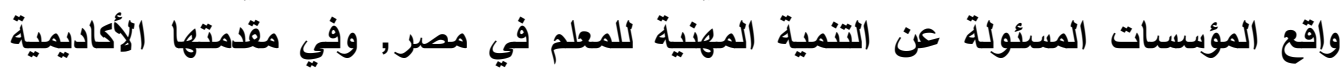
المهنية للمعلمين وإحداث تطوير حقيقي في جهودها وأدوارها تجاه المعلم. وكذلك ما توصلت إليه "دراسة ماهر أحمد محمود 2005م, ودراسة نبيل رمضان السيد وآخرون 2008م, ودراسة ماهر أحمد حسن 2011م" من أن برامج التنمية المهنية

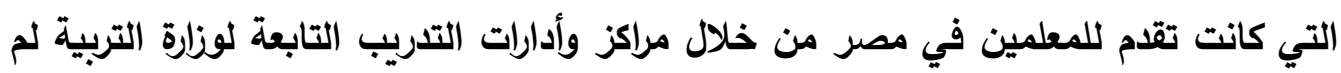
تحقق الأهداف المرجوة منها, فضلاً عن أنها تفتقد إلي الارتباط بالواقع التعليمي ومشكلاتله ماته

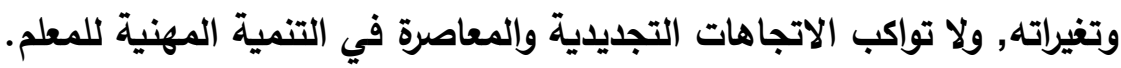


كما تبرز مشكلة الدراسة الحالية من الفجوة الواسعة بين موقف الأكاديميات المهنية للمعلمين في كثير من دول العالم الآن من تطبيق نظام الترخيص للمعلم بمزاولة المهنة

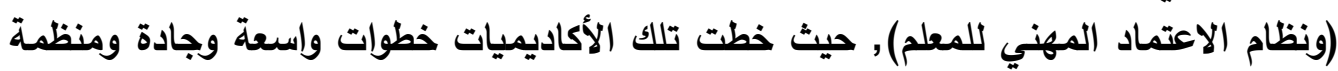

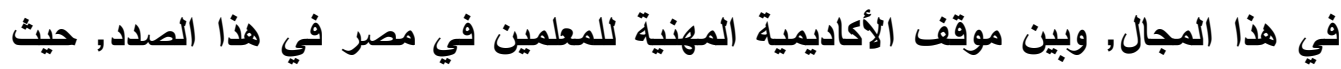

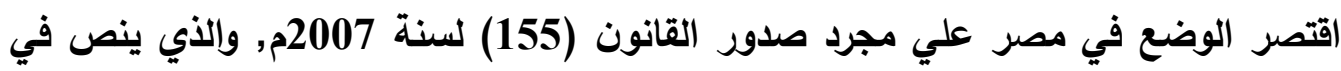
بعض مواده علي ضرورة حصول المعلم علي ترخيص بمزاولة المهنة من الأكاديمية المهنية

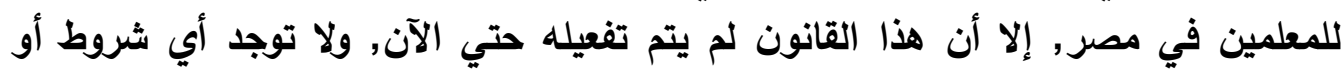

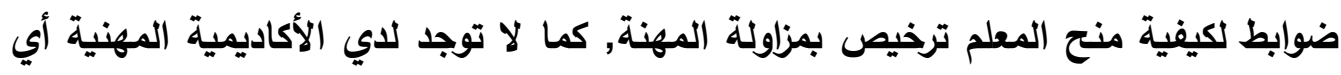
صلاحيات لتفعيل هذا القانون.

ومما سبق يمكن تحديد مشكلة الدراسة الحالية في أن الأكاديمية المهنية للمعلمين في

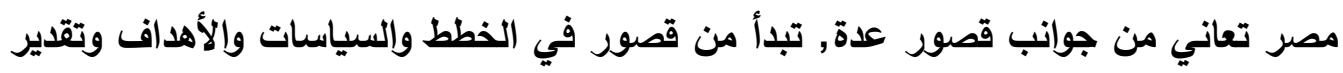

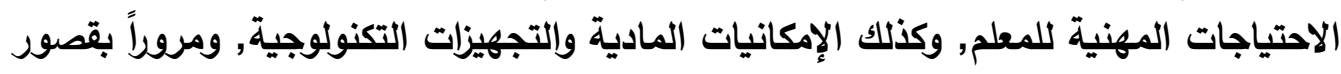

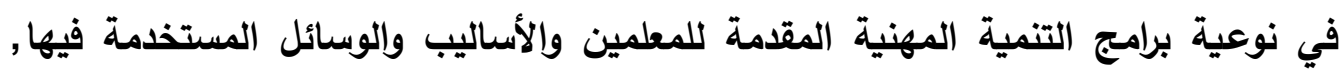

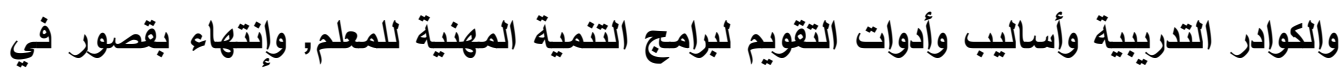
النواحي الإدارية والإثرافية. بجانب عن عدم مواكبة أدوار الأكاديمية المهنية للمعلمين المهنية للمعلمين في مصر للاتجاهات الحديثة وللأبعاد التجديدية والمستقبلية فوالإنية في مجال

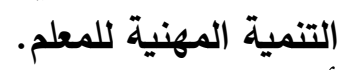
أسئلة الدر استة:

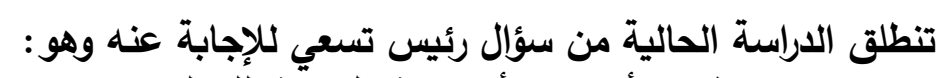

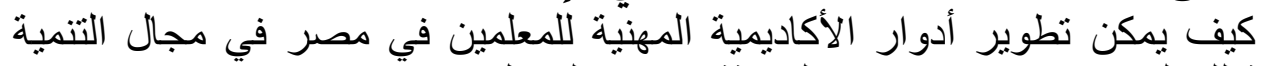

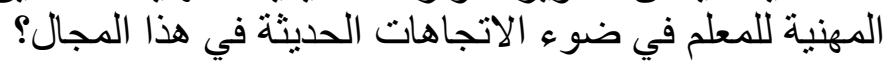

وإجابة هذا السؤال تتطلب إجابة مجموعة من الأسئلة الفرعية التي تعتبر بمثابة نقاط

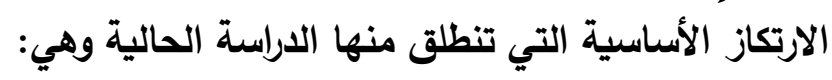
1- ما أهداف الأكاديمية المهنية للمعلمين في مصر؟ وما فلسفتها ومقوماتها ومبررات تطويرها؟.

2- ما أهم الاتجاهات الحديثة في مجال التنمية المهنية للمعل؟. 
3- ما واقع أدوار الأكاديمية المهنية للمعلمين في مجال التنمية المهنية للمعلم في مصر؟ وما أهم المعوقات التي تواجهها؟.

4- ما ملامح التصور المقترح لتطوير أدوار الأكاديمية المهنية للمعلمين في مصر في ضوء

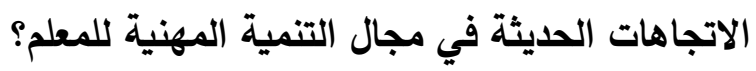

$$
\text { أهداف الدراست: }
$$

يتمثل الهدف الرئيس للاراسة الحالية في تطوير أدوار الأكاديمية المهنية للمعلمين في

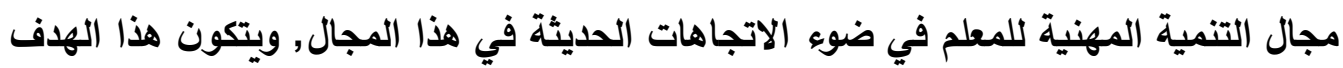

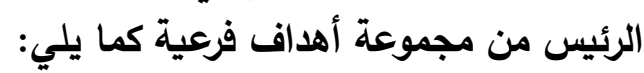

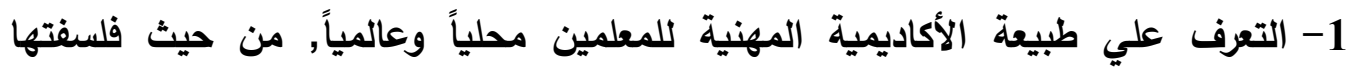
وأهدافها ومقوماتها, وإبراز مدي الاهتمام العالمي بتطوير الأكاديمية المهنية للمعلمين

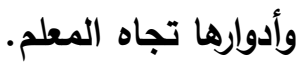
2- التعرف علي أهم الاتجاهات التربوية الحديثة في مجال التنمية المهنية للمعلم, والاسترشاد

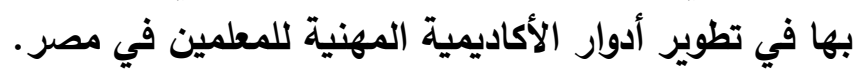
3- إبراز أهم المبررات التي تدعو إلي تطوير الأكاديمية المهنية للمعلمين في الوقت الرئ الراهن,

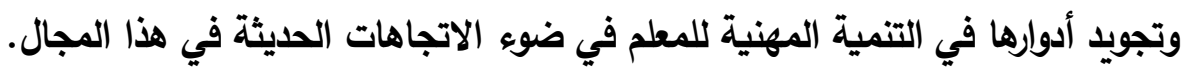
4- التعرف علي أهم النماذج والخبرات العالمية الرائدة في مجال عمل الأكاديمية المهنية للمعلمين, وكيفية الإفادة منها في مصر .

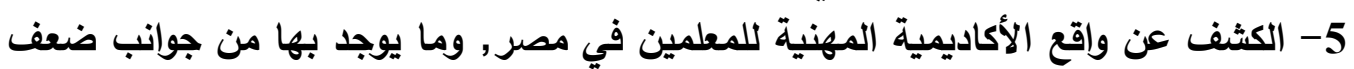
وقصور تؤثر في أدوارها في مجال التنمية المهنية للمعلم. 6- الكثف عن أهم المعوقات التي تواجه الأكاديمية المهنية للمعلمين, وتحد من أدوارها في في المالية مجال التنمية المهنية للمعلم, وكيفية التفلب عليها.

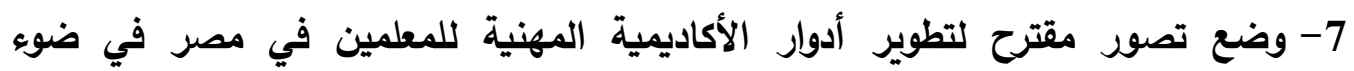
الاتجاهات الحديثة في مجال التنمية المهنية للمعلم. أهمية الدر اسة وقيمتها التربوية: تظهر أهمية الدراسة الحالية وقيمتها التربوية من خلال أهميتها النظرية وكذلك أهميتها التطبيقية وذلك علي النحو التالي: أولاً: الأهمية النظرية ولية للدر استة: تكتسب الاراسة الحالية أهميتها النظرية من خلال ما يلي: 
1- أهمية الموضوع الذي تتصدي له الدراسة الحالية ألا وهو الأكاديمية المهنية للمعلمين في

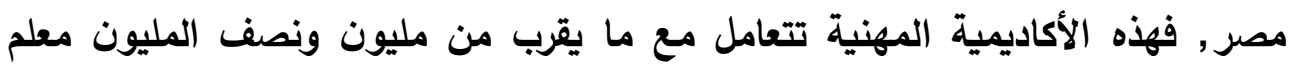

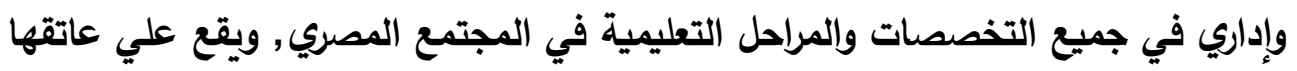

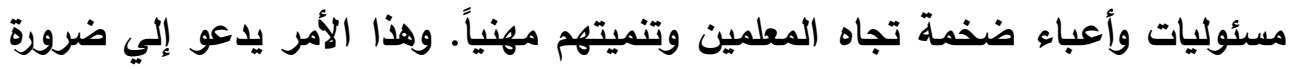

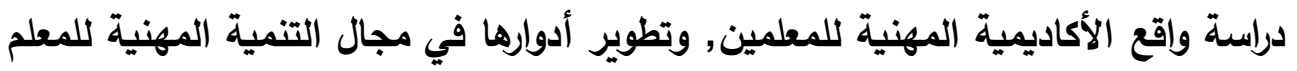
في ضوء الاتجاهات الحديثة.

2- تعد الأكاديميات المهنية للمعلمين من أكثر المؤسسات المهنية نمواً وإنتثاراً حول العالم,

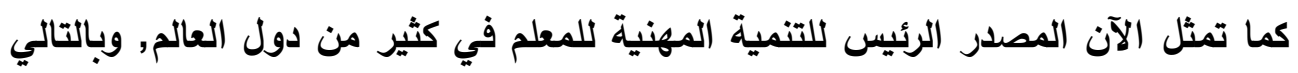

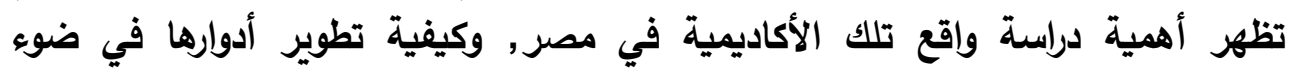

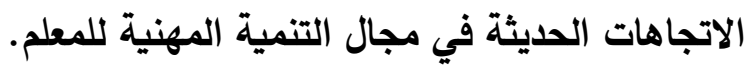

3- تأتي الدراسة الحالية مواكبة للتوجهات التربوية المحلية والعالمية الحديثة, والتي تدعو التاتئ

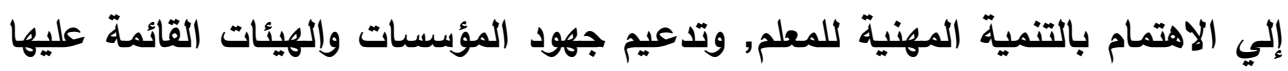
وفي مقدمتها الأكاديمية المهنية للمعلمين.

4- تأتي الدراسة الحالية استجابة لتوصيات عديد من المؤتمرات والدراسات التربوية في السنوات الأخيرة, والتي طالبت بضرورة تطوير جهود جميع المؤسسات والهيئات المعنية بالتنمية المهنية للمعلم في مصر.

5- إن تطوير مؤسسات التنمية المهنية للمعلمين بصفة عامة, وتطوير الأكاديمية المهنية

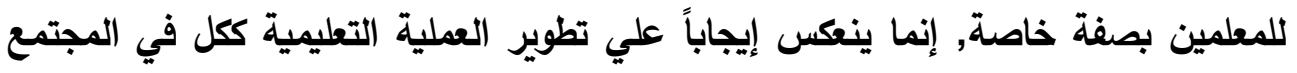

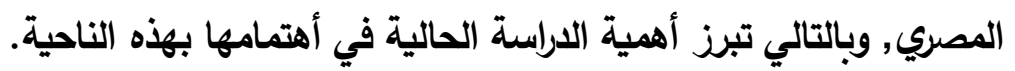

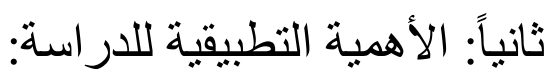
تكتسب الدراسة الحالية أهميتها التطبيقية من خلال ما لإلية:

1- تقدم الدراسة الحالية للقائمين علي الأكاديمية المهنية للمعلمين في مصر تصوراً مقترحاً

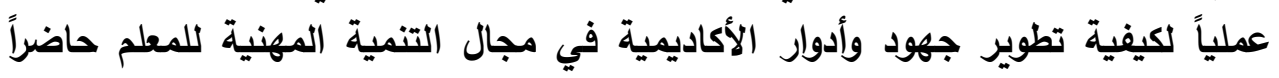
ومستقبلاً, وذلك في ضوي الاتجاهات الحديثة في هذا المجال. 2- توجه الاراسة الحالية نظر المسئولين عن الأكاديمية المهنية للمعلمين للإفادة من خبرات

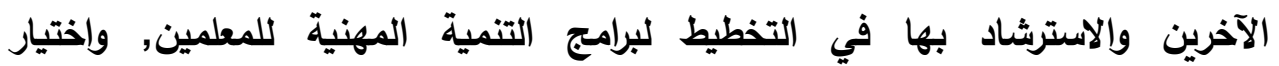
موضوعاتها, وأساليب تقديمها, واختيار كوادرها التدريبية, ووسائل تقويمها. 
3- تساعد الدراسة الحالية مخططي السياسات التعليمية وصانعي القرار في الكثف عن مثكلات التنمية المهنية للمعلم في مصر , وسبل التغلب ملية عليها وحلها.

4- تفيد الاراسة الحالية المسئولين عن إدارات وأقسام التدريب والتخطيط بوزارة التربية والتعليم والمديريات والإدارات التعليمية في كيفية تطوير منظومة التنمية المهنية للمعلم المئم في مصر, والمساعدة في تجديد المؤسسات المعنية بالمعلم.

5- تفيد نتائج الدراسة الحالية فئات مهنية وبحثية عديدة مثل: مسئولي التعليم بجميع مراحله, ومديري المديريات والإدارات التعليمية, ومديري المدارس, والقائمين علي ولئي وحدات

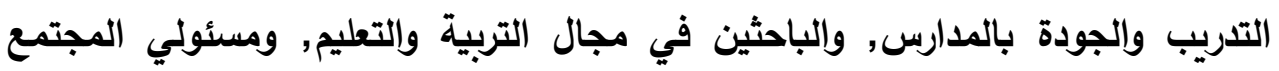

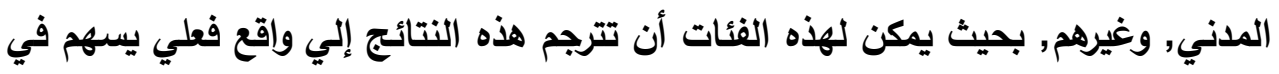

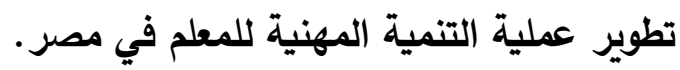

6- يمكن تطبيق التصور المقترح للاراسة الحالية عملياً في أكثر من مؤسسة أو هيئة معنية بتنمية المعلم مهنياً. وهذا ما يبرز الأهمية التطبيقية للاراسة الحالية.

من المؤكد أن موضوع الدراسة يفرض نوع المنهج المستخدم فيها, وعلي ضوء طبيعة منهج الدر اسة:

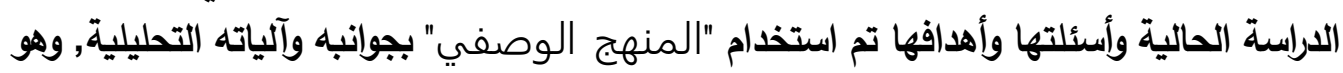
منهج لا يقف عند مجرد وصف الظاهرة موضع الاراسة, بل يسعي لتحليلها وتفسيرها لاستنباط

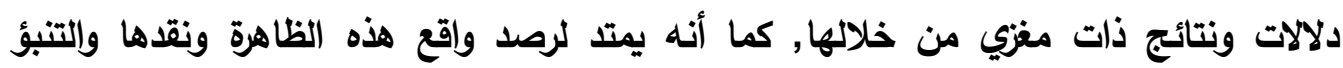
بمستقبلها.

وقد استخدم المنهج الوصفي في الاراسية الحالية من خلال الإجراءات والخطوات المنهجية التالية:

1- جمع وتحليل الأدبيات التربوية المرتبطة بتطوير مؤسسات التنمية المهنية للمعلم وفي

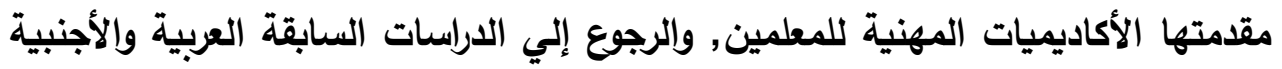
والكتابات والمؤتمرات والرسائل العلمية وغيرها في مجال الدراسة الإئ الحالية. 2- الرجوع للقوانين والتشريعات التي تناولت إنشاء الأكاديمية المهنية للمعلمين في مصر, وكري وكذلك اللوائح والقرارات الوزارية التي تنظم العمل فيها وتحدد اختصاصاتها وهياكلها الإدارية والتنظيمية. 
العدد (33) يناير 2013م

3- تحليل جوانب الأكاديمية المهنية للمعلمين من حيث: فلسفتها وأهميتها وأهدافها

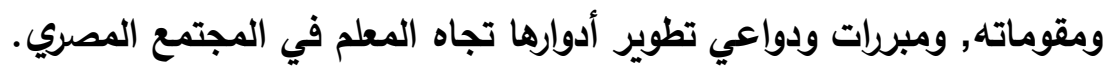

4- تحليل أهم الاتجاهات الحديثة في مجال التنمية المهنية للمعلم وخاصة في الدول المتقدمة تعليمياً وتربوياً, وتحديد أهم جوانب الاستفادة منها في مجال المال عمل الأكاديمية المهنية للمعلمين في مصر - المعيا وتربون

5- استقراء وعرض بعض النماذج والخبرات العالمية الناجحة في مجال عمل الأكاديمية

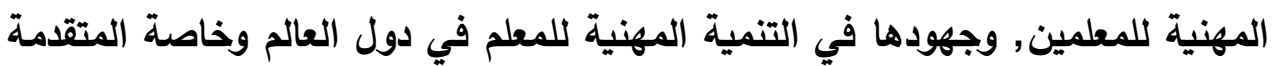
منها, وكيفية الاستفادة منها في الاراسة الحالية.

6- الإعداد للاراسة الميدانية وبناء أدواتها (الاستبيان, واستمارة المسح الميداني للإككانيات

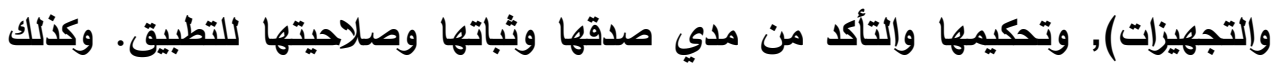

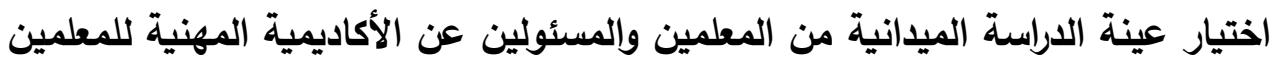
وفروعها في مصر, وتطبيق أدوات الدراسة واستخلاص النتائج ومعالجتها إحصائياً

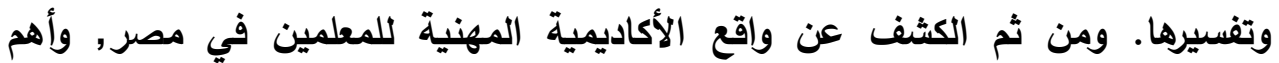
المعوقات التي تحد من أدوارها في مجال التنمية المهنية للمعلم. 7- توظيف جميع الإجراءات والخطوات السابقة في بناء التصور المقترح لكيفية تطوير أدوار الأكاديمية المهنية للمعلمين في مصر في ضواء الاتجاهات الحديثة في مجال التنمية

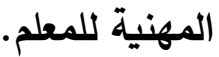




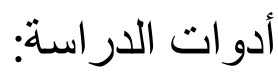

لتحقيق أهداف الاراسة الحالية وللإجابة عن بعض أسئلتها, وخاصة تلك الأسئلة المتعلقة بالجانب التطبيقي والميداني للدراسة والمرتبطة بالكشف عن واقع الأكاديمية المهنية للمعلمين

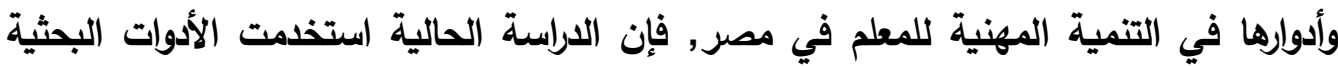
التالية:

1-استمارة مسح ميداني للإمكانيات المادية و البشرية بالأكاديمية المهنية للمعلمين وفرو عها في مصر , وهي من إعداد الباحث, وذلك للتعرف علي واقع المباني والتجهيزات والإمكانات المادية والبشرية بالأكاديمية المهنية للمعلمين وفروعها في مصر , حيث ركزت هذه ودئ الاستمارة

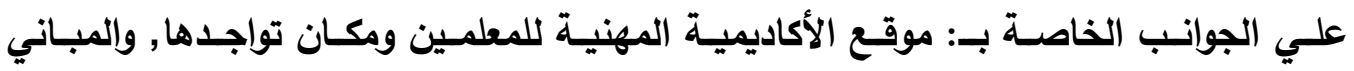
ومواصفاتها الهندية, وقاعات التدريب وورش العمل وتجهيزاتها, وحجرات الإدارة والخدمات,

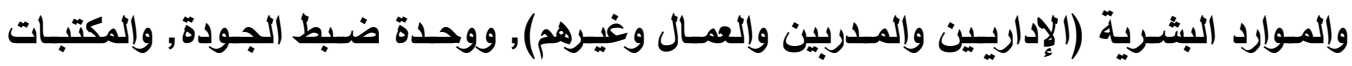

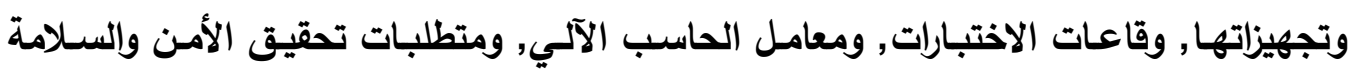

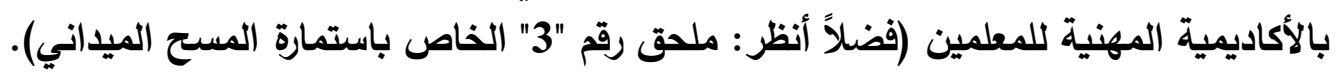
وقد تم تطبيق استمارة المسح الميداني علي الأكاديمية المهنية للمعلمين في مقرها

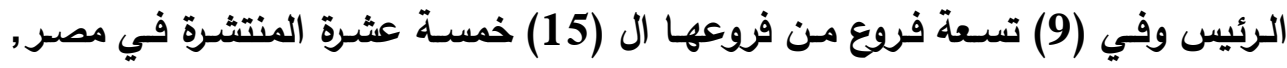

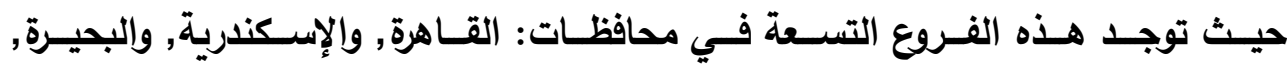

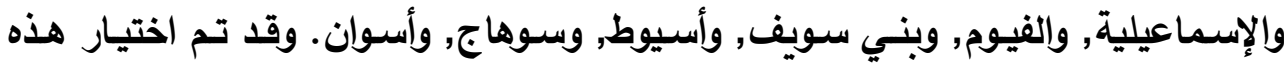

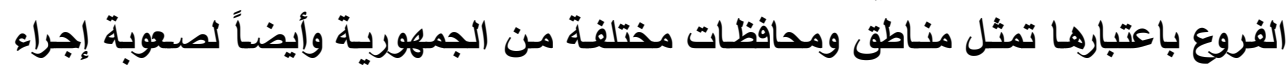

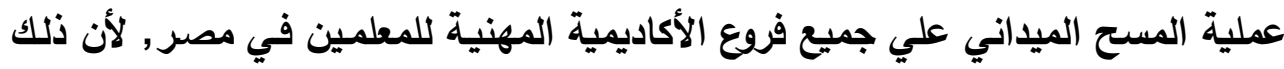
يتطلب الكثير من الوقت والجها والتكاليف.

2-استبيان حول و اقع الأكاديمية المهنية للمعلمين في مصر و أدوارهـا في التنمية المهنيـة

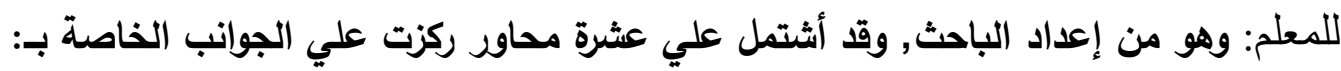
الإمكانيات المادية والتجهيزات, ووضـع الخطط المستقبلية للعمل وتقدير الاحتياجـات المهنية للمعلم, وإدارة برامج التنمية المهنية, ونوعية برامج التنمية المهنية المقدمة للمعلمين, والتيطية والكوادر

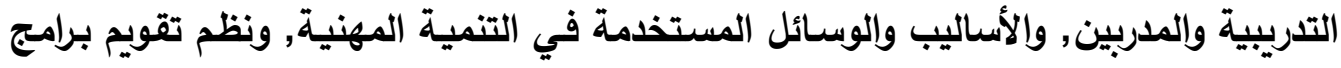

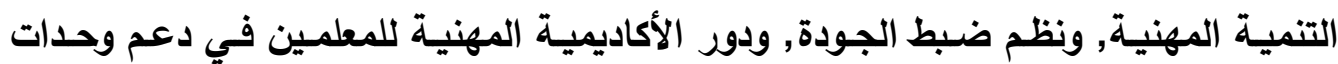

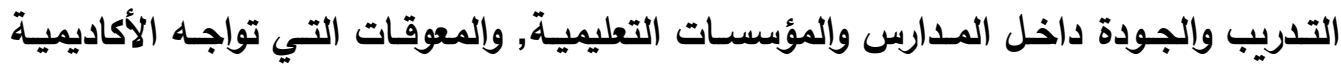

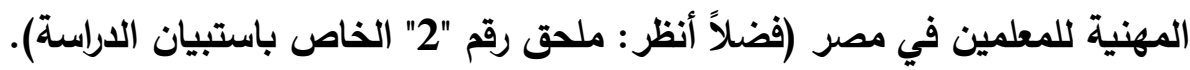


العدد (33) يناير 2013م

وقد تم تطبيق هذا الاستبيان علي عينة اختيرت بطريقة عشوائية من المعلمين أثناء

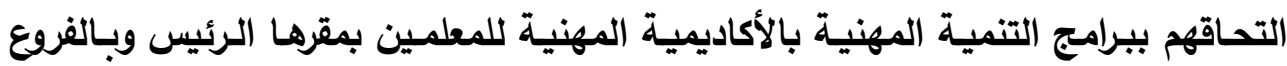

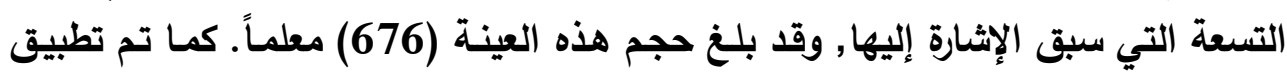

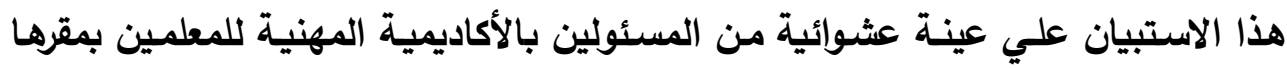

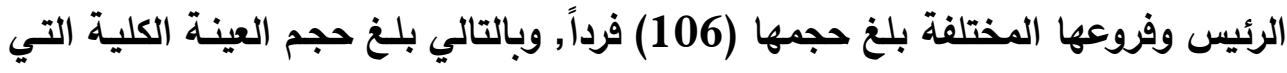

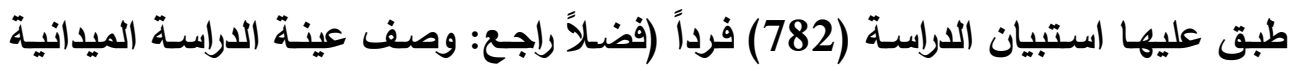
وتفصيلاتها في القسم الرابع من الدراسة الحالية).

2-المقابلات الثخصية غير المقنتة: مـع بعض المسئولين في الأكاديمية المهنية للمعلمين, وذلك للاستفادة من آرائهم، والتعرف عن قرب علي أهم المشكلات والمعوقات التي تواجـه

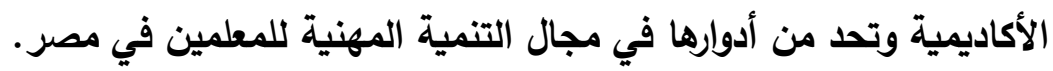

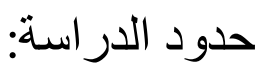
لأي دراسة علمية مجموعة من الددود التي تساعد في توضح جوانب التركيز الأساسية

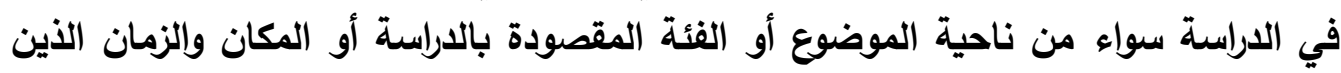

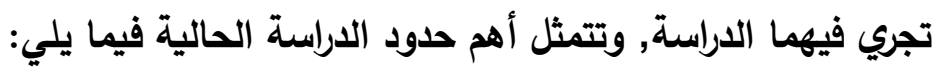
أولاً: الحدود الموضو فية المبة: تمثلت هذه الحدود في التركيز على موضوع الأكاديمية المهنية للمعلمين في مصر , المارد

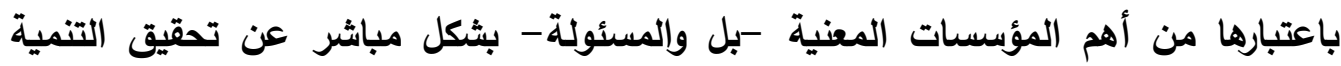

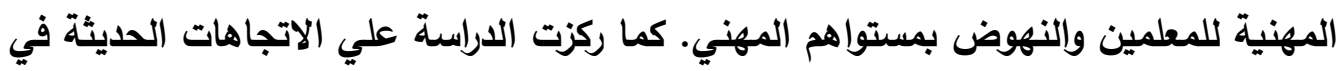
مجال التنمية المهنية للمعلم, وكيفية الاستفادة منها في تطوير أدوار الأكاديمية المهنية المهية للمعلمين في المجتمع المصري.

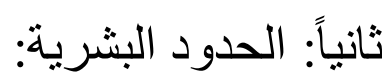
تمثلت هذه الحدود في التركيز علي: المبرد:

1- المعلمين الملتحقين ببرامج التنمية المهنية بالأكاديمية المهنية للمعلمين, وتم المتئية المتيار عينة عشوائية منهم بغرض التعرف من قرب علي واقع الأكاديمية المهنية للمعلمين في

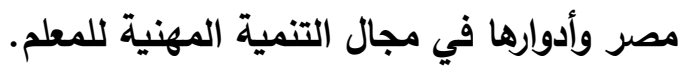

2- المسئولين بالأكاديمية المهنية للمعلمين في مصر, واختيار عينة عشوائية منهم لتعرف

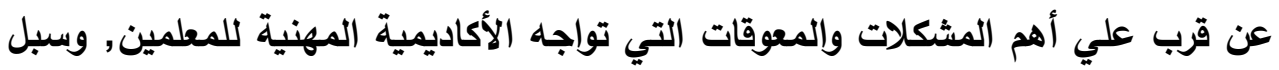


مواجهة هذه المشكلات والمعوقات, وكيفية تطوير الأكاديمية المهنية للمعلمين في ضوء الاتجاهات الحديثة في مجال التنمية المهنية للمعلم.

$$
\text { ثالثاً: الحدود المكانية: }
$$

وتمثلت في المجال المكاني الذي إجريت فيه الاراسة وهو المجتمع المصري بصفة الماني

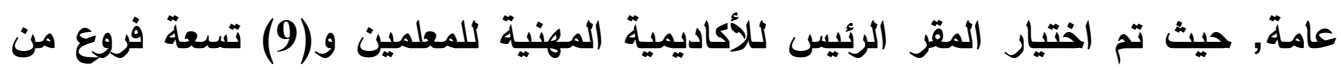

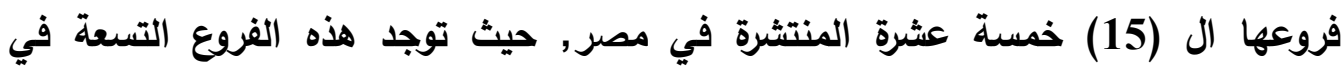

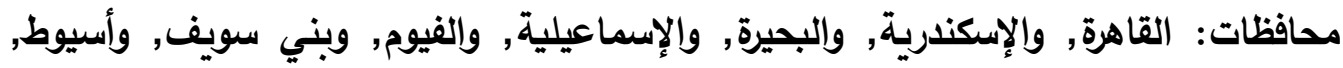

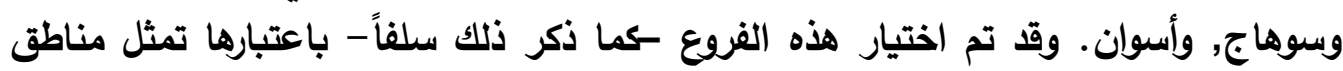

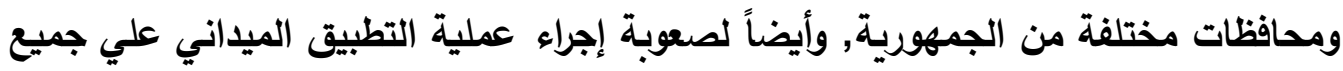

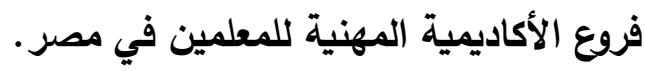
مصطلحات الدر استة: استخدمت الدراسة الحالية بعض المصطلحات الأساسية مثل: الأكاديمية المهنية

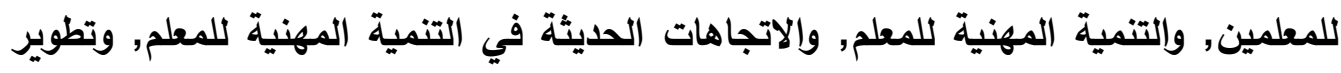
أدوار الأكاديمية المهنية للمعلمين, وهذه المصطلحات يعرضها الباحث هنا بثكل مختصر , ولاتهات

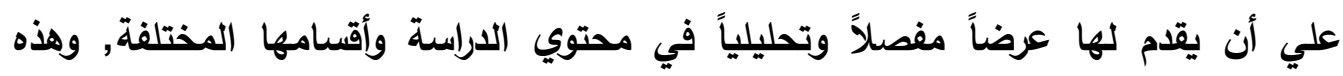

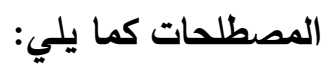
(1) الأكاديمية المهنية للمعلمين: حدد القانون رقم 155 لسنة 2007م (الصادر بتعديل بعض أحكام قانون التعليم رقم 139 لسنة 1981م) في مادته رقم (75) علي أن: تنشأ أكاديمية للمعلمين تسمى لقدئه

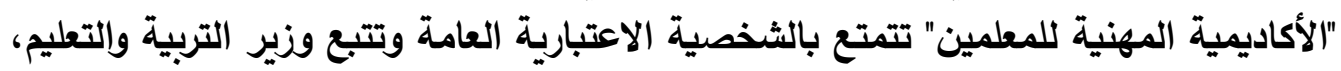
ويصدر بتنظيمها وبتحديد اختصاصاتها قرار من رئيس الجمهورية، على أنه أن يكون مقرها

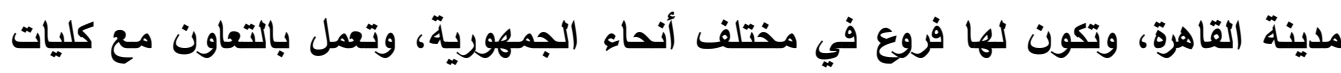
التربية، على أن تتولي هذه الأكاديمية تحقيق التنمية المهنية المستمرة للمعلمين, ومنح شهادة الصلاحية للتريس المنصوص عليها في المادة (74) من هذا القانون (ج.م.ع. (3ن) . 3 , 2007

كما صدرت اللائحة التنفيذية للقانون رقم (155) لسنة 2007م بقرار رئيس مجلس الوزراء رقم (2840) لسنة 2007م (رئاسة مجلس الوزراء بمصر, 2007م), كما صدر القرار الجمهوري رقم (129) لسنة 2008م بتظيم الأكاديمية المهنية للمعلمين وتحديد اختصاصـاتها (ج. م. ع. لورئ 
2008م). وقد اعُتبرت الأكاديمية المهنية للمعلمين بمصر منذ إنثـائها إحدي الهيئات المعاونـة

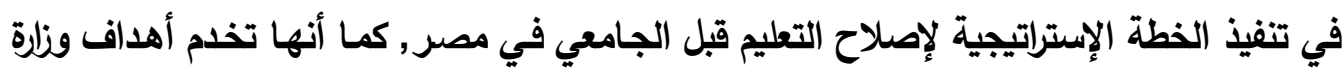

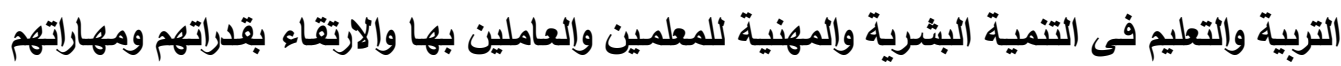
بصورة مستمرة.

(2) التنمية المهنية للمعلم: يمكن تحليد مفهوم التنمية المهنية للمعلم بإنها: تلك العمليات والأنشطة المنظمة التي تقدم للمعلمين بمختلف فئاتهم وتخصصاتهم بهدف الارتقاء بمستوي المعارف والمهارات

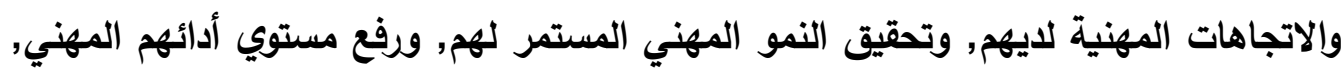

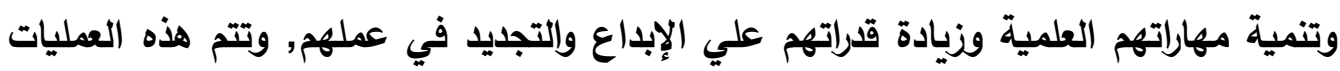

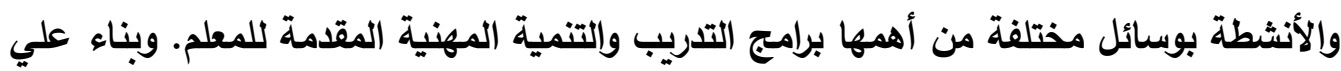
ذلك يتسع مفهوم التنمية المهنية للمعلم ليشمل كل محاولة تسهم في تحسين وتطوير أداء المعلمين لأدوارهم, ومن بينها برامج التدريب المختلفة.

$$
\text { (3) تطوير الأكاديمية المهنية للمعلمين: }
$$

يقصد بالتطوير النمو والتغيير في البنية والوظيفة والتنظيم, كما أنه استخدام القدرات

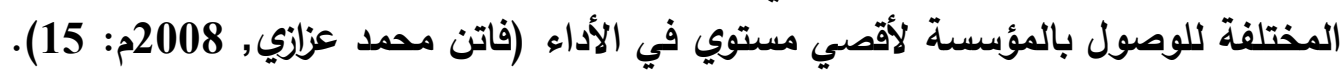

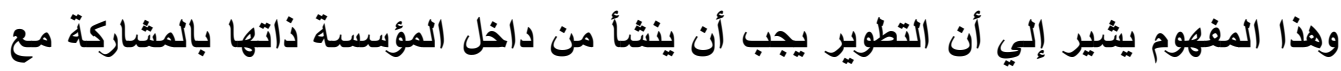

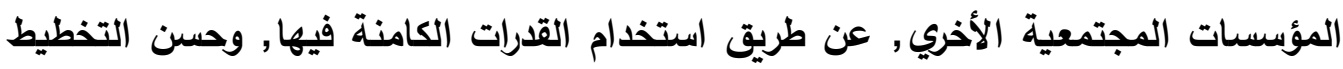
لها واستثمارها.

أما عن تطوير الأكاديمية المهنية للمعلمين والإرتقاء بأدوارها في التنمية المهنية للمعلم, فيعني جميع الجهود التي تبذل بهدف إحداث تغييرات جوهرية في منظومة العمل داخل الأكاديمية المهنية للمعلمين, وهذه التغييرات تثمل جميع العناصر المشاركة في العمل من:

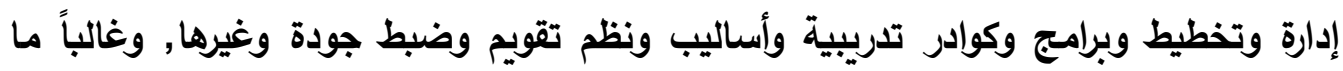
تتجاوز نتائج هذه التغييرات وإيجابياتها حدود منظومة العمل داخلية والئل الأكاديمية إلي المعلمين

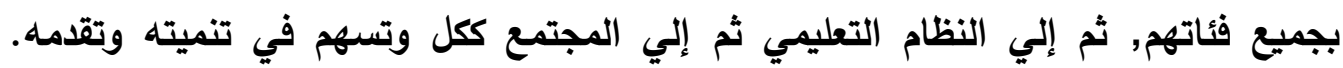
وبالتالي ينصرف التظوير في النهاية إلي تحقيق الكفاية والكفاءة للمعلم وللعملية التعليمية

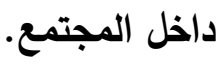
(4) الاتجاهات الحديثة في التنمية المهنية للمعلم: 
هي تلك التوجهات التربوية المعاصرة التي تسود دول العالم الآن وخاصة الدول المتقدمة

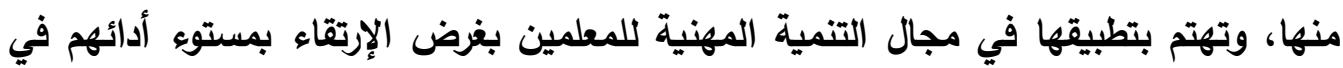

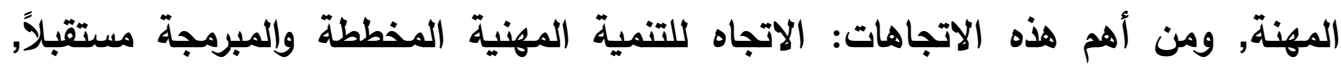

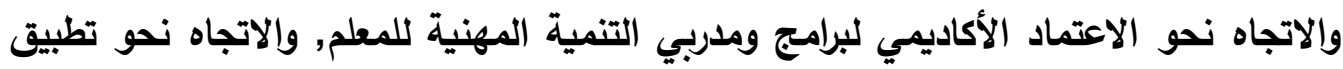

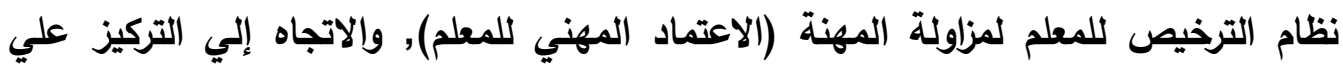

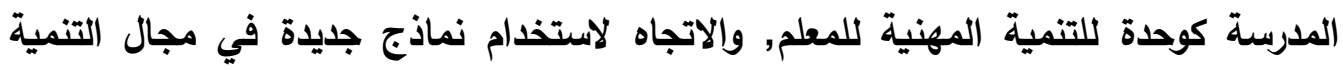
المهنية للمعلم, والاتجاه لاستخدام أساليب وطرق حديثة, واستخدام البحوث الإجرائية وإلميدانية

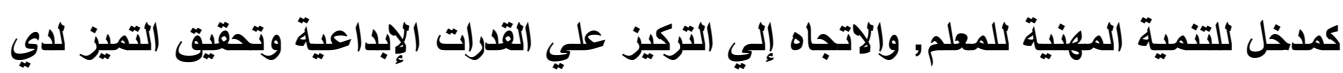
المعلم. خطة السير في الدراسة: للإجابة عن أسئلة الدراسة ولتحقيق أهدافها المختلفة, جاءت خطة السير في الداسة وفقاً للخطوات التالية: ت أبهن القسم الأول من الدر اسة: وجاء بعنوان: (الإطار العام للاراسة), وتركز في إبراز مشكلة الاراسة

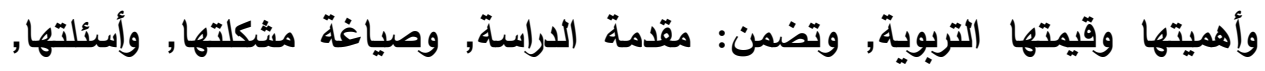

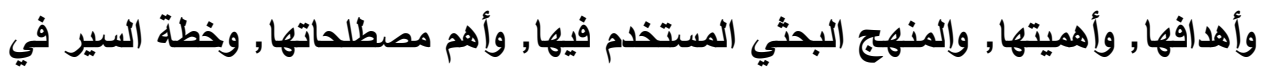
الاراسة.

القسم الثاني من الدراسة: وهو يجيب عن السؤال الأول من أسئلة الاراسة, وجاء بعنوان:

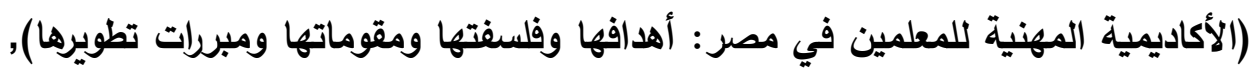

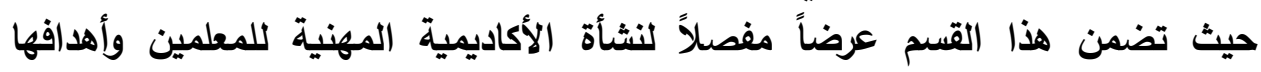

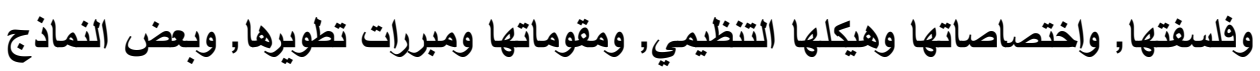
العالمية الرائدة للأكاديميات المهنية للمعلمين.

القسم الثالث من الدراسة: وهو يجيب عن السؤال الثاني من أسئلة الدراسة, وجاء بعنوان:

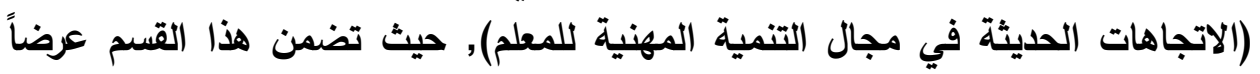

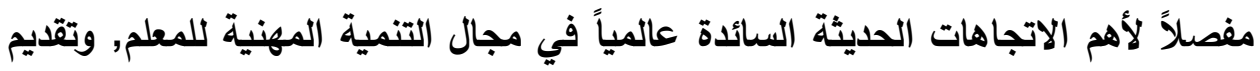

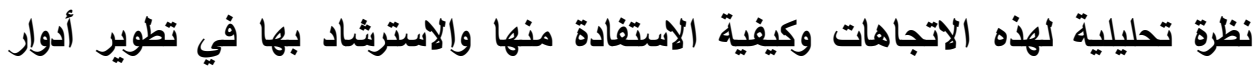
الأكاديمية المهنية للمعلمين في مصر.

القسم الرابع من الدراسة: وهو يجيب عن السؤال الثالث من أسئلة الدراسة, وجاء بعنوان: (الدراسة الميدانية وأهم نتائجها), وتناول إجراءات الداب الداسة الميدانية وإظهار نتائجها 
العدد (33) يناير 2013م

وتفسيرها, والوقوف علي واقع الأكاديمية المهنية للمعلمين في مصر وأدوارها في مجال

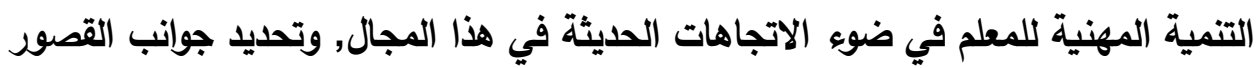

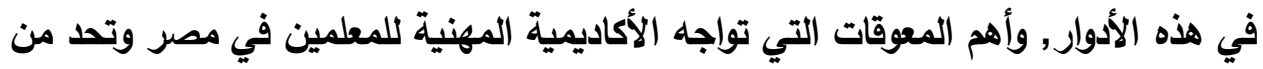
أدوارها تجاه المعلمين.

القسم الخامس من الدراسة: وهو يجيب عن السؤال الرابع من أسئلة الدراسة, وجاء بعنوان: (تصور مقترح لتطوير أدوار الأكاديمية المهنية للمعلمين في مصر في ضوي الدوال الاتجاهات الحديثة في مجال التنمية المهنية للمعلم).

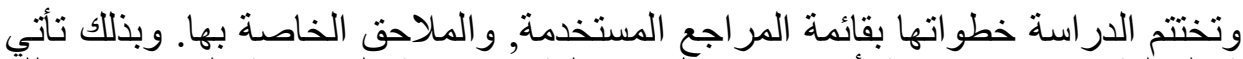
الدراسة الحالية منضمنه خمسة أقسام (فصول) مختلفة بالإضافة الثافة إلى قائمة المر اجع وكذلك

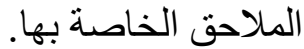


العدد (33) يناير 2013م

$$
\text { ملخص القسم الثاني من الدراسة }
$$

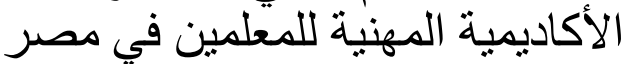

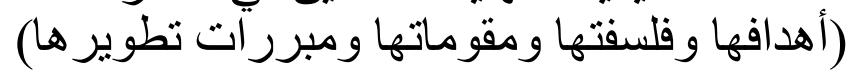

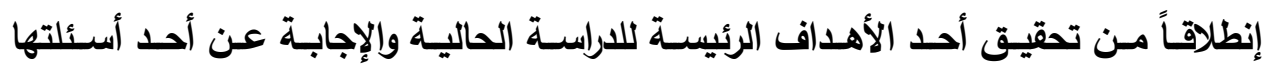

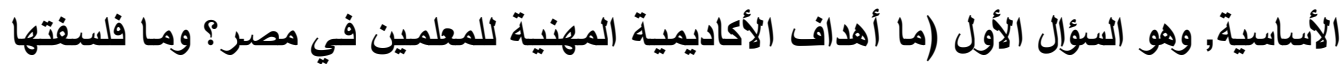

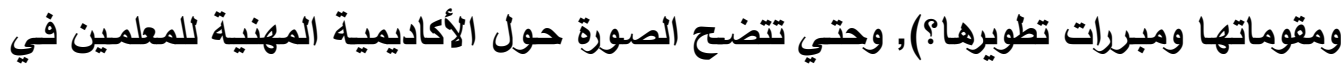

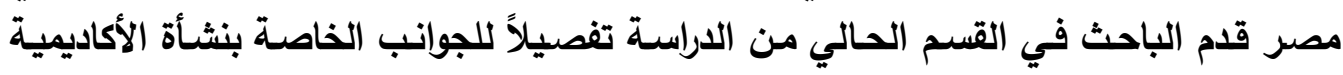

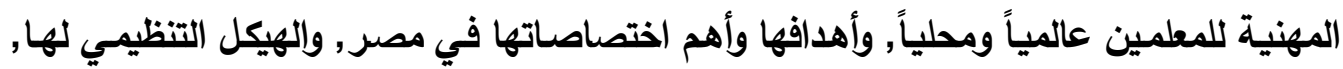

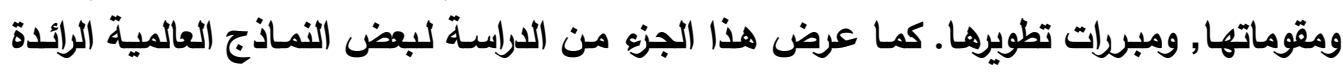

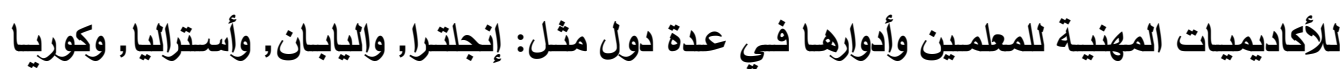
الجنوبية, والولايات المتحدة الأمريكية, والصين, وسنغافورة, وماليزيا.

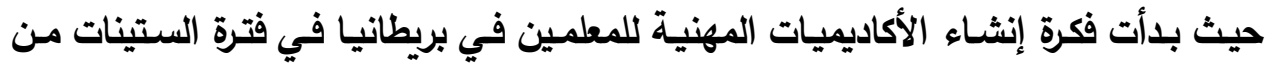

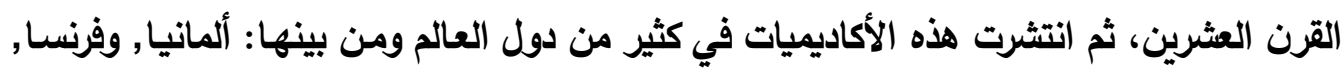

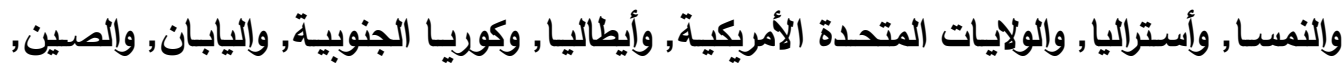

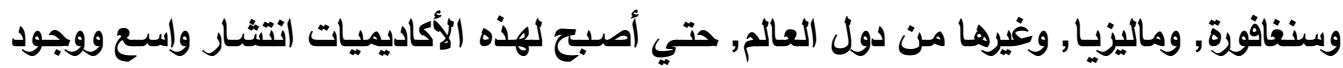
مؤثر في كثير من الدول وتسهم بفاعلية في تطوير أنظمتها التعليمية. وفي مصر تم إنثاء الأكاديمية المهنية للمعلمين في عام 2007م, وذلك بصدور القانون

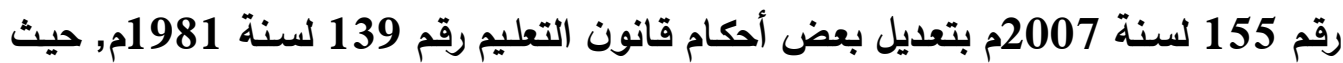
نص هذا القانون في مادته رقم (75) علي أن: تنشأ أكاديمية للمعلمين تسمى "الأكاديمية

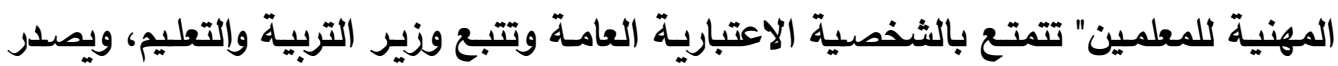

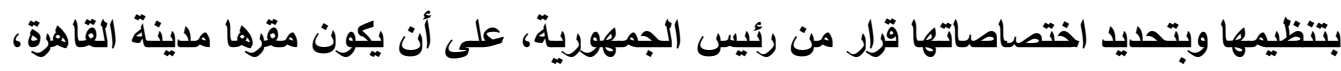

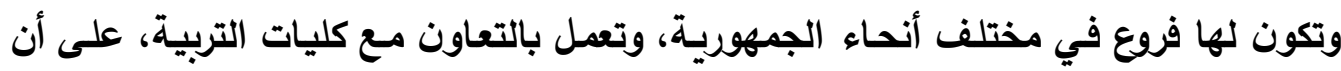

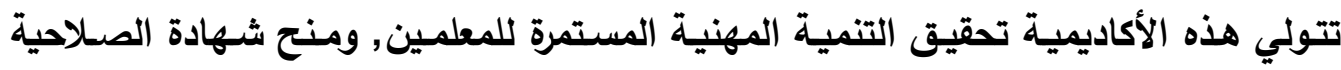

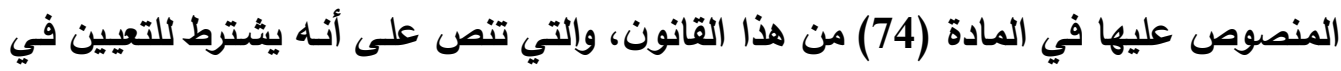

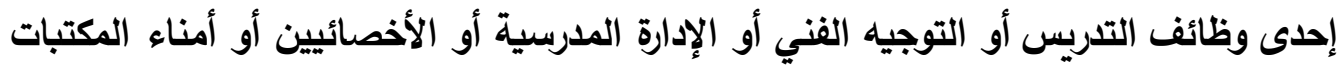

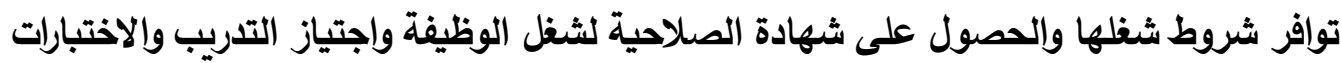

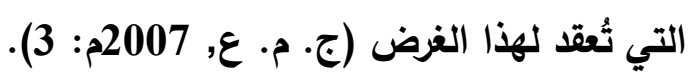

وبنـاء عليه صدرت اللائحة التفيذيـة للقانون رقم (155) لسنة 2007م بقرار رئيس مجلس الوزراء رقم (2840) لسنة 2007م (رئاسـة مجلس السوزراء بمصر , 2007م), كمـاء 
صدر القرار الجمهوري رقم (129) لسنة 2008م بتظيم الأكاديمية المهنية للمعلمين وتحديد

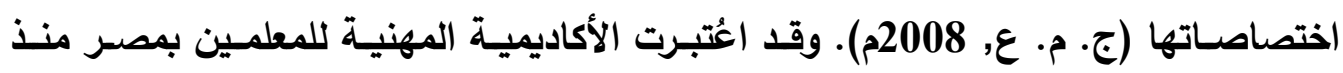

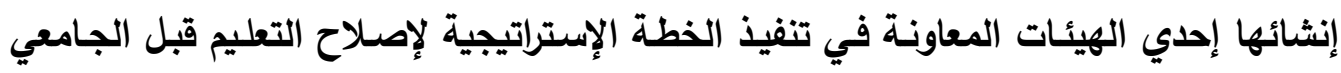

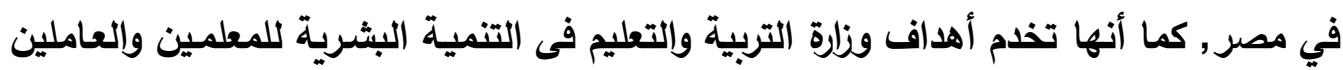
بها والارتقاء بقدراتهم ومهاراتهم.

وبناء علي ذلك تم إنشاء عدد كبير من الفروع للإكاديمية المهنية للمعلمين بالمحافظات

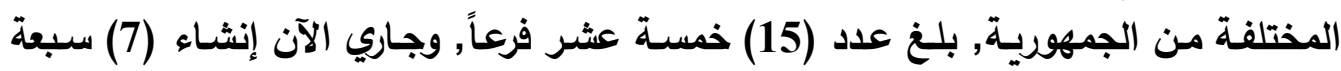

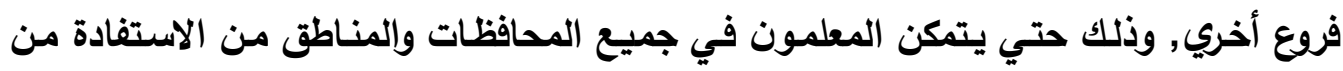
الخدمات التي تقدمها الأكاديمية المهنية للمعلمين.

وقد قدمت الدراسـة في هذا القسم عرض نظري تحليلي للجوانب المرتبطة بالأكاديمية

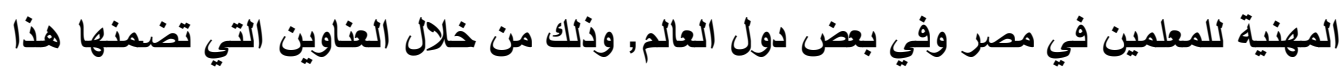

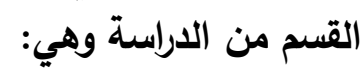
أولاً: نثأة الأكاديمية المهنية للمعانية المعلين عالمياً ومحلياً.

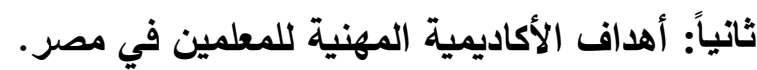

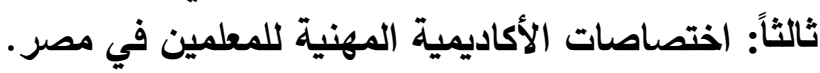
رابعاً: فلسفة عمل الأكاديمية المهنية للمعلمين في مجادية المهنية لمعلمين في مصنية التنمية المهنية.

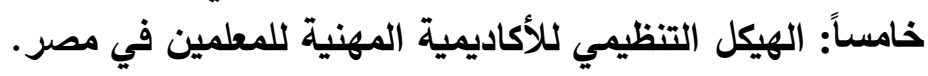
سادساً: مقومات الأكاديمية المهنية للمعلمين وأهم عناصر منظومية لإكادية العمل فيها.

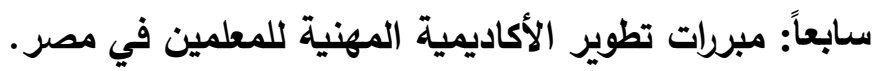

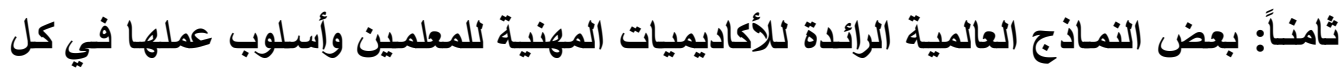

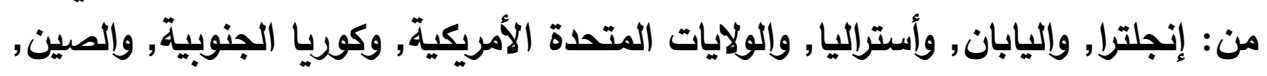

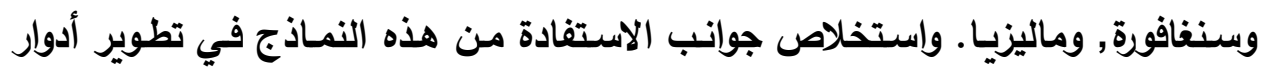
الأكاديمية المهنية للمعلمين في مصر في مجال ولفينال التنمية المهنية للمعلم. 


$$
\text { ملخص القسم الثالث من الدار اسة }
$$

الاتجاهات الحديثة في مجال التتمية المهنية للمعلم

لقد ظهرت في السنوات القليلة الماضية كثير من الاتجاهات الحديثة في مجال التنمية المهنية للمعلم, ويأتي ظهور هذه الاتجاهات نتيجة تفاعل المؤسسات القائمة علي إعداد المعلم وتنميته مهنياً مع متغيرات العصر ومتطلباته من المعلم, وكذلك نتيجة السعي لتوفير المعلم المواكب لكل زمان ومكان، في ظل ثورة التكنولوجيا والمعلومات, وتوفير الخدمة التربوية ولمبية التلازمة

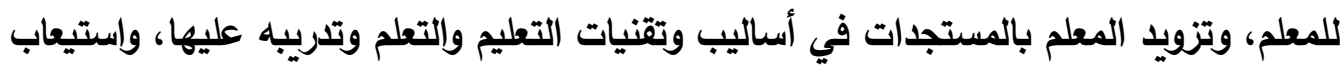

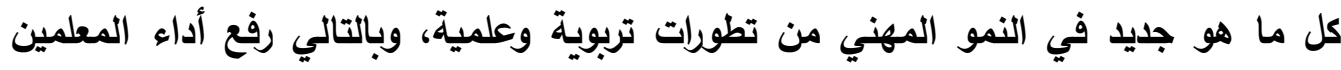
وإنتاجيتهم من خلال تطوير كفاياتهم المهنية بجانبيها المعرفي والسلوكي.

وإنطلاقاً من تحقيق أحد الأهداف الرئيسة للاراسة الحالية والإجابة عن أحد أسئلتها

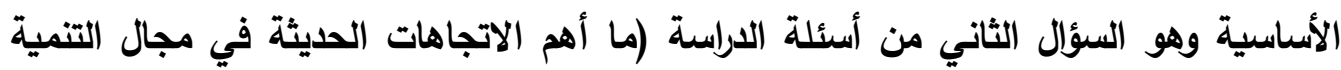

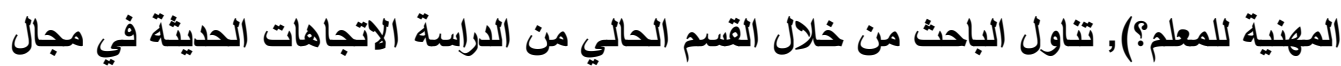

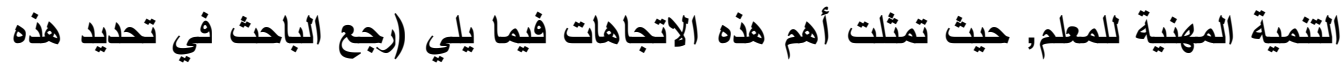

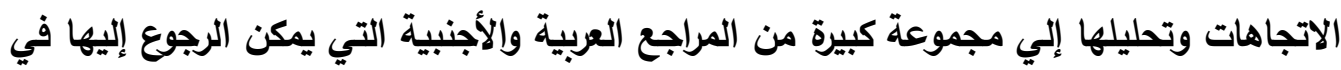
القسم الثالث في أصل الاراسة): أو لاً: الاتجاه للتنمية المهنية المخططة والمبرمجة مستقبلاً, وبناء خطط للتنمية المهنية للمعلم تراعي متغيرات المستقبل, وتساعد المعلم في التعامل بنجاح معها.

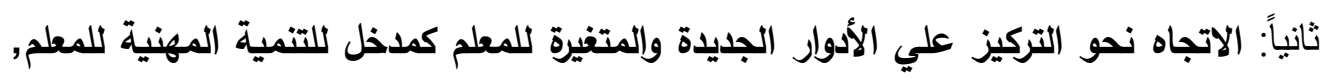
ومساعدة المعلم في تفهم تلك الأدوار والققيام بها مستقبلاً بفاعلية. ثالثاً: الاتجاه نحو الاعتماد الأكاديمي لبرامج وملربي التنمية المهنية للمعلم, وتحقيق نظم ومعايير الجودة والاعتماد من خلال هذين العنصرين. رابعاً: الاتجاه نحو تطبيق نظام الترخيص للمعلم لمزاولة المهنة (الاعتماد المهني للمعلم), وربط التجديد لهذا الترخيص بكفاءة المعلم وإستمراره في التنمية المهنية. خامساً: الاتجاه إلي التركيز علي المدرسة كوحدة للتنمية المهنية للمعلم, وإنثاء وحدات للتدريب والتقويم والجودة داخل المدارس والمؤسسات التئيس التعليمية. 
سادساً: الاتجاه لاستخدام نماذج جديدة في مجال التنمية المهنية للمعلم مثل: النموذج المتمركز

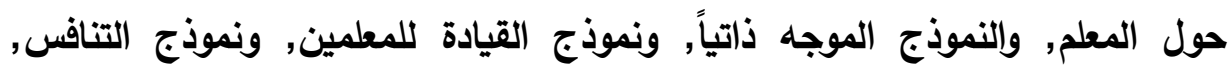
ونموذج الخطوات المتعاقبة, والنموذج الجماعي المشترك.

سابعاً: الاتجاه لاستخدام أساليب وطرق حديثة في التنمية المهنية للمعلم مثل: أسلوب فرق

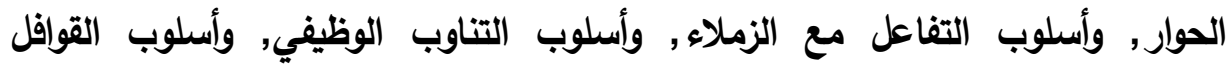
التدريبية, وأسلوب التدريس النموذجي, وأسلوب مؤتمرات العمل. ثامناً: الاتجاه نحو استخدام البحوث الإجرائية وإلميدانية كمدخل للتنمية المهنية للمعلم, وتدربب

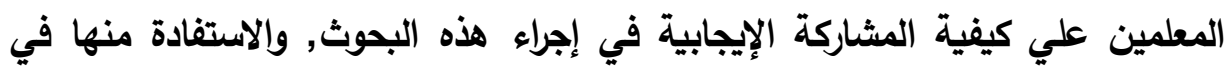
مجال المهنة وإلتدريس ومواجهة المشكلات التعليمية.

تاسعاً: الاتجاه لاستخدام نظم التدربب من بُعد والتدريب الإكتروني في تلبية الاحتياجات المهنية

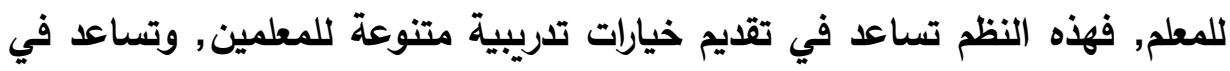
تخطي حاجز المكان والزمان, والوصول إلي أكبر عدد ممكن من المعلمين.

عانراً: الاتجاه إلي التركيز علي القدرات الإبداعية وتحقيق التميز كمدخل للتنمية المهنية

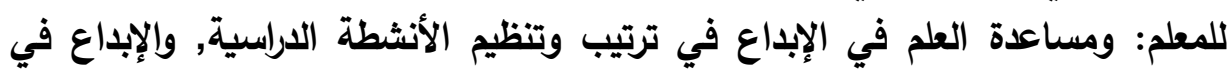

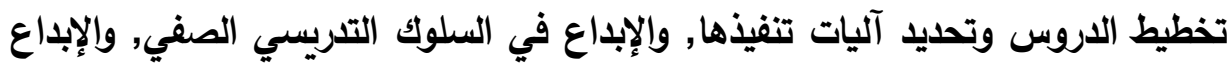
في التقويم وتقديم البرامج العلاجية والتتزيزية لتلاميذه.

كما قدمت الدراسة في نهاية هذا القسم من الدراسة نظرة تحليلية للاتجاهات الحديثة في مجال التنمية المهنية للمعلم, واستخلاص أهم الجوانب والمبادئ التي ركزت عليها لهابها هذه الاتجاهات في مجال التنمية المهنية للمعلم, وجوانب الاستفادة منها في تطوير أدوار الأكاديمية المهنية للمعلمين في مجال التنمية المهنية للمعلم في مصر. 
العدد (33) يناير 2013م

$$
\text { ملخص القسم الر ابع من الدر استة الديدانية }
$$

(حول و اقع الأكاديمية المهنية للمعلمين في مصر وأدوانة المهيد ها في التنمية المهنية للمعلم في ضوء الاتجاهات الَحديثة في هذا المجآ

تأتي أهمية الدراسـة الميدانيـة وإبراز إجراءاتها وأهم نتائجها في الدراسـة الحاليـة من

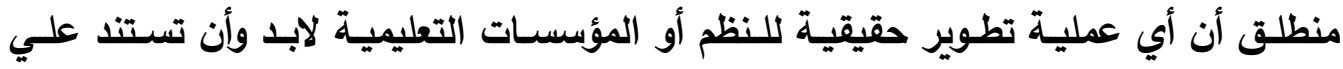

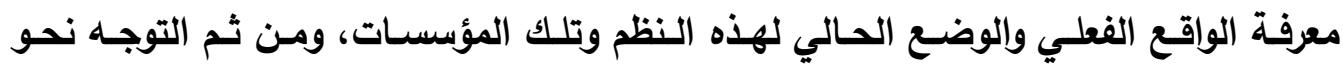

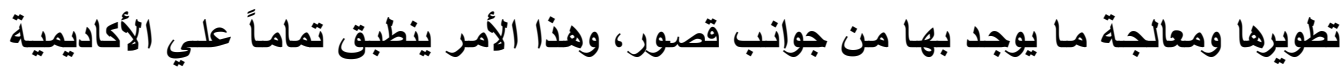

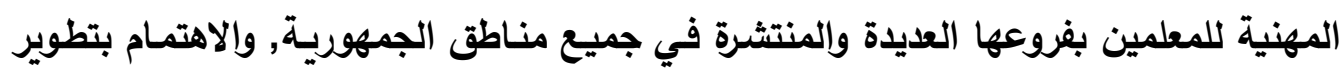

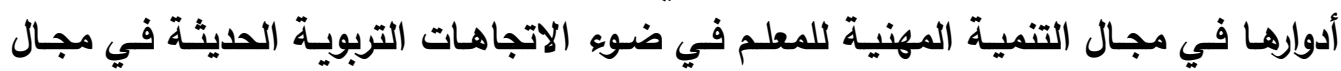
التنمية المهنية للمعلم.

وقد جاءت الدراسة الميدانية استكمالاً لخطة السير في الدراسة وإجابة عن أحد أسئلتها

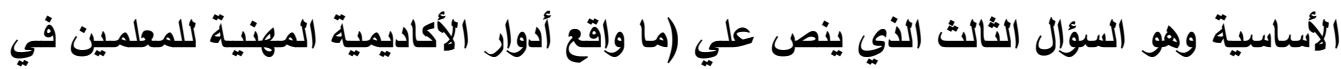

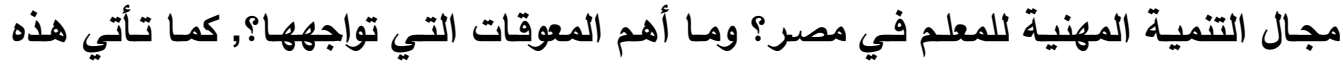

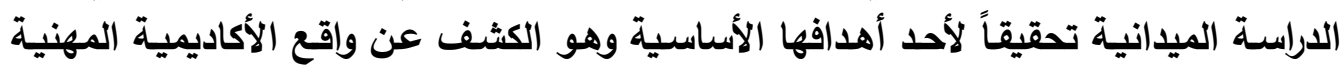
للمعلمين في مصر وتحديد جوانب القصور في أدوارها في مجال التنمية المهنية للمعلم. ولـذلك تضـمن القسـم العـالي مـن الدراسـة: أهـاف الدراسـة الميدانيـة, ووصـفاً مـوجزاً

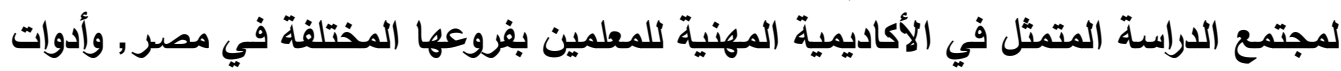

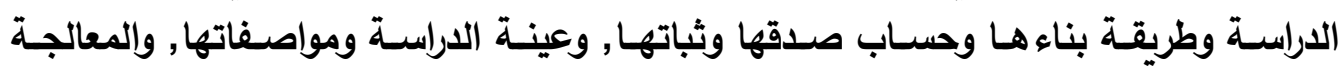

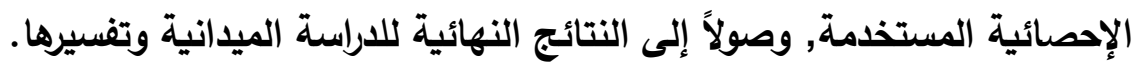

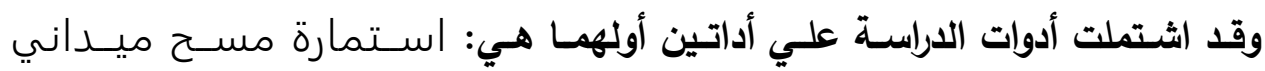

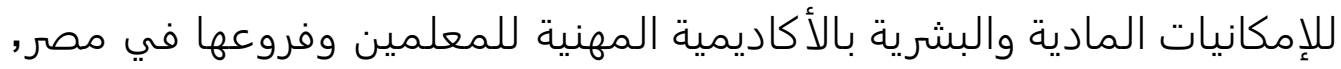
وهـي مـن إعداد الباحث بهدف التعرف علـي واقع المباني والتجهيزات والإمكانـات الماديـة

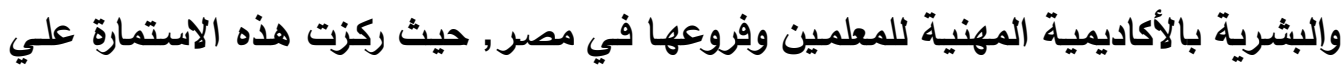

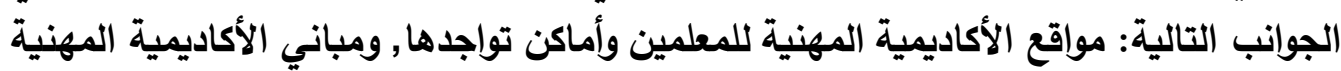
للمعلمين ومواصفاتها الهندسية, وقاعات التدريب وورش العمل وتجهيزاتها بالأكاديمية المهنية الاكية المادية المهية للمعلمين, وحجرات الإدارة والخدمات بالأكاديمية المهنية للمعلمين, والموارد البشرية الإلية الإداريين

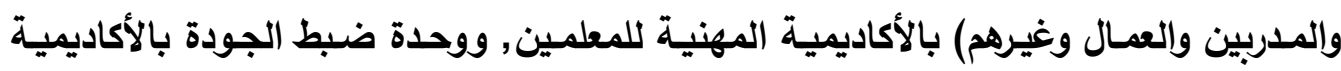


المهنيـة للمعلمـين, ومكتبـة الأكاديميـة المهنيـة للمعلمـين وتجهيزاتهـا, وقاعـة الاختبـارات

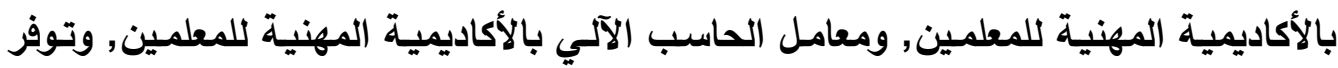
الثروط الصحية بالأكاديمية المهنية للمعلمين, ومتطلبات تحقيق الأمن والسـلامة بالأكاديمية المهنية للمعلمين. أما الأداة الثانية التي استخدمتها الدراسة فتمثلت في: استبيان حول واقع الأكاديمية المهنية للمعلمين في مصر وأدوارها في التنمية المهنية للمعلم, وهو من إعداد الباحث, وقد أثتمل هذا الاستبيان علي عثرة محاور ركزت علي جوانب: الإمكانيات المادية

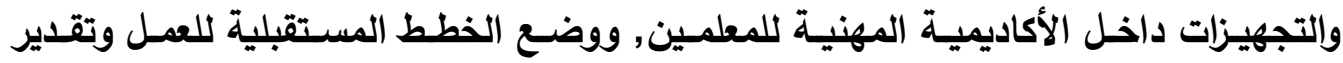
الاحتياجات المهنية للمعلم, وإدارة برامج التنمية المهنية, ونوعية براميه التهية التنمية المهنية التيطي تقدمها الأكاديمية المهنية للمعلمين, والكوادر التدرببية والمدربين, وفاعلية الأساليب والوسائل والئل

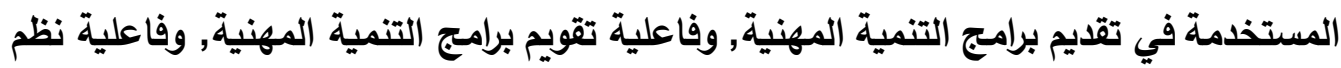

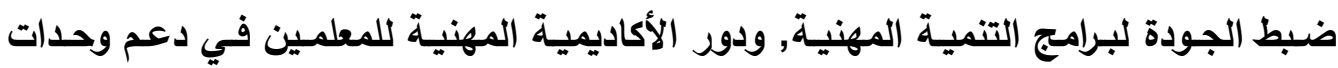

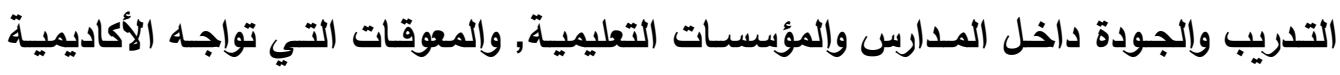

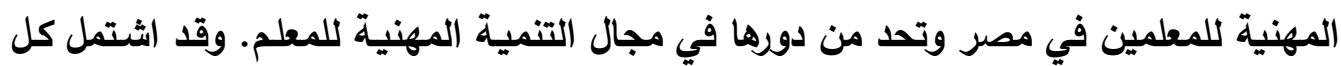
محور من المحاور العشرة علي عدد يتراوح ما بين (12 إلي 14) عبارة مختلفة، وقد تضدئ تضمن الاستبيان في صورته النهائية عدد (123) عبارة.

وقد تم التأكد من صدق أداتي الدراسـة (الاستبيان واستمارة المستح الميداني) من خلال

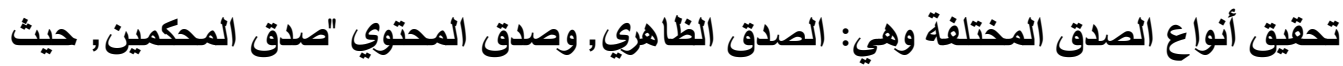

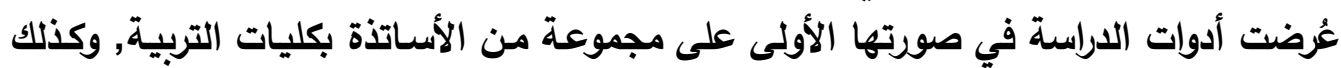

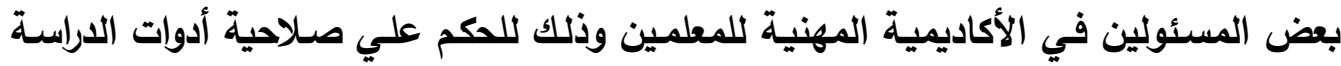
(أنظر الملحق رقم "1" في أصل الدراسـة الخاص بأسماء السـادة المحكمين لأدوات الداسئة),

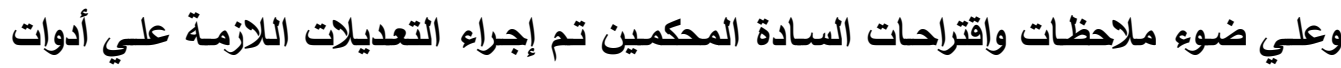
الاراسة.

كما تم حساب ثبات استبيان الدراسة بطريقة إعادة التطبيق علي عينة من المعلمين الذين

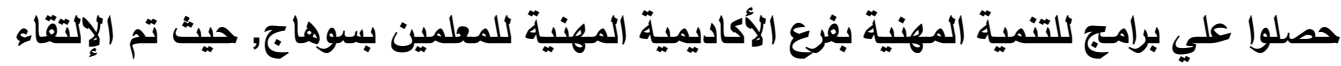

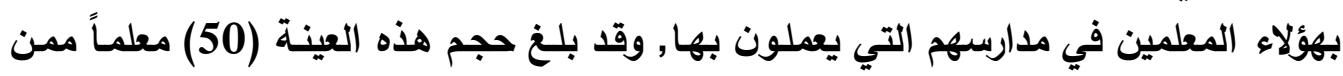

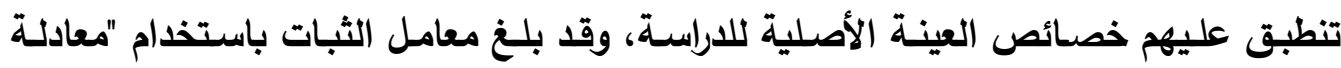
سبيرمان - براون للثبات" (0,94) وهو معامـل ثبات مرتفع يشير إلـي صـلاحية الاستبيان معادل 
للتطبيق ولتحقيق أغراض الدراسة. ومن ثم أصبحت أدوات الدراسة صالحة للتطبيق في صورتها

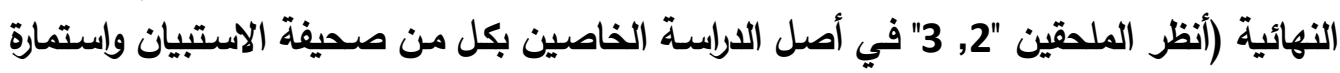
المسح الميداني في صورتهما (النهائية). وقد تم تطبيق استمارة المسح الميداني في المقر الرئيس للأكاديمية المهنية للمعلمين, و(9) تسعة فروع من فروعها ال (15) خمسة عشرة القائمة في مصر حالياً, حيث توجد هذئه

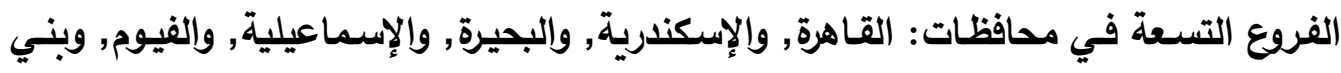

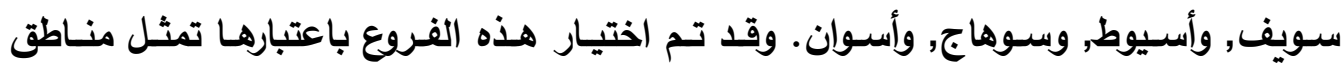

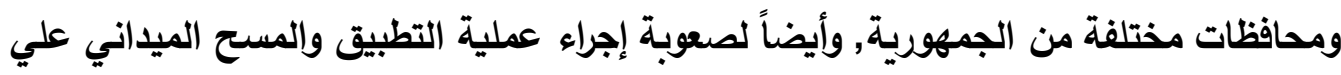

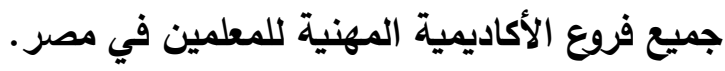
كمـا طُبق استبيان الدراسـة علي عينـة اختيرت عشـوائياً مـن المعلمين أثنـاء التحـاقهم

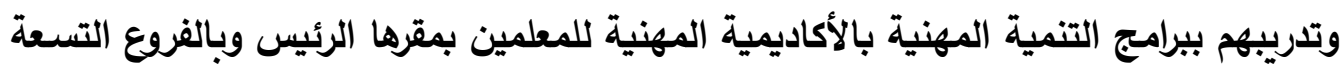

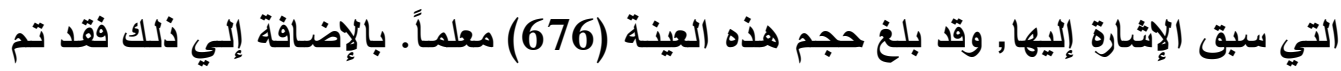

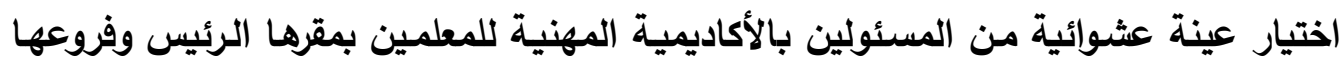

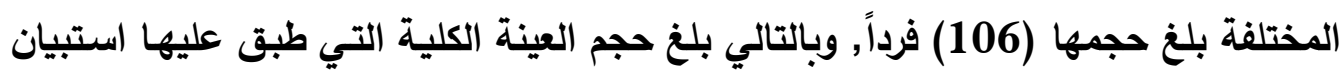
الاراسة (782) فرداً.

وبعد الانتهاء من عملية التطبيق تم إجراء المعالجة الإحصائية لنتائج تطبيق الاستبيان

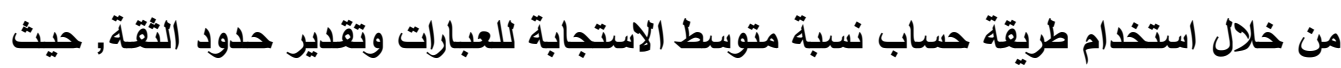

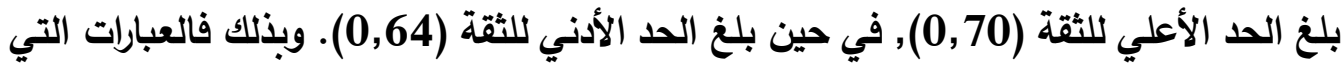

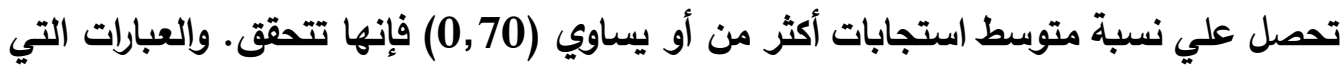
تحصل علي نسبة متوسط استجابة أقل من أو يساوي (0,64) فإنها

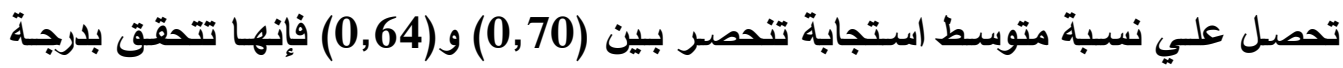
متوسطة. 


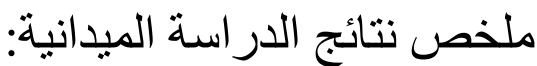

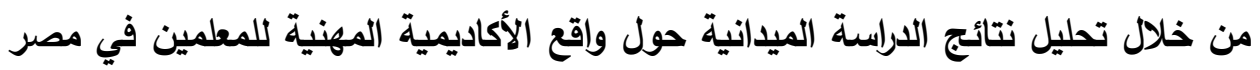

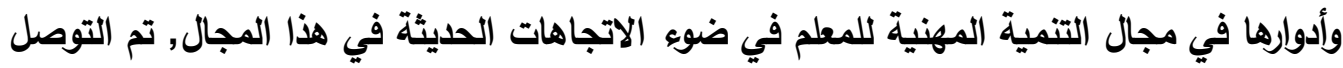
إلي مجموعة من النتائج النهائية كما يلي:

1- يوجد قصور واضح في الإمكانيات المادية والتجهيزات والأجهزة والتقنيات ومصادر التمويل

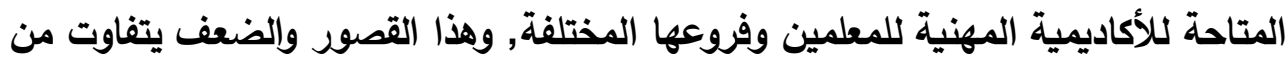

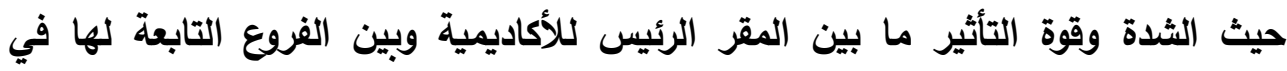

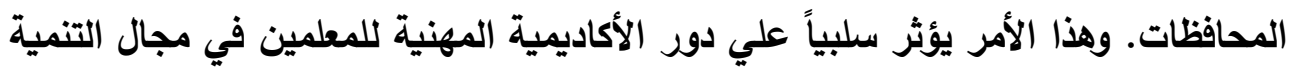
المهنية للمعلم في مصر.

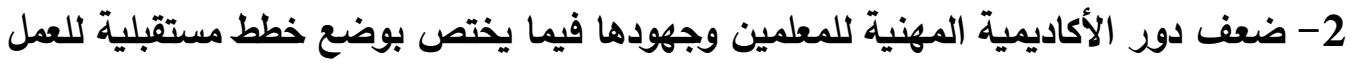

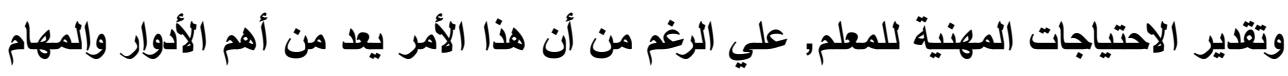

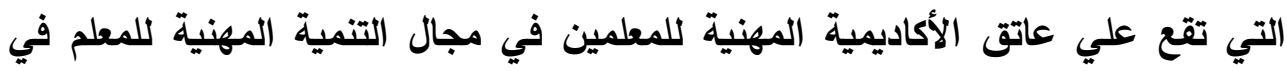
مصر.

3- محدودية دور إدارة الأكاديمية المهنية للمعلمين في تطوير عملية إدارة برامج التنمية

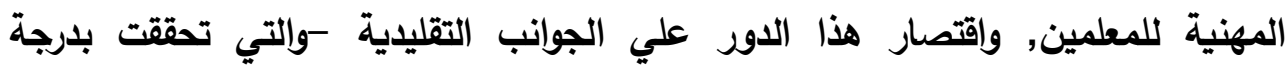
متوسطة من وجهة نظر أفراد العينة- كتوفير المتطلبات المادية للتريب, وتطبيق التباتب التعليمات

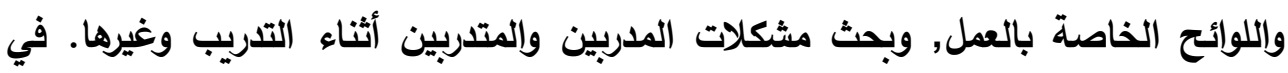

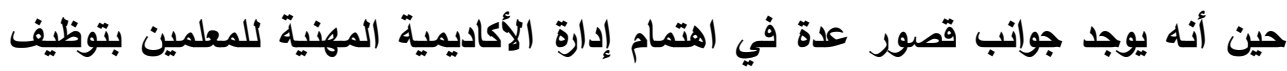

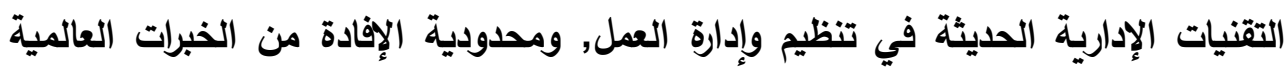

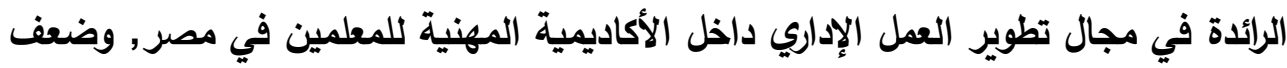

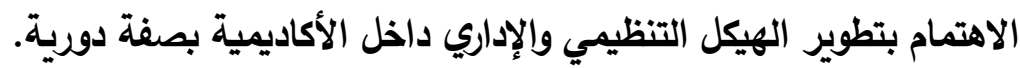

4- قصور رؤية الأكاديمية المهنية للمعلمين فيما يتعلق باختيار نوعية برامج التنمية المهنية

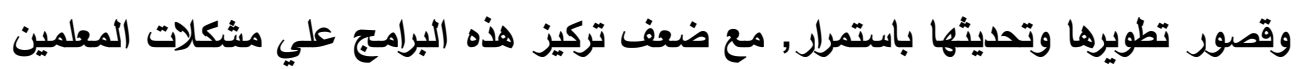
واحتياجاتهم المهنية والتطورات في مجال التدريس والتعليم.

5- قصور رؤية وجهود الأكاديمية المهنية للمعلمين ودورها فيما يتعلق باختيار المدربون

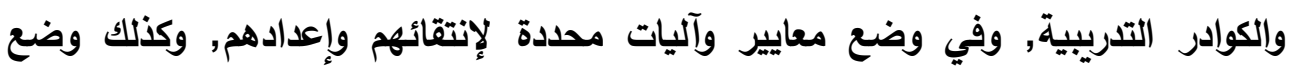
معايير وضوابط أخلاقية لعملهم داخل الأكاديمية, وضوضع خطط للتطوير المهني المستمر وإئر 
لهذه الكوادر, وإجراء عمليات تقييم دورية ومستمرة لهذه الكوادر داخل الأكاديمية المهنية للمعلمين في مصر.

6- قصور أساليب التدريب ووسائله المستخدمة في برامج التنمية المهنية للمعلم المقدمة من

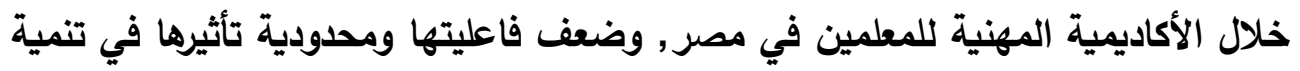

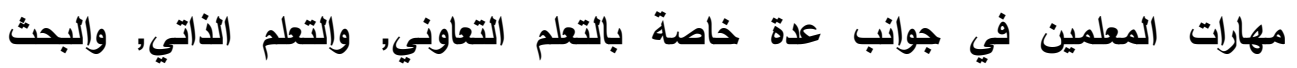
والاستقاء, وحل المشكلات, والعصف الذهني, وإجراء البحوث الجماعية وإلتطبيقية,

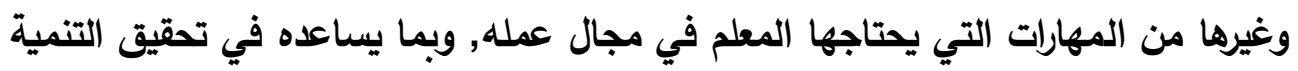
المهنية المستمرة.

7 - قصور أساليب ووسائل تقويم برامج التنمية المهنية المقدمة من خلال الأكاديمية المهنية للمعلمين, مع ضعف الاستفادة من نتائج التقويم في تحسين أداء عناصر العملية التدريبية من مدرب ومتدرب وإداري وغيرهم, وكذلك في تطوير برامج التنمية المهنية للمعلمين. 8- ضعف اهتمام الأكاديمية المهنية للمعلمين بتطبيق نظم ضبط الجودة لبرامج التنمية

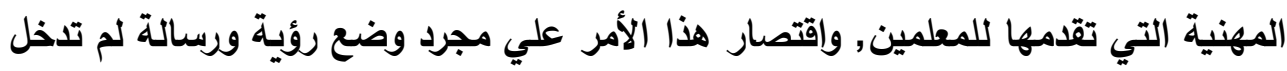

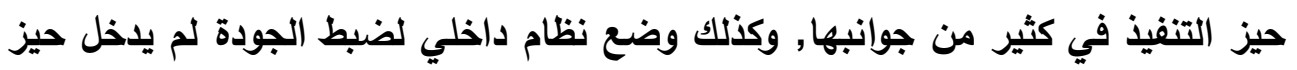

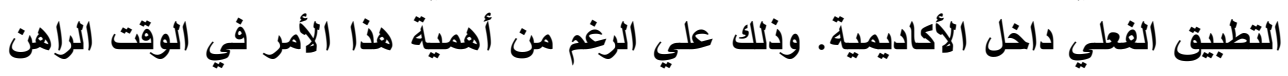

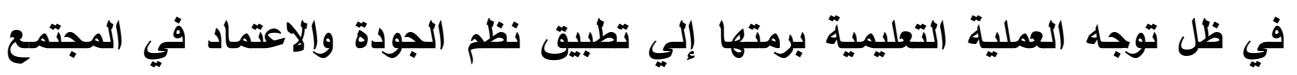

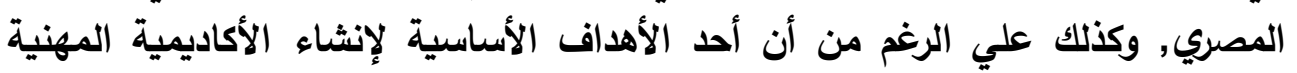

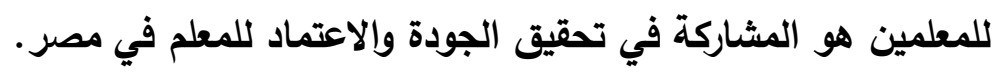
9- ضعف دور الأكاديمية المهنية للمعلمين في دعم وحدات التدريب والجودة داخل المدارس

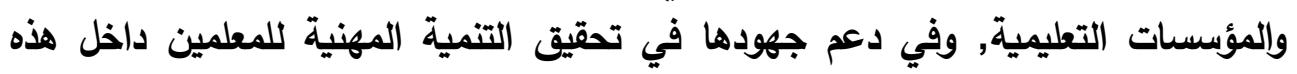
المدارس, واقتصار هذا الاور علي مجرد التواصل مع إدارات التدريب بالمديريات والإدارات

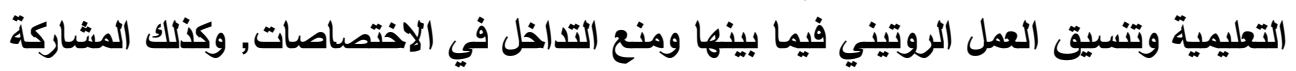

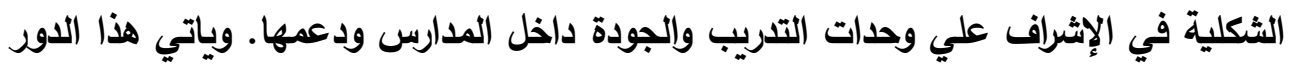
الضعيف من جانب الأكاديمية المهنية للمعلمين علي الرغم التوجه العام الآن للاهتمام

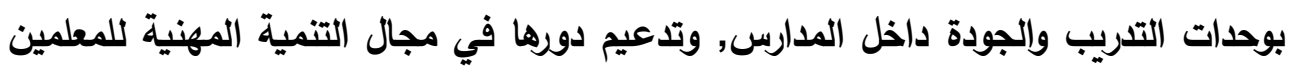
داخل المدارس.

10- وجود عديد من المعوقات التي تواجه الأكاديمية المهنية للمعلمين في مصر وتحد من دورها

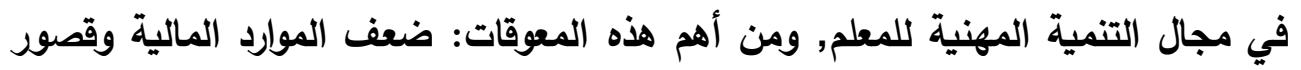


المباني والإمكانات والتجهيزات, وابتعاد مقار الأكاديمية المهنية عن أماكن إقامة المعلمين

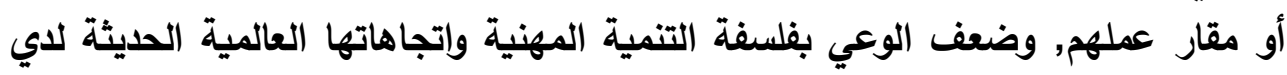
المسئولين في الأكاديمية المهنية للمعلمين, وضعف الوفيل الحوافز التشجيعية للمعلمين للإقبال علي برامج التنمية المهنية, وسوء اختيار مواعيد تقديم برامج التنمية المهنية للمعلمين وخاصة خلال العام الداسي, وضعف استخدام الوسائط والتقنيات التدربيية الحديثة

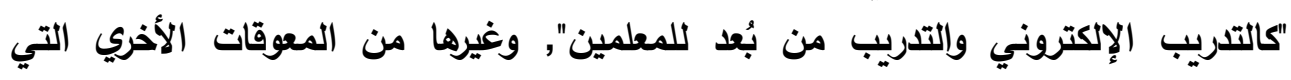
أظهرتها نتائج الدراسة الميدانية.

ويستخلص من النتائج السابقة وجود عدة جوانب قصور في أدوار الأكاديمية المهنية

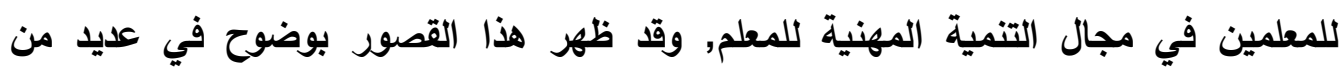
الجوانب والعناصر الأساسية داخل الأكاديمية المهنية للمعلمين في مصر وهية وهي: الإلمكانيات

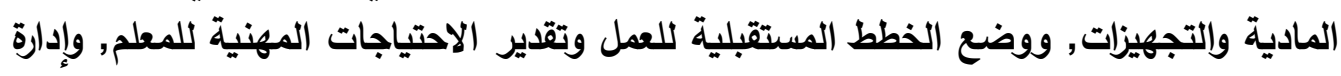

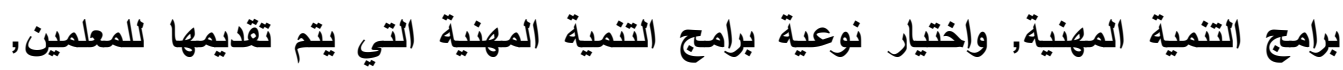
والكوادر التدريبية والمدربين المشاركين في تقديم برامج التنمية المهنية, والأساليب واللوسائل المستخدمة في تقديم برامج التنمية المهنية, وأساليب تقويم برامج التنمية المهنية المئية المقدمة للمعلم, وفاعلية نظم ضبط الجودة لبرامج التنمية المهنية داخل الأكاديمية المهنية. وهذا الأمر يدعو إلي تطوير منظومة العمل داخل الأكاديمية المهنية للمعلمين في مصر

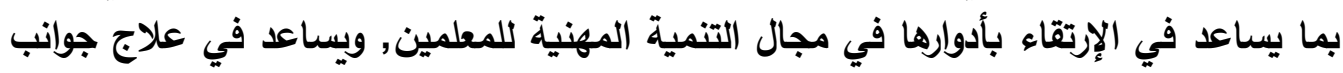

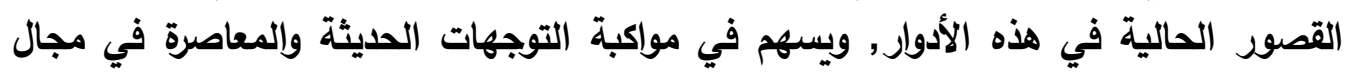

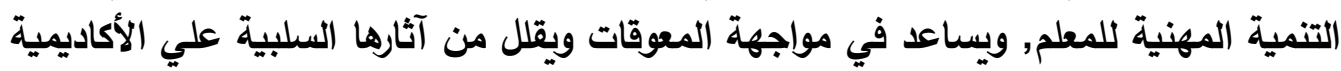

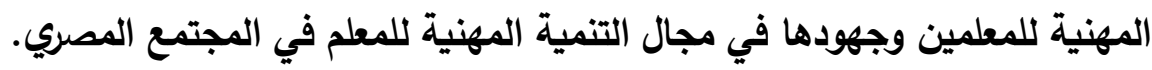


العدد (33) يناير 2013م

$$
\text { ملخص القسم الخامس من الدر اسة }
$$

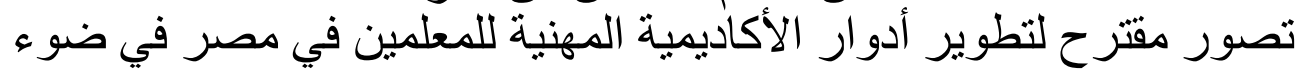
الاتجاهات الحديثة في مجال التمية المهنية للمعلم المينة

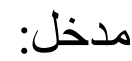

من منطلق أن الهدف الرئيس للاراسـة الحالية يتمثل في بناء تصور مقترح يمكن من

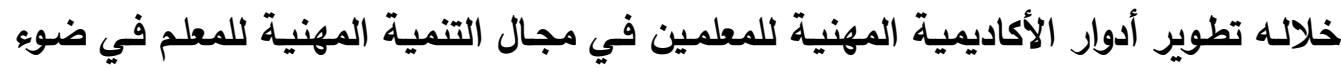

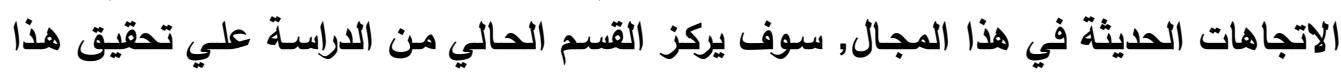

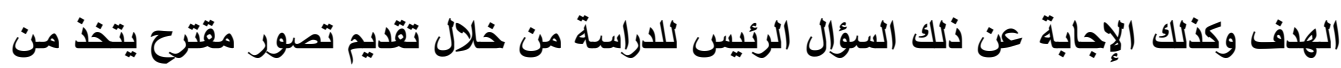

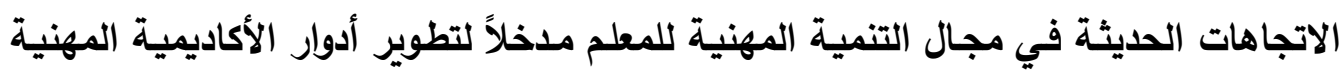
للمعلمين في الاهتمام بالمعلم وتنميته مهنياً. وقد كثفت الدراسة النظرية في الدراسة الحالية أن الأكاديمية المهنية للمعلمين أصبحت

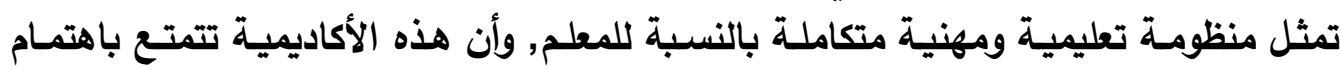

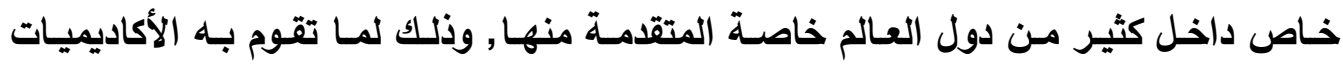

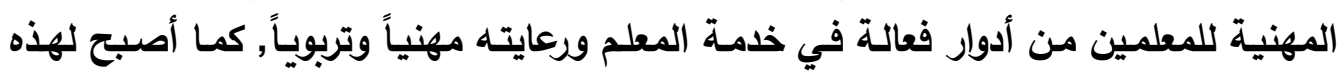

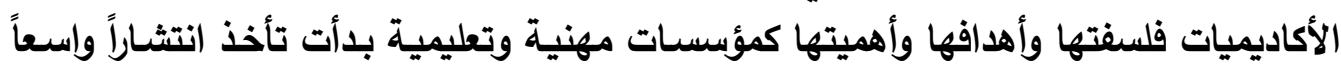

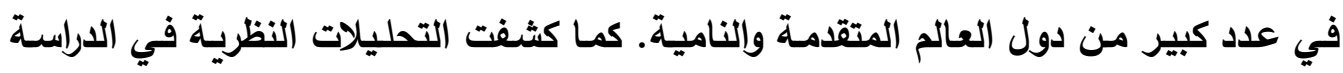

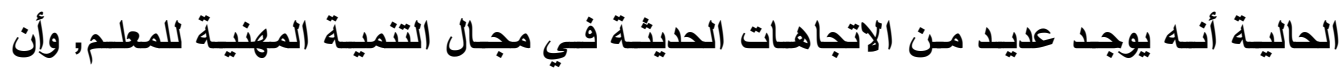

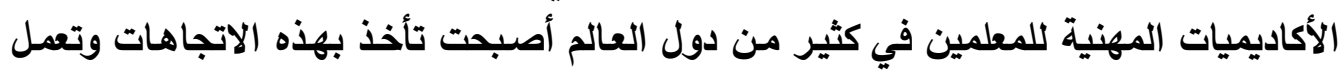

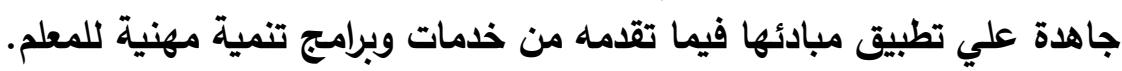
في حين أظهرت نتائج الدراسة الميدانية أن أدوار الأكاديمية المهنية للمعلمين في مجال

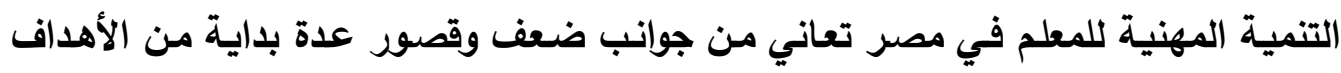

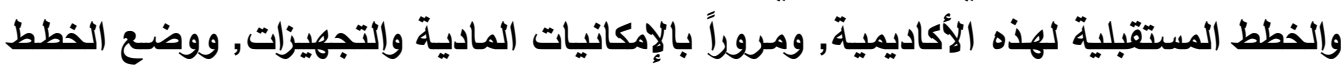
المستقبلية للعمل وتقدير الاحتياجـات المهنية للمعلم, وإدارة برامج التنميـة المهنية, واختيـيار

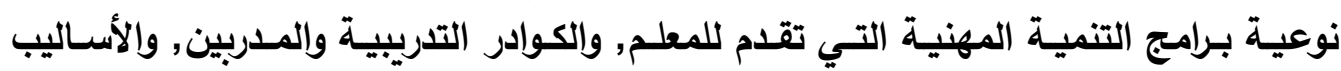

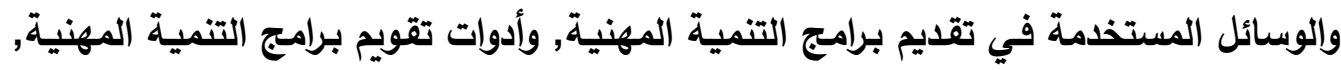

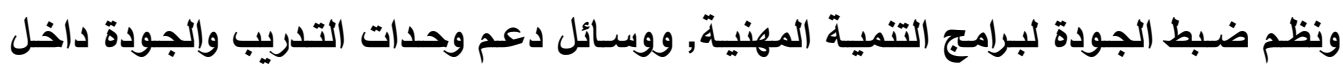

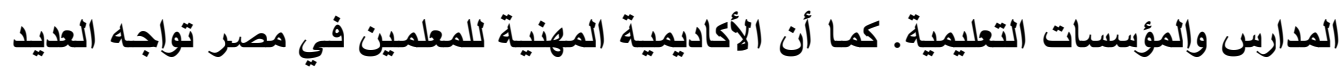
من المعوقات التي تحد من دورها في مجال التنمية المهنية للمعلم. 
وبذلك فإن الأكاديمية المهنية للمعلمين في مصر غير قادرة حالياً علي تلبية الحاجات

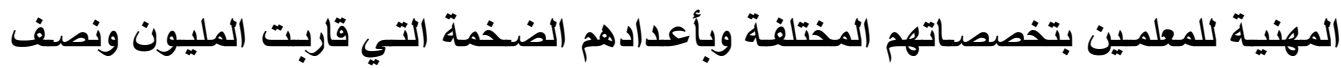

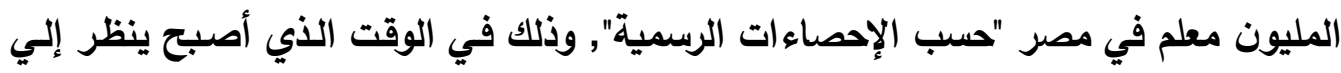

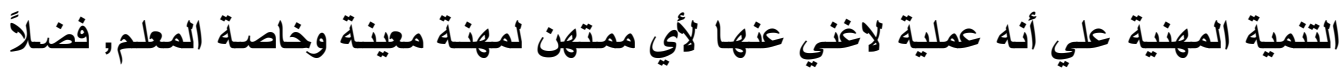
عن أن الأكاديمية المهنيـة للمعلمين في مصر لا تسـاير إلـي حد كبير الاتجاهـات التربويـة التهية الحديثة في مجال التنمية المهنية للمعلم.

ومن هذا المنطلق تقدم الدراسـة في هذا القسم تصوراً مقترحاً لتطوير أدوار الأكاديمية

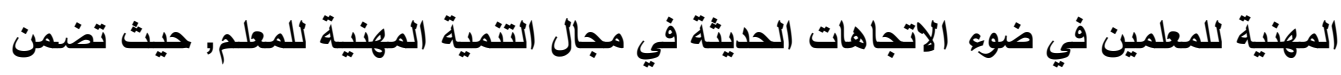

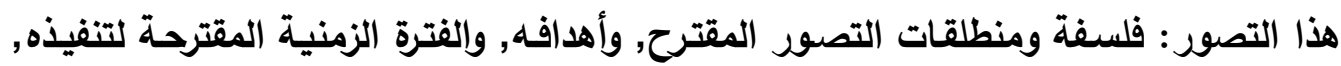

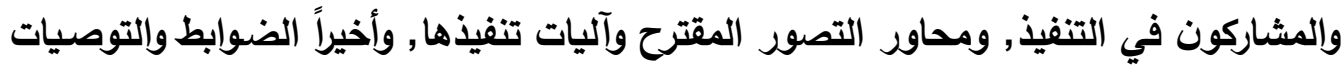
التي ينبغي مراعاتها لنجاح تطبيق التصور المقترح. أولاً: فلسفة التصور المقترح و أهم منطلقاته: تقوم فلسفة التصور المقترح علي أساس أن الأكاديمية المهنية للمعلمين في مصر هي إحدي المؤسسات سبل وأهمها في الوقت الراهن - المسئولة عن تدريب المعلم المادئه وتنميته مهنياً, ومساعدته في أن يكون متابع جيد لكل جديد في مجال مهنته, وتطوير مهاراته المهنية وطريقة ولهي

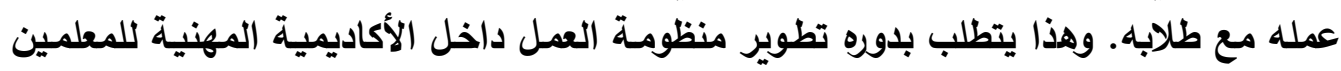

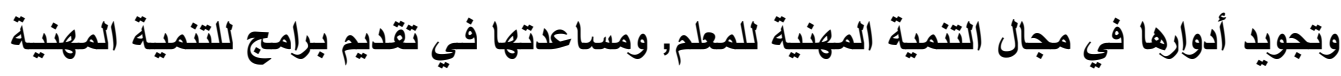
تستوعب الأعداد الضخمة والمتزايدة من المعلمين الذين يرغبون في التنمية المهنية المستمرة والتدريب وقد لا يجدونه. كما تأتي فلسفة التصور المقترح من منطلق أن تطوير الأكاديمية المهنية للمعلمين في

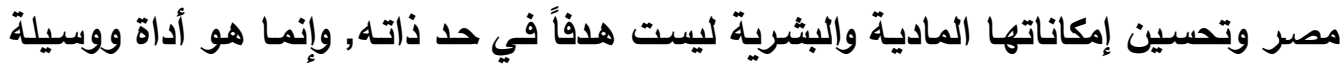

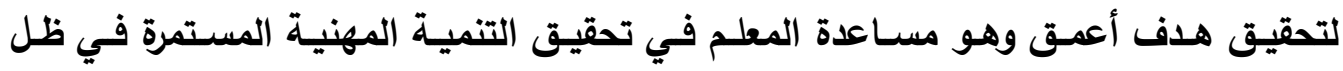

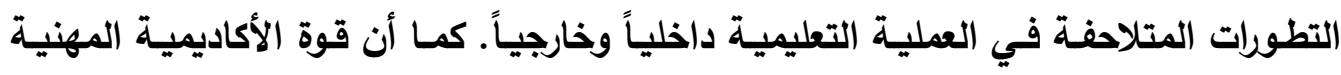

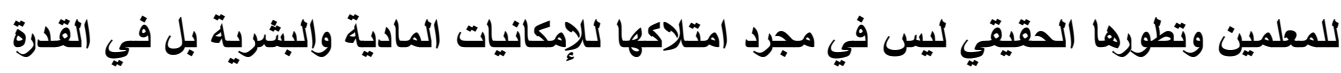

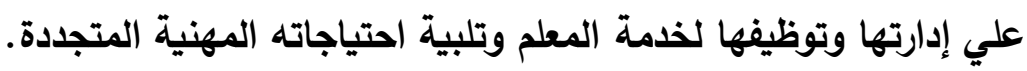
كما تقوم فلسفة التصور المقترح علي مجموعة من المعيات والمنطلقات توضح أهمية

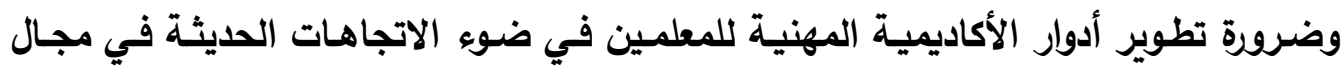

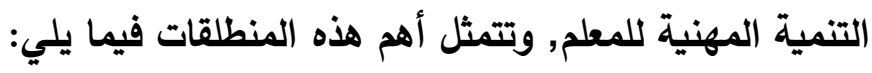


1- تزايد الحاجات المهنية للمعلم وتطور نوعياتها وتغيرها في الوقت الراهن وفي المستقبل,

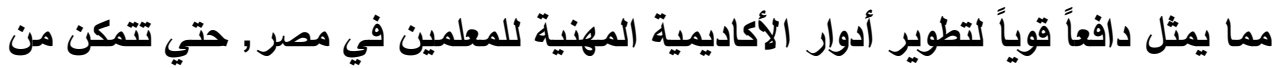
دراسة وتحليل هذه الاحتياجات بدقة وموضوعية وبالتالي العمل علي تلبيتها لاي المعلمين.

2- أن الأكاديمية المهنية للمعلمين في مصر تواجه حالياً أشكالية مزدوجة تتمثل في المعوقات المختلفة التي تواجهها وتحد من دورها في مجال التتمية المهنية للمعلم من فن فئه

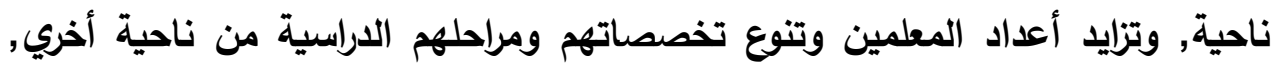
وبالتالي فعليها أن تتعامل مع هذه الأثكالية بعقلية وفكر وتخطيط مختلف, يستطيع

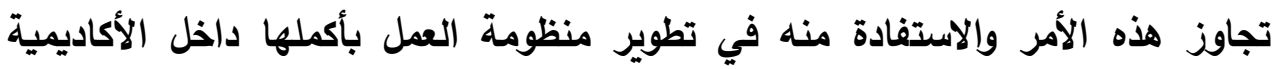
المهنية للمعلمين.

3- إن تطوير الأكاديمية المهنية للمعلمين وعياً وفكراً وممارسةً, والإفادة من الاتجاهات الحديثة في مجال التنمية المهنية للمعلم, وتأكيد النظرة المستقبلية في تحديد الحاجات المهنية للمعلم وتلبيتها, تعد متطلبات مهمة في تطوير منظومة العمل داخل الأكاديمية المهنية للمعلمين في مصر .

4- أن الاهتمام العالمي بإنشاء الأكاديميات المهنية للمعلمين وتطوير نظم العمل فيها, إنما يدعو إلي تطوير نظيرتها في مصر والارتقاء بأدوارها تجاه المعلم وتنميته مهنياً. 5- أن عملية تطوير أدوار الأكاديمية المهنية للمعلمين في مصر, وتجديد منظومة العمل بلاخلها لا يمكن تنفيذها من جانب طرف واحد, بل تتطلب تعاون وتكاتف عديد من الجهات مثل: وزارة التربية والتعليم ونقابة المعلمين وكليات التربية وغيرها.

6- أن تطوير منظومة العمل داخل الأكاديمية المهنية للمعلمين والإرتقاء بأدوارها المختلفة إنما يحتاج إلي إعادة النظر في جميع العناصر الفاعلة في برامج التنمية المهنية للمعلم من: خطط وبرامج وإدارة وأساليب تدريب ومدربين وإثراف وغيرها. 7- لا يمكن إحداث أي تغيير أو تطوير في منظومة التعليم إلا من خلال تنمية قدرات المعلم

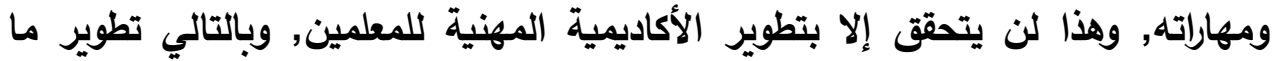
تقدمه من برامج تنمية مهنية للمعلم. ثانياً: أهداف التصور المقتر ح: 
في ضوء فلسفة التصور المقترح وأهم المنطلقات والمعطيات التي يقوم عليها, فأنسه يمكن تحديد أهداف التصور المقترح في النقاط التالية:

1- تحسين أداء الأكاديمية المهنية للمعلمين وتثجيع المسئولين فيها علي متابعة الجديد في مجال التنمية المهنية, ومن ثم التطوير في مجال عملهم مع المعلمين وتنميتهم مهنياً. 2- مساعدة الأكاديمية المهنية للمعلمين في التغلب علي نقاط الضعف وأوجه القصور فيما

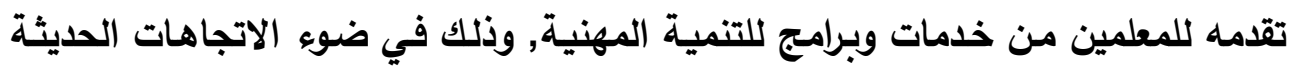

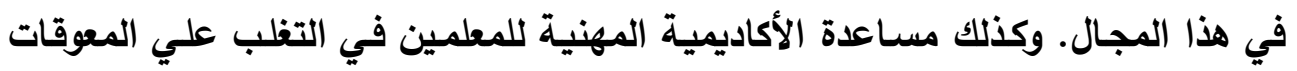
التي تواجهها وتحد من أدوارها تجاه المعلمين وتنميتهم مهنياً. 3- وضع خطوط عريضة وملامح لتطوير أدوار الأكاديمية المهنية للمعلمين في مجال التنمية

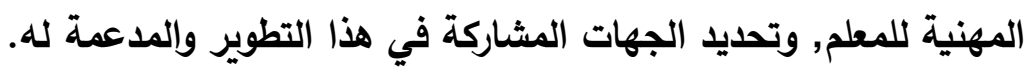

4- تقديم بعض الآليات والطرق التي يمكن أن تستخدمها الأكاديمية المهنية للمعلمين في مصر في تطوير أدوارها في مجال التنمية المهنية للمعلم في ضوء النئ الاتجاهات الحديثة في هذا المجال.

5- مساعدة متخذي القرار لرسم خطط مستقبلية لمـا يجب أن تكون عليه الأكاديمية المهنية للمعلمين في مصر في المستقبل. وكذلك مساعدة الأكاديمية المهنية للمعلمين في كيفية مئه

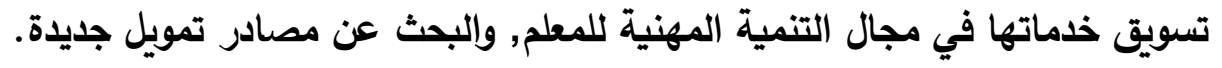
6- تقديم مجموعة من التوصيات والضوابط التي ينبغي علي الأكاديمية المهنية للمعلمين في مراتي مصر مراعاتها للإرتقاء بجهودها في مجال التنمية المهنية للمعلم.

7- الإفادة من الاتجاهات الحديثة للتنمية المهنية للمعلم, وكذلك من الخبرات العالمية وخاصة

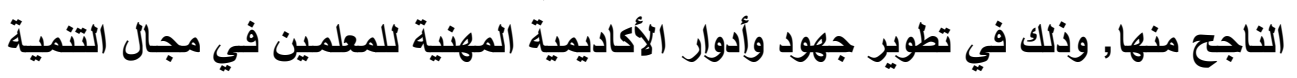

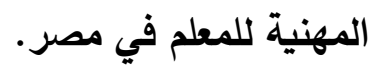


ثالثاً: الفترة الزمنية لتنفيذ التصور المقتر ح:

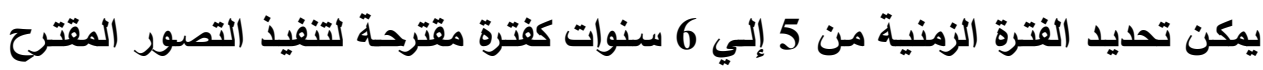

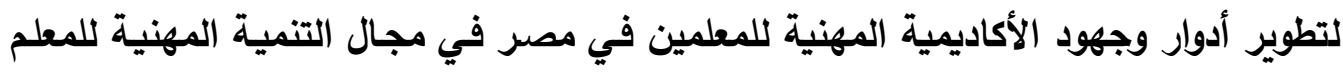

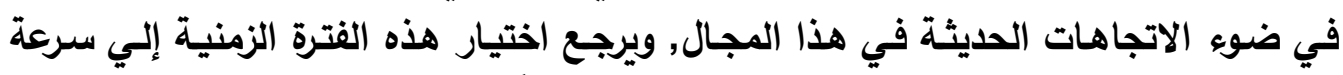

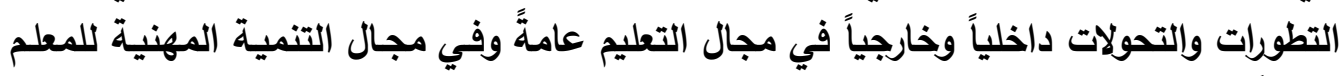

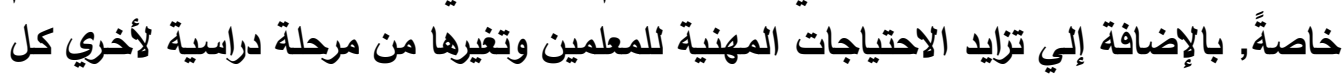

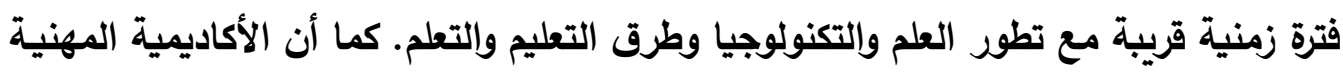

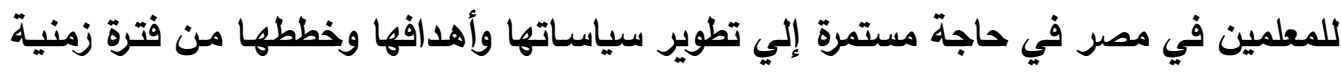

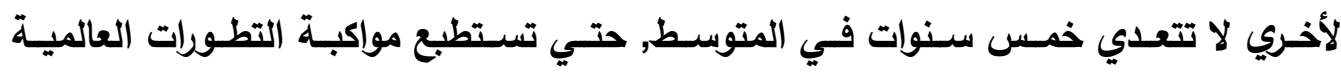
المتلاحقة والاتجاهات الحيثة في مجال التنمية المهنية للمعلم.

$$
\text { رابعاً: المشاركون في تنفيذ التصور المقترح: }
$$

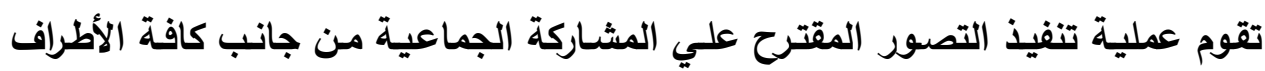

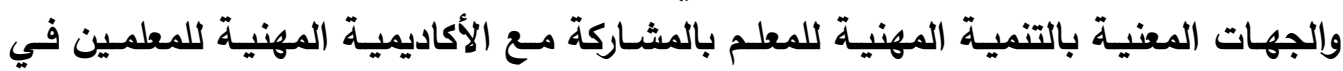

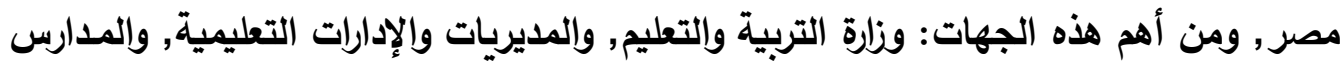

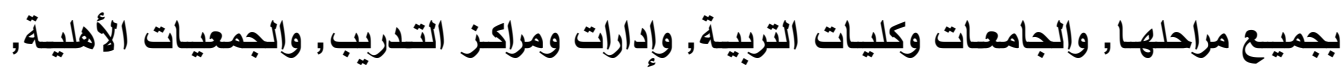
ومؤسسات المجتمع المدني وغيرها من الجهات المهتمة بالتنمية المهنية للمعلم.

$$
\text { خامساً: محاور التصور المقترح و آليات تتفيذها: }
$$

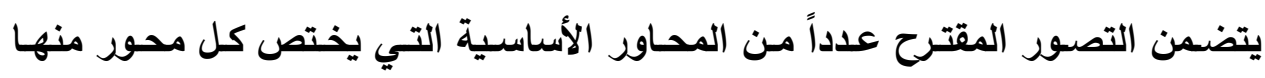

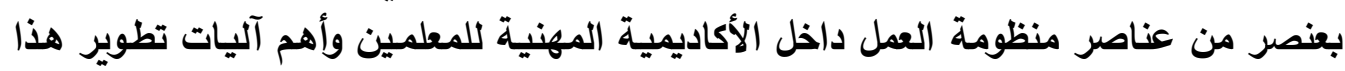
العنصر , وتتمثل هذه المحاور فيما يلي: المحور الأول: تطوير أهداف الأكاديمية المهنية للمعلمين:

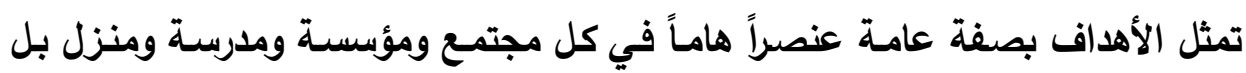

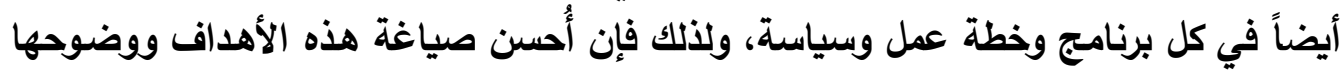

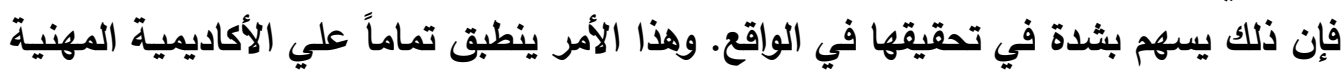

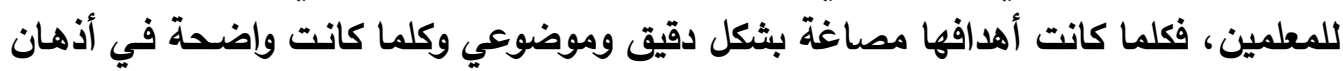

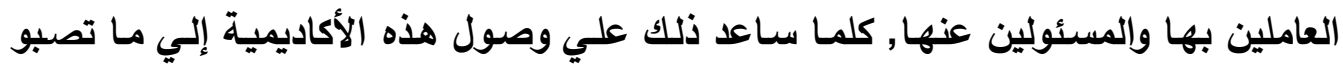


إليه في المجتمع, وكلما ساهم أيضاً في تحفيز العاملين بها علي القيام بأدوارهم في تحقيق هذه الأهد|ف.

ومن أهم الآليات والجوانب المقترحة لتطوير أهداف الأكاديمية المهنية للمعلمين في مصر ما يلي:

إعادة صياغة الأهداف العامة للأكاديمية المهنية للمعلمين في مصر بما يساير التطورات في مجال التربية والتعليم بصفة عامة, وفي مجال التنمية المهنية للمعلم وأهم اتجاهاتها الحديثة بصفة خاصة.

ربـط أهـداف الأكاديميـة المهنيـة للمعلمـين بالحاجـات المهنيـة الفعليـة للمعلمـين بمختلـف

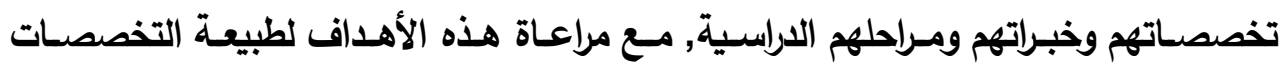
المختلفة للمعلمين.

اثشتقاق أهداف الأكاديمية المهنية للمعلمين من الفلسفة التربويـة للمجتمع المصري ومبادئها

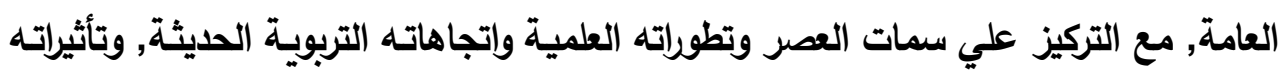
في عمل المعلم وأدواره.

صـياغة الأهداف في صسوة إجرائيـة, بحيث يسـهل تخطيطها وتطبيقها وتقويم مـدي

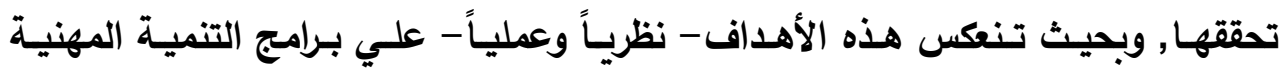
المقدمة للمعلمين.

تركيز الأهداف علي مـا يقوم بـه المعلم من أدوار متغيرة في الحاضر والمستقبل, وكذلك مـا

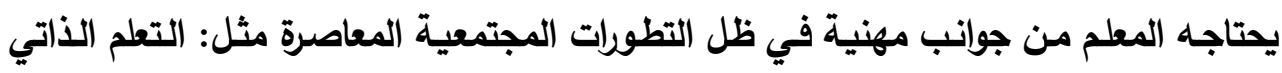

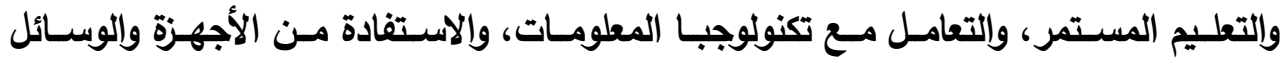

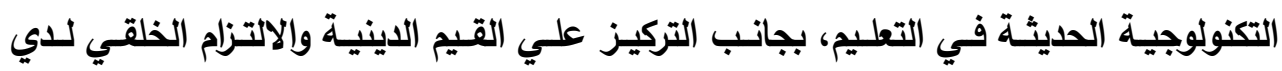
المعلم. التركيز علي وضوح أهداف الأكاديمية المهنية للمعلمين في أذهان العاملين بها، وتحقيق ذلك

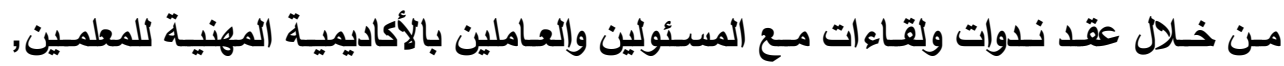
وتعريفهم بلورهم في تحقيق هذه الأهداف في ظل التطورات والاتجاهات التربويـة المعاصرة في بـالادئ مجال التنمية المهنية للمعلم. ويقترح الباحث مجموعة من الأهداف التي يمكن أن تضاف للأهداف الحالية الخاصة

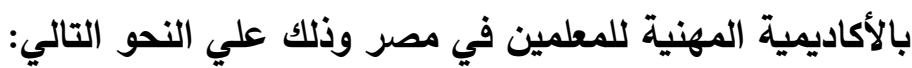


العدد (33) يناير 2013م

1- تحقيق التنمية المهنيـة لأعضـاء هيئة التعليم، ورفع المستوي المهني للمعلمين تربويـاً

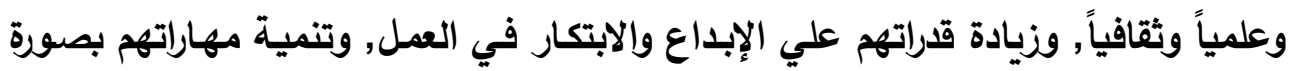
مستمرة بما يؤدي إلي رفع مستوي العملية التعليمية.

2- وضع الخطط والسياسات ومعايير الجودة الخاصة ببرامج التنمية المهنية بمـا يكفل تحقيق

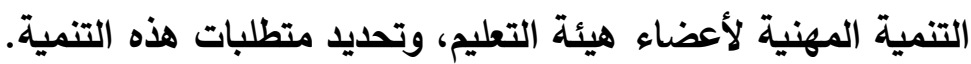

3- ربط خطط التنمية المهنية للمعلم بخطط وسياسـات تطوير التعليم والبحث العلمي, وكذلك

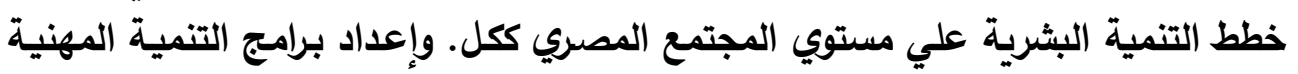
لأعضاء هيئة التعليم وفقاً للخطط والسياسـات التعليمية ومتطلبـات التنمية المهنية للمعلم في مصر.

4- التعاون مع الهيئات والمؤسسات التربوية والتعليمية في تطوير منظومـة التعليم في مصر, والنهوض بها من خلال الاهتمام بالمعلم.

5- تنويع مجالات التنمية المهنية للمعلم وعدم اقتصارها علي برامج التدريب, وإدخال أسـاليب

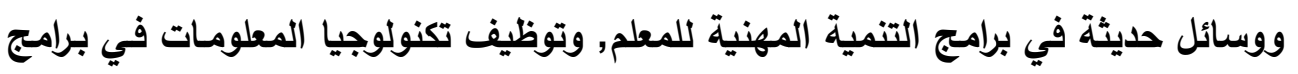
التنمية المهنية.

6- متابعة الاتجاهات الحديثة والمعاصرة في مجال التنمية المهنية للمعلم, والإفادة منها في تطوير برامج التنمية المهنية المقدمة للمعلم.

7- الإفادة من الخبرات العالمية الناجحة في مجال التنمية المهنية للمعلم في تطوير منظومـة

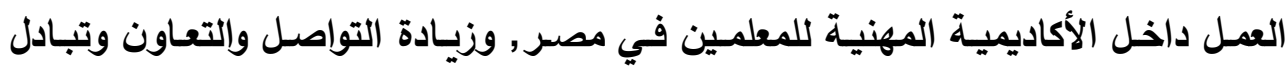

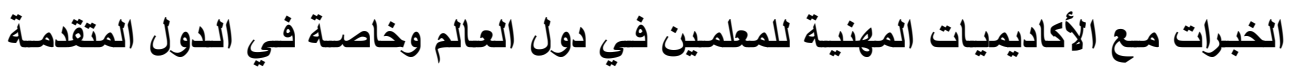
علمياً وتربوياً.

8- استثمار الامكانيات المتاحة لمراكز التدربب التابعة لوزارة التربية والتعليم, ومراكز البحوث,

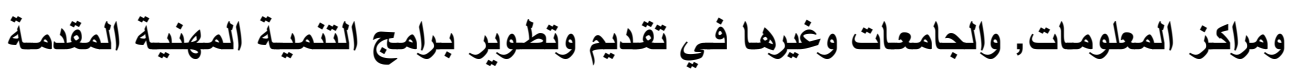
للمعلمين.

9- اقتراح سياسات ونظم تقويم الأداء المهني لأعضاء هيئة التعليم وتطويرها, واقتراح معايير

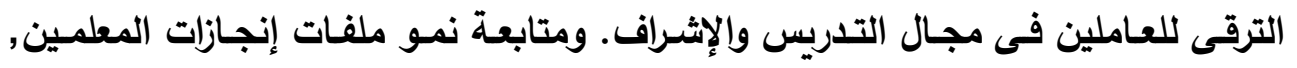

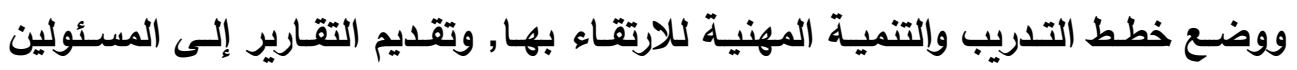
والمعلمين أنفسهم. 
10- تقـويم الأجهزة والإدارات المسئولة عن إدارة بـرامج التنميـة المهنيـة للمعلـم سـواء علـي مستوي الدولة أو مستوي المديريات والإدارات التعليمية.

11- التعاون مع كليات التربية والمراكز البحثية والتدريبية وهيئات التنمية المهنية في كل مـا يحقق أهداف الأكاديميـة. ودعم البحوث والدراسـات في مجـالات التنميـة المهنيـة للمعلم

وتشجيع الاستفادة بنتائجها.

12- توفير الاستشارات الفنية والمهنية لجميع المؤسسات التعليمية وفي مقدمتها: وزارة التربية

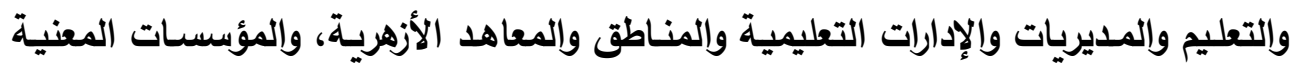
وذلك في مجال التعليم والتنمية المهنية.

13- دعم ومتابعة وحدات التدريب والجودة بالمدارس والمعاهد الأزهرية, ومساعدتها في تخطيط

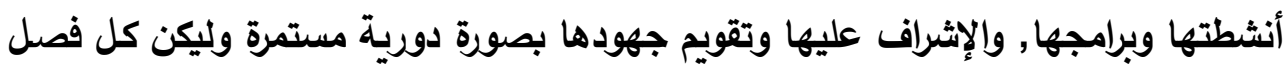
دراسي.

14- تنمية الزمالة المهنية, ومنح شهادات الصلاحية للمعلم بمزاولة المهنة, وتعميق الإحساس بالانتماء المهني لاي المعلمين والعاملين في قطاع التعليم.

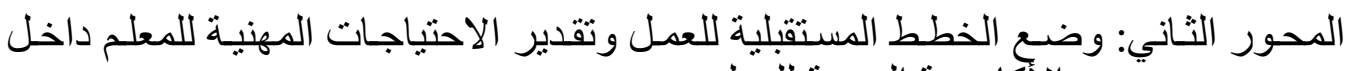
الأكاديمية المهنية للمعلمين:

التخطسيط هـو البدايـة الحقيقيـة لأي عمـل نـاجح وفعـال, وأي مؤسســة تعليميـة أو

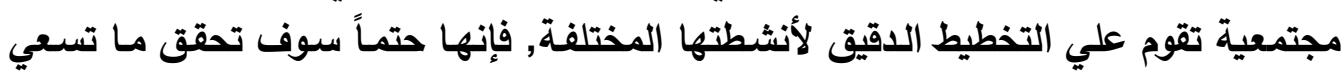
إليه من أهداف وغايات, والأكاديمية المهنية للمعلمين -كمؤسسة تعليمية ذات الاتهية فاعلية وأهمية

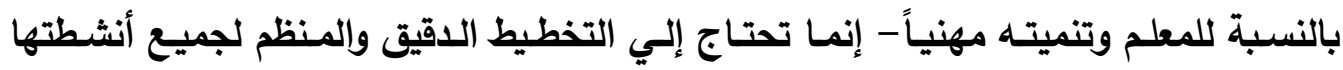
وبرامجها حتي تستطيع النجاح في عملها والاستمرار فيه.

ويمكن اقتراح بعض الآليات التي تساعد الأكاديمية المهنية للمعلمين في مصر في النجاح في وضع الخطط المستقبلية للعمل وتقدير الاحتياجات المهنية للمعلم, وذلك كما يلي: الاكية - تحديد الأكاديمية المهنية للمعلمين مدد زمنية معينة -ولتكن كل ثلاث سنوات بحد أقصي -

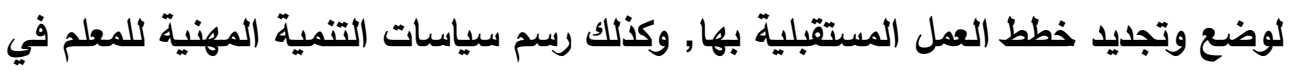
المجتمع المصري. 
العدد (33) يناير 2013م

2- ارتباط الخطط المستقبلية للأكاديمية المهنية للمعلمين مع الخطة العامة للاولة بصفة

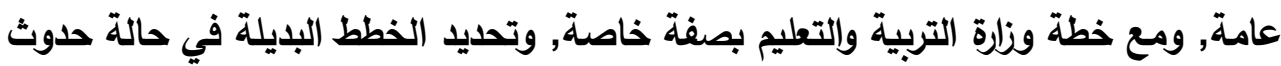
تغيرات أو تطورات تربوية مفاجئة عالمياً أو محلياً.

3- إشراك الأكاديمية المهنية للمعلمين جميع المسئولين والمختصين وجميع العاملين داخل

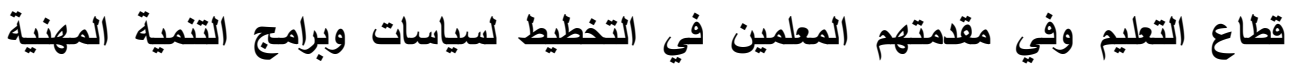

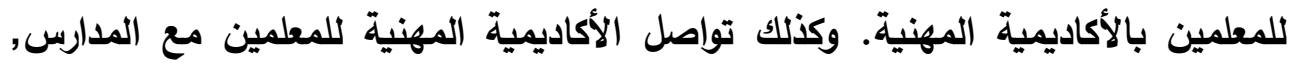
وإثراكها في التخطيط المستقبلي للاحتياجات المهنية للمعلمين بها.

4- دخول الأكاديمية المهنية للمعلمين في شراكة حقيقية مع الجامعات وكليات التربية ومراكز

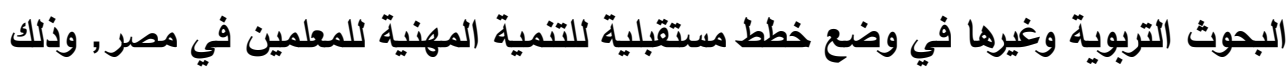
لمدد تتراوح ما بين ثلاث وخمس سنوات وعئه

5- تحقيق التكامل بين ما تضعه الأكاديمية المهنية للمعلمين من خطط مستقبلية, وبين ما

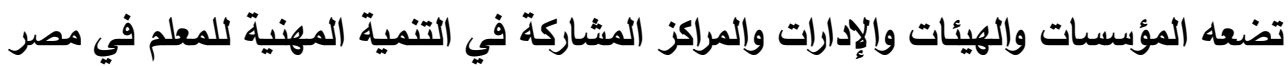
من خطط مستقبلية للتنمية المهنية للمعلم.

6- استخدام الأكاديمية المهنية للمعمين للأساليب الحديثة للتخطيط "كأسلوب النظم وأسلوب

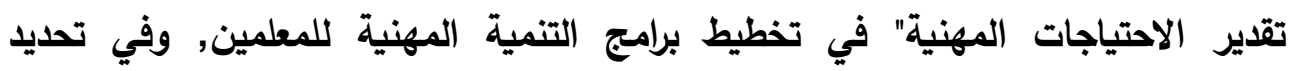
الاحتياجات المهنية للمعلم حاضراً ومستقبلاً.

7 - تحقيق الأكاديمية المهنية للمعلمين اللامركزية في التخطيط ووضع سياسات العمل, وكذلك

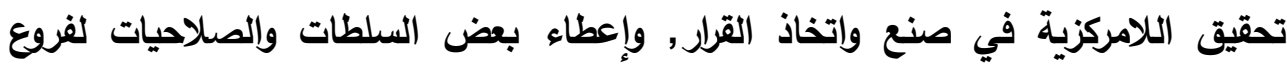
الأكاديمية المهنية للمعلمين, مع ترسيخ مبادي المحاسبية والمساءلة وتقييم النتائج بثكل واتهات دوري لهذه الفروع.

8- مثاركة الأكاديمية المهنية للمعلمين في إجراء دراسات مستقبلية بالتعاون مع وزارة التربية

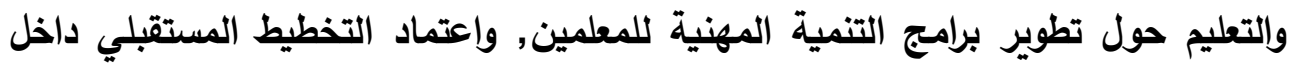
الأكاديمية المهنية للمعلمين علي تحليل المعلومات والبيانات الإستراتيجية والمهمة دافئ داخل قطاع التعليم في مصر.

9- قيام الأكاديمية المهنية للمعلمين بإجراء دراسات للوضع الراهن وتحليل بيئتها الاخلية

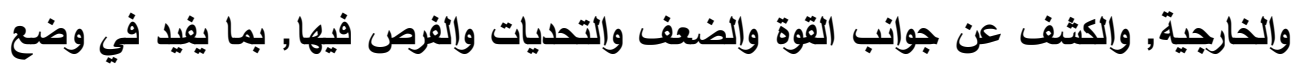
الخطط المستقبلية الدقيقة للتنمية المهنية للمعلمين وتقدير احتياجاتهم المهنية. 
10- وضع الأكاديمية المهنية للمعلمين خطط مستقبلية للتوسع في استخدام التقنيات التدريبية الحديثة "كالتدريب من بُعد والتدريب الإكتروني للمعلمين وغيرها", بما يساعد في التوسع فئ فئه في تقديم برامج التنمية المهنية للمعلم.

11- قيام الأكاديمية المهنية للمعلمين بوضع خطط بديلة أو احتياطية للاستعداد لمواجهة متطلبات إجراء أو تطبيق أي سياسات للتطوير في المناهج أو أساليب الإدارة في أي مرحلة

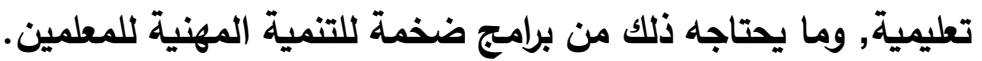

12- وضع الأكاديمية المهنية للمعلمين لخطط مستقبلية لتسويق خدماتها الترببية والاستشارية,

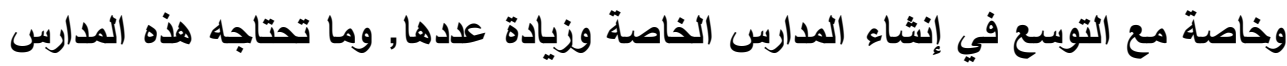
من برامج للتدريب والتتمية المهنية لمعلميها. 13- قيام الأكاديمية المهنية للمعلمين بتخطيط وإعداد قواعد بيانات متكاملة للمعلمين والمدربين والبرامج التدريبية والاحتياجات المهنية للمعلمين وغيرها.

14- وضع الأكاديمية المهنية للمعلمين خطط مستقبلية لسد احتياجاتها من المباني والمرافق, ومواجهة القصور في التجهيزات والإمكانيات المادية والبشرية.

15- إفادة الأكاديمية المهنية للمعلمين من الخبرات العالمية وتجارب الدول الأخري ـوخاصة تلك

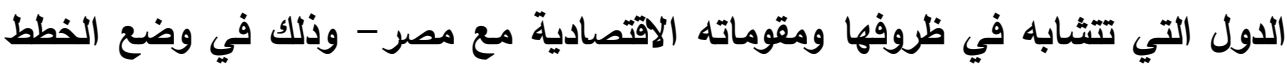

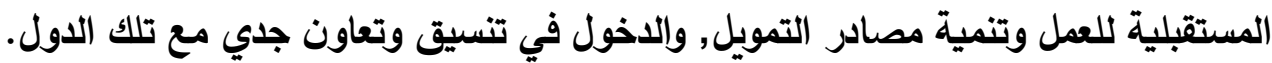
16- قيام الأكاديمية المهنية للمعلمين بلراسة ووضع تخطيط دقيق للاحتياجات المهنية للمعلمين بناء علي: التقارير الفنية لمراقبة العمل وأداء المعلمين مع طلابهم, ومؤشرات الرضهات الوظيفي لاي المعلمين وشكاويهم في العمل, ودراسة مشكلات المعلمين, ودراسة التطورات

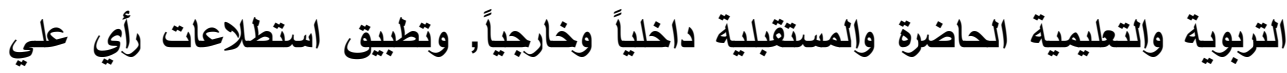
المعلمين وتوصياتهم. 
المحور الثالث: توفير الإمكانيات الماديـة والتجهيز ات ومصـادر التمويل داخل الأكاديميـة المهنية للمعلمين:

أن توفير الإمكانيات المادية والتجهيزات ومصـادر التمويل يعد أحد الجوانب الأساسية

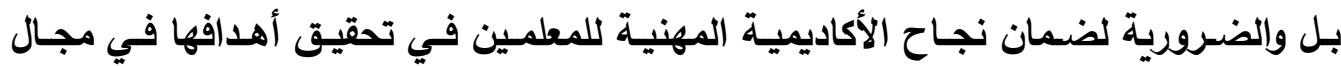

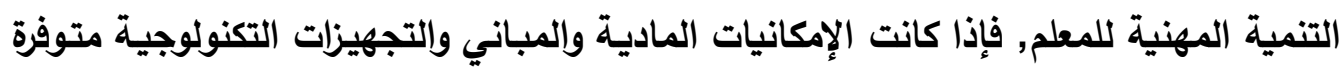

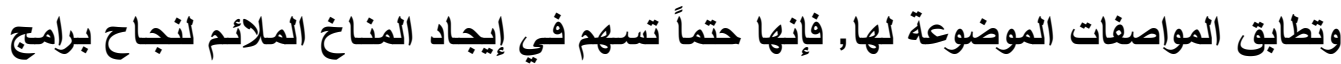

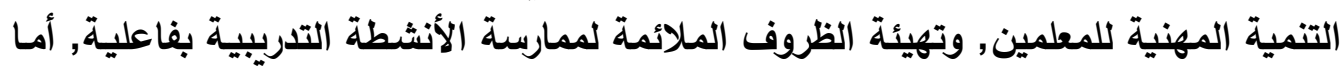
إذا كان هناك قصور في المباني والتجهيزات المادية ومصادر التمويل داخل الأكاديمية المهنية المئية

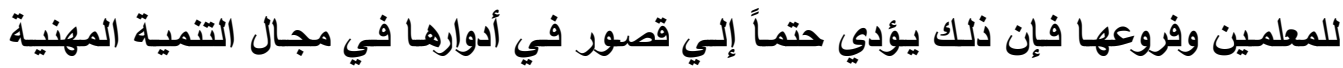
للمعلم.

ويمكن اقتراح بعض الآليات وجوانب التطوير المقترحة للمباني والتجهيزات ومصـادر التمويل بالأكاديمية المهنية للمعلمين من خلال النقاط التالية:

1- خضوع مباني الأكاديمية المهنية للمعلمين لمواصفات قياسية عند إنثائها لضمان نجاحها في أداء مهامها, مع توفير الاعتمادات المالية اللازمة لتطوير المباني الحالية للأكاديمية المهنية للمعلمين وفروعها.

2- إنثاء قاعات للتدريب وش العمل ذات سعات مناسبة ومجهزة بكافة وسائل التدريب

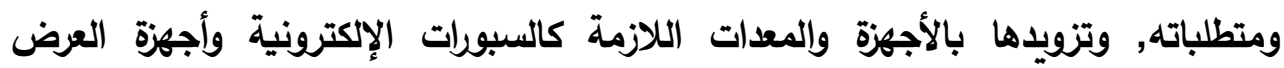

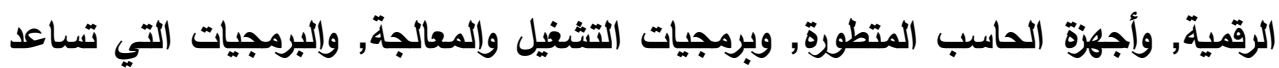
في التعامل بسهولة مع المواد التدريبية.

3- مراعاة تناسب عدد قاعات التدريب والمعامل وسعاتها والأثاث الموجود بها مـع الأنثطة التدريبية واحتياجات المعلمين الملتحقين ببرامج التنمية المهنية. 4- تـوفير المرافق الكافيـة لحاجـة المتدربين (دورات ميـاه, وأمساكن للصـلاة, وأمساكن ومقاعد

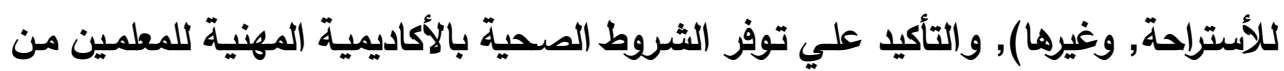

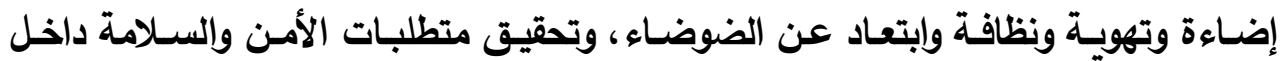
الأكاديمية وفي قاعات التربب. 
5- دراسة البدائل والخيارات المستقبلية لتوفير الاحتياجات من المباني والمرافق التي تتطلبها

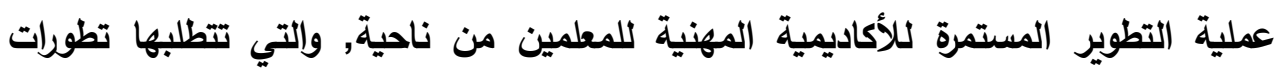
العملية التعليمية والتتمية المهنية للمعلم من ناحية أخري.

6- تبني الأكاديمية المهنية للمعلمين لعملية تقديم بعض الخدمات والأنشطة الخاصة بالتدريب

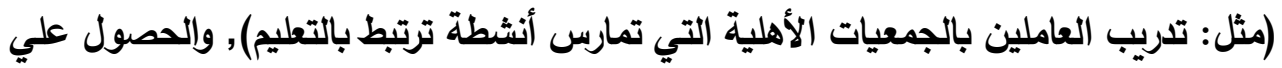
مقابل مالي لهذه الخدمات والأنثطة, وبالتالي دعم موارد الأكاديمية. 7- دخول الأكاديمية المهنية للمعلمين في شراكات وعقد اتفاقات مع بعض المؤسسات الخدمية لتصميم برامج تدرببية للعاملين بها, والحصول علي مقابل تلك الخدمة. وذلك

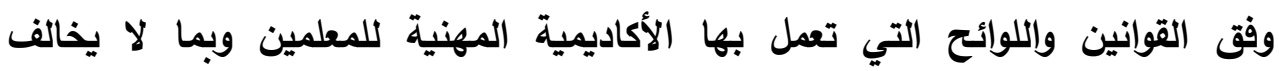
نصوصها.

8- إمكانية إنثاء الأكاديمية المهنية للمعلمين نظام إليكتروني حليث (تحت مسمي مراكز أو شبكات التدريب الإكتروني للمعلمين) يتولي تقديم خدمات وبرامج التنمية مهنية الإلكترونية

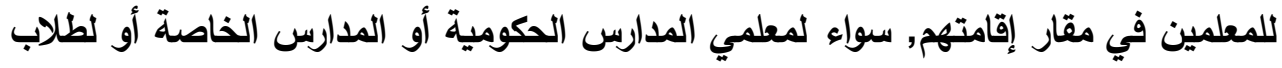

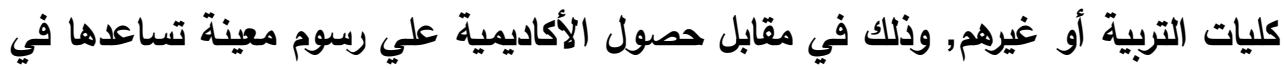
دعم مواردها المالية في المستقبل. 9- تجهيز مطبعة بالأكاديمية المهنية وفروعها بأحلث تقنيات الطباعة, لتوفير الاحتياجات اللازمة لعقد برامج التنمية المهنية للمعلمين من مطبوعات وكتيبات وأدلة ومواد مطبوعة. 10- إمكانية إنشاء شبكة موحدة لخدمات التدربب والتنمية المهنية للمعلمين تشارك فيها جميع

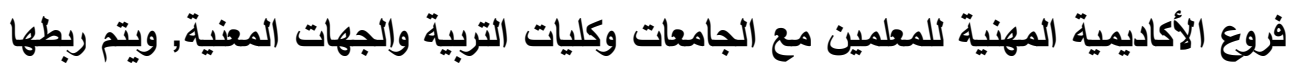
بمراكز التدريب والتعليم الإكتروني داخل الجامعات, وتوفير التجهيزات والأدوات المساعدة لزيادة التواصل مع المعلمين.

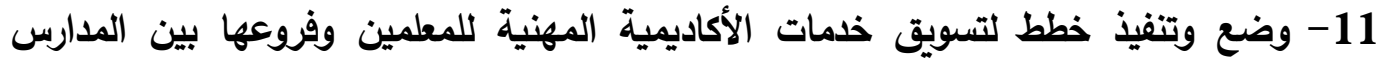
الخاصة والمؤسسات التعليمية والجمعيات الخيرية, بما يساعد في زيادئ فيادة موارد الأكاديمية, ويزيد قراتها علي تقديم مزيل من برامج التنمية المهنية للمعلمين.

12 - إمكانية إنشاء صندوق لاعم وتمويل الأكاديمية المهنية للمعلمين, ويكون هذا الصندوق ذا

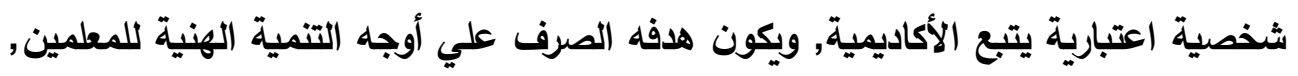


ويمكن أن يقبل هذا الصنوق ما يقدمه المواطنون من إعانات وتبرعات وهبات ووصايا ومساهمات عينية أو مادية.

13- الإفادة من الخبرات الدولية الناجحة في مجال تمويل أنشطة وخدمات الأكاديمية المهنية

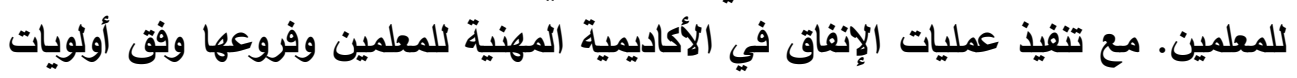
محددة, وبما يتناسب مع الموارد المتاحة.

14- زيادة المخصصات المالية لفروع الأكاديمية المهنية للمعلمين, وإعادة تخصيص الميزانيات

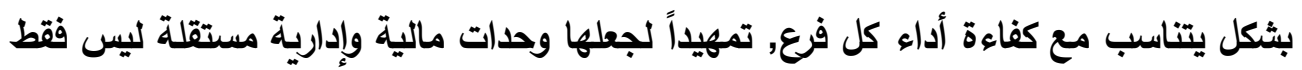
في الإنفاق ولكن أيضاً في التمويل وتدبير الموارد المالية.

15- تثكيل مجالس أمناء استشارية للأكاديمية المهنية للمعلمين وفروعها, تضم في عضويتها

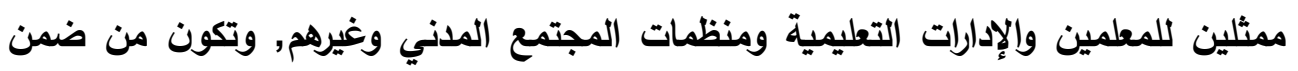
مهامها دعم الأكاديمية مادياً وتنظيمياً ومعنوياً.

16- إجراء صيانة فنية دورية ومستمرة -علي الأقل سنوياً- للمباني والتجهيزات والأجهزة

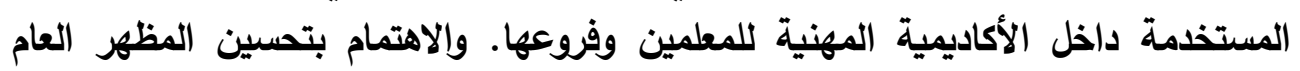

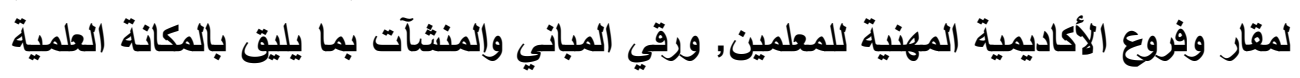
والمهنية للأكاديمية.

17- تحقيق عديد من الجوانب في المكتبات المتوفرة بالأكاديمية المهنية للمعلمين وفروعها

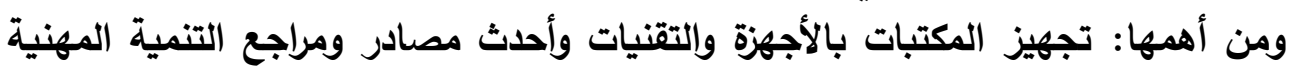

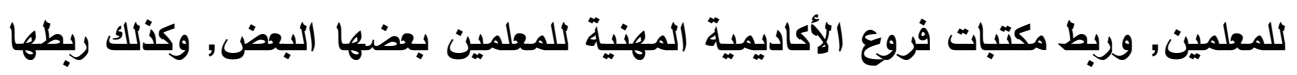

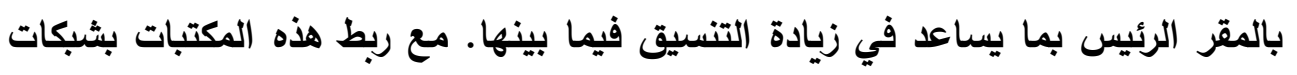
المعلومات والمكتبات الرقمية (E-Library) والاستعانة بخدماتها في تحقيق فيادة التنمية المهنية للمعلمين, وتوفير أمناء مكتبات مؤهلين لتقديم الخدمات المكتبية المتطورة

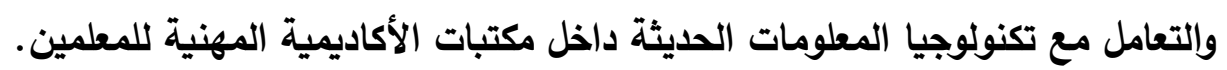
وبصفة عامة فإنه كلما كانت الإمكانيات المادية والتجهيزات ومصادر التمويل والبنية

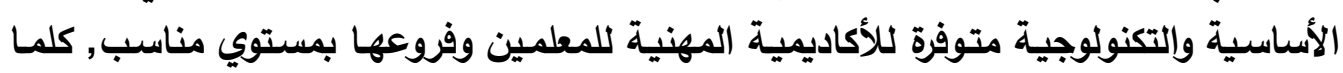

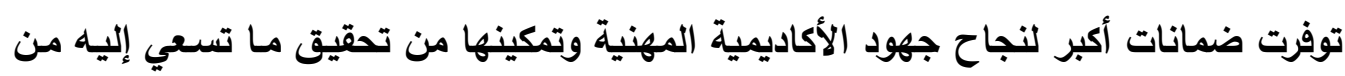

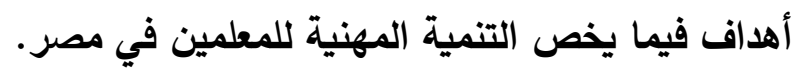


ويجب الإثـارة إلـي أن الوصـول للمسـتوي المطلـوب والقياسـي في البنيـة التحتيـة

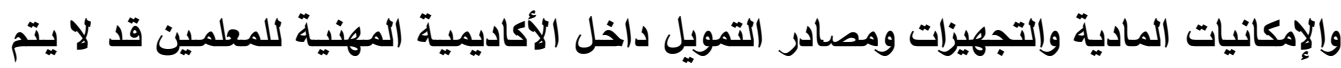
دفعة واحدة وفي مرحلة ووقت قصير , وإنما يتطلب جهوداً متتابعة بثكل مرحلي. المحور الر ابع: تطوير إدارة بر امج التتمية المهنية داخل الأكاديمية المهنية للمعلمين:

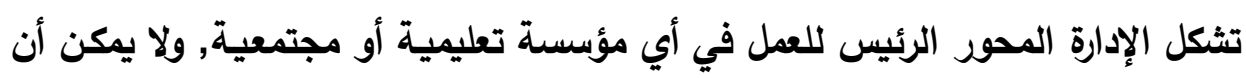

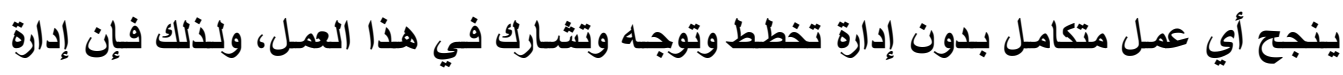

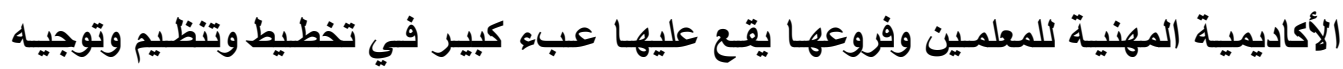

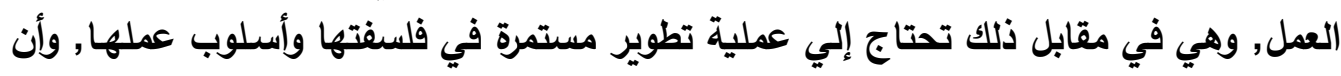

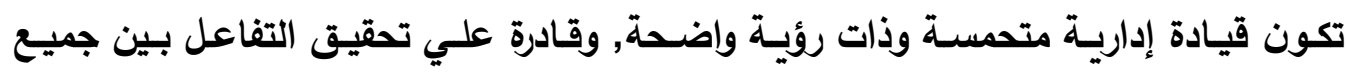

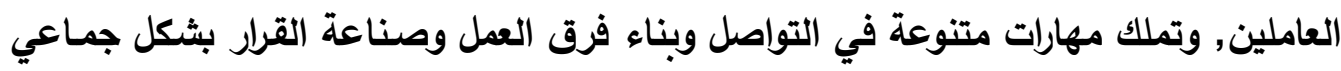
داخل الأكاديمية المهنية للمعلمين.

ويمكن اقتراح مجموعـة مـن الآليـات والجوانب التـي يمكن مـن خلالهـا تطوير إدارة

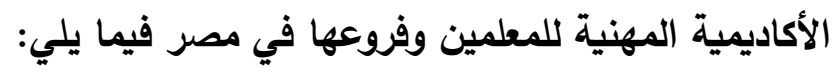
- عقد دورات تدريبية دورية لمسئولي الأكاديمية المهنية للمعلمين وفروعها في المحافظات المختلفة, ويمكن عقد هذه الاورات بالمقر الرئيس للأكاديمية, علي أن تركز هذه الاديه الدورات

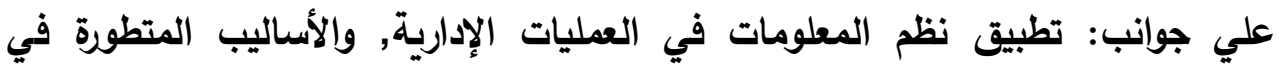
الإدارة , وصنع القرار واتخاذه.

2- وضع معايير علمية ومهنية دقيقة لاختيار القيادات الإدارية داخل الأكاديمية المهنية

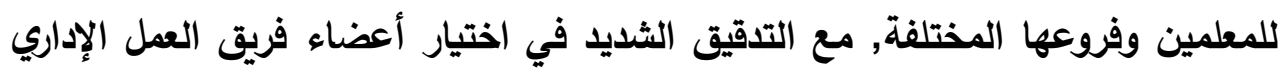
والفني داخل الأكاديمية المهنية للمعلمين وفروعها.

3- تكوين هيكل إداري عالي الكفاءة لايه الوعي بالاحتياجات المهنية الحالية والمستقبلية

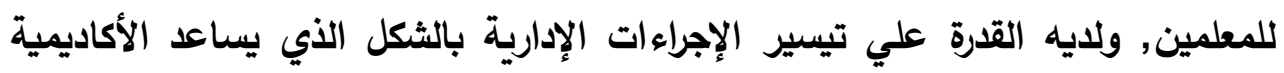
المهنية للمعلمين علي تحقيق أهدافها.

4- تجنب مخاطر التضخم الإداري داخل الأكاديمية المهنية للمعلمين وفروعها, نتيجة زيادة عدد الإداريين والعاملين داخلها عن حاجة العمل والتنظيم الإداري بها. 
العدد (33) يناير 2013م

5- توظيف التقنيات الإدارية والمعلوماتية الحديثة في تنظيم وإدارة العمل داخل الأكاديمية

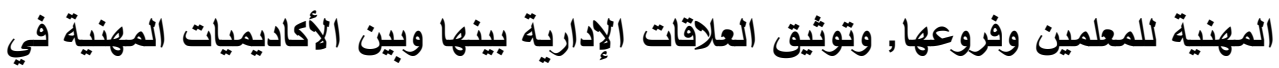
دول أخري من خلال استخدام تلك التقنيات.

6- وضع خطة زمنية لتأهيل الكوادر الإدارية الثابة داخل الأكاديمية المهنية للمعلمين, بما يضمن استمرارية عملية التطوير والتحسين في العمل. 7- وضع توصيفات دقيقة للوظائف الإدارية والإثرافية داخل الأكاديمية المهنية للمعلمين, يتم من خلالها تحديد اختصاصات كل فرد في الجهاز الإداري والإثرافي علي برامهج التنمية المهنية التي تقدم للمعلمين.

8- تفعيل أساليب المساءلة والمحاسبية في تنظيم العمل وإدارته داخل الأكاديمية المهنية للمعلمين, وتطبيق نظاماً فعالاً لتلقي الشكاوي والمقترحات من المعلمين وبحثها من خلال إدارة الأكاديمية.

9- توفير قدر واسع من الحرية الإدارية لمديري ومسئولي فروع الأكاديمية المهنية للمعلمين,

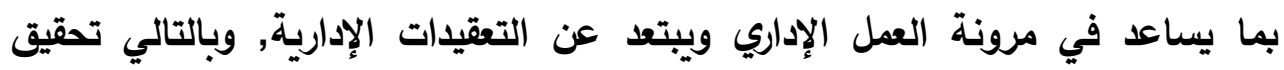
متطلبات تطوير العمل وبرامجه داخل الأكاديمية وفروعها.

10- تثكيل مجالس أمناء استشارية داخل الأكاديمية المهنية للمعلمين وفروعها, تضم في عضويتها المهتمين بنشاط الأكاديمية وممثلين للمعلمين والمسئولين والإدارات التعليمية الاكية المئية

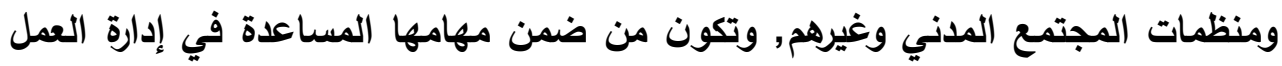
داخل الأكاديمية, ودعمها مادياً وتنظعيمياً ومعنوياً.

11 - التخلي -ولو جزئياً - عن اختيار القيادات الإدارية داخل الأكاديمية المهنية للمعلمين

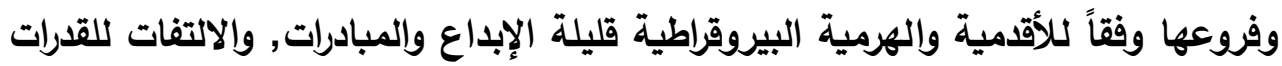
الثبابية المبدعة التي تستطيع التطوير والإبداع في العمل. 12- يمكن الاستعانة ببعض رجال التربية والتعليم البارين, وأساتذة كليات التربية, ومنسقو البرامج, ومتخصصي أمن المعلومات والثبكات, والمستشارين القانونيين وغيرهم ممن والين

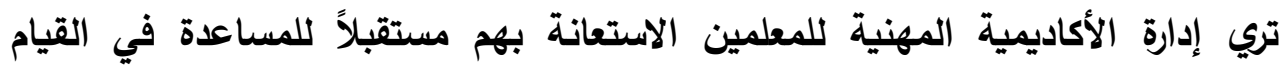
بالأعمال الإدارية والفنية حسب مقتضيات العمل. 
13- بناء قنوات اتصال وتواصل بين إدارات الأكاديمية المهنية للمعلمين وبين المسئولين

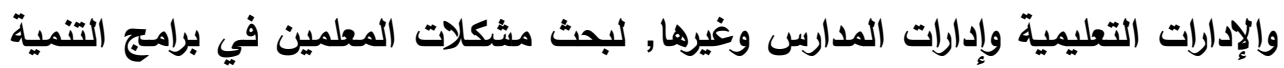

$$
\text { المهنية وسبل حلها. }
$$

14- الإستفادة من التجارب والخبرات العالمية الناجحة في مجال إدارة العمل داخل الأكاديمية

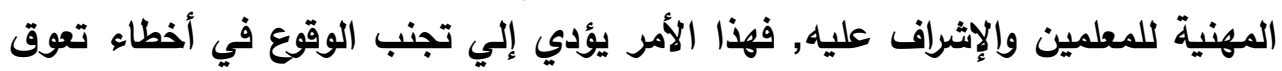
العمل أو تبعده عن مساره الصحيح.

وبصفة عامسة فعنصر الإدارة والإثراف بمثابة العمود الفقري في أي منظومسة تعليمية

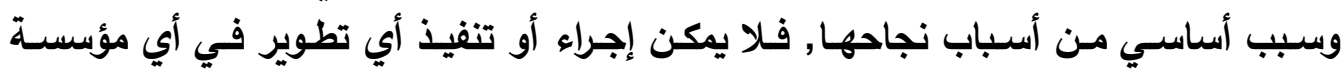

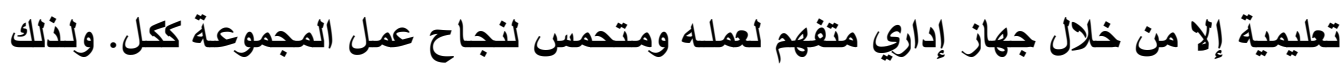

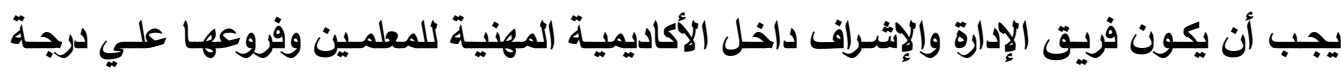

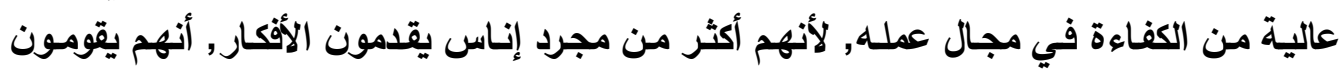
مجتمعين بعملية التنمية المهنية للمعلمين, ويقومون بالتأكيد بكم هائل من التفئل التصيلات المطلوبـة لنجاح هذا الهدف.

المحسور الخـامس: تطـوير نوعيـة بـر امج التنميـة المهنيـة التي تقدمها الأكاديميـة المهنيـة للمعلمين: تصوبر نو

تمثل برامج التنمية المهنية ركناً أساسياً من أركان العمل داخل الأكاديمية المهنية

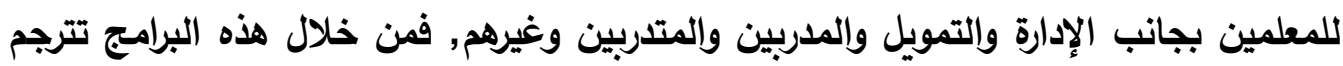

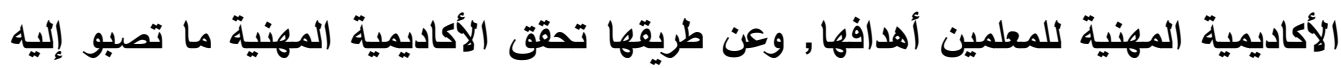

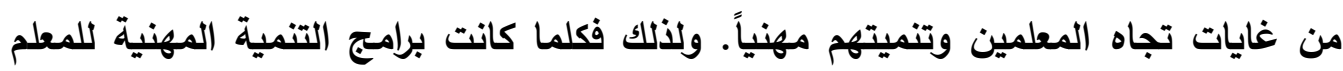

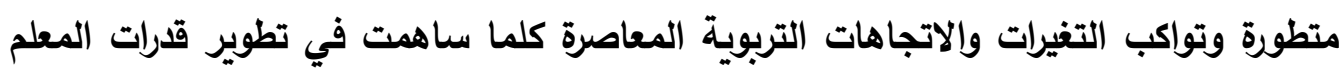

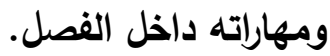

وتتبني الدراسة الحالية بعض الآليات والجوانب المقترحة التي يمكن أن تسهم في

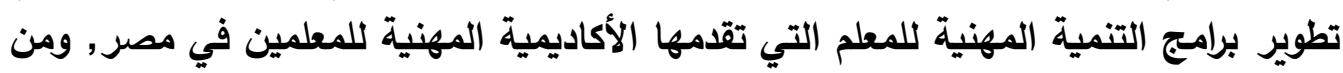

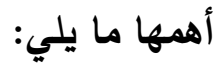

1- وضـع مواصفات لبـرامج التنميـة المهنيـة المقدمسة للمعلمين, بحيث تتسـم هذه البرامج بالتجديد والبعد عن النمطية, مع وضع المتغيرات والاتجاهات العالمية والنظرة المستقبلية في مجال التنمية المهنية للمعلم في الاعتبار. 
2- تركيز الأكاديمية المهنية للمعلمين في بناء برامجها للتنمية المهنية علي علوم المستقبل

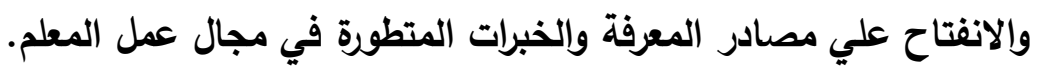

3- الاسترشـاد بالتجارب والخبرات العالمية عند اختيار وبنـاء برامج التنمية المهنية للمعلم,

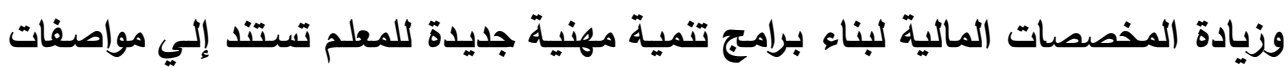
ذات صبغة عالمية.

4- الاستعانة بالمراكز التربوية المتخصصة, ومراكز التخطيط التربوي وغيرها من الجهات ذات

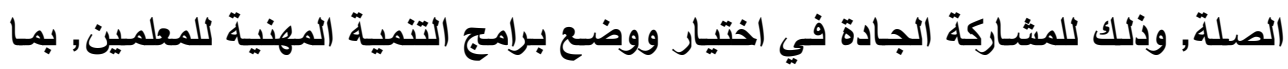
يسهم في رفع مستوي الأداء لاي المعلمين مهنياً وأكاديمياً. 5- وضـع الأكاديميـة المهنيـة للمعلمـين خطط دوريـة لتحديث برامجهـا المقدمـة للمعلمـين,

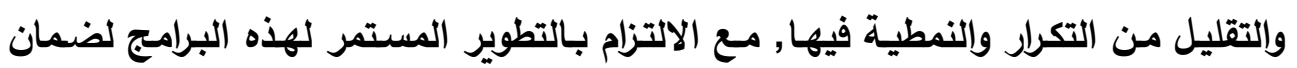

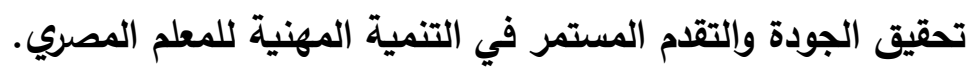
6- تصميم نوعية جديدة من برامج التنمية المهنية للمعلم تعتمد في تنفيذها علي نظام القنوات

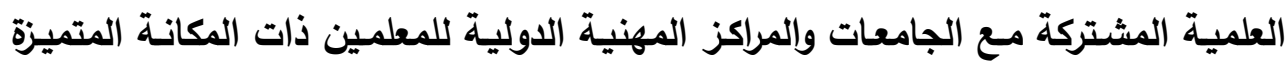
علمياً ومهنياً, وبحيث تساير تلك البرامج تطورات العملية التعليمية ومشكلاتها في مصر. 7- تركيز الأكاديمية المهنية للمعلمين في عملية تطوير برامجها للتنمية المهنية للمعلمين

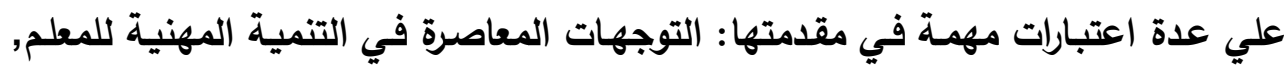

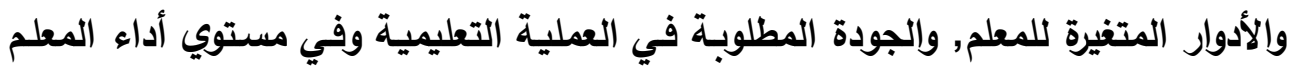
داخل الفصل, والاحتياجات المهنية المتجددة للمعلم.

8- اسـتناد الأكاديميـة المهنيـة للمعلمين إلـي رؤيسة مستقبلية واضـحة وفلسـفة محددة عند

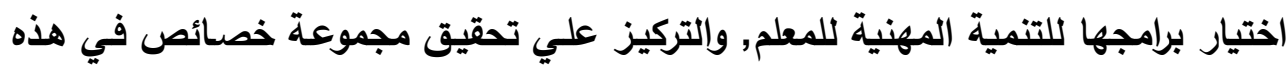

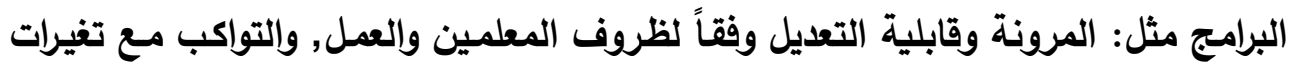

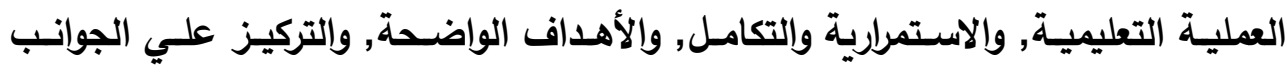
التطبيقية, والاستخدام الواسع لمزايا تكنولوجيا المعلومات والاتصال. 9- بنـاء قواعد بيانـات لبرامج التنمية المهنيـة التي تم إنجازهـا وتقديمها للمعلمين, وكذلك

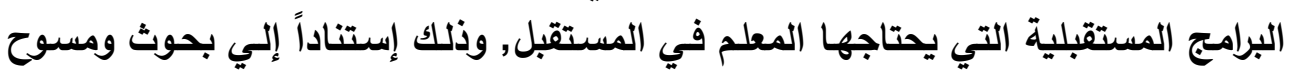
واقعية للاحتياجات المهنية للمعلم. 
10- مراعـاة الأكاديميـة المهنية للمعلمين لأبعاد الثقافة القوميـة والبعد الـوطني في تطويرهـا

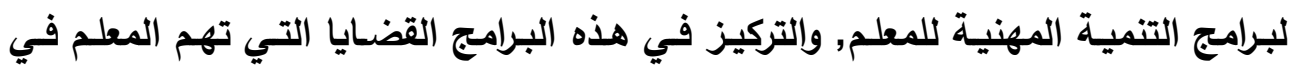
المجتمع المصري.

11- إتاحة فرص الاختيار أمام المعلم بين برامج التنمية المهنية التي يرغب الالتحاق بها وفقاً

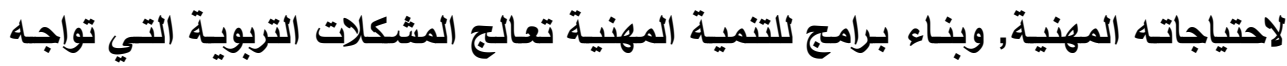
المعلمين داخل الفصول وفي تنظيم المجتمع المدرسي ومجالات الأنشطة. 12- تركيز الأكاديمية المهنية للمعلمين علي اختيار وبناء برامج التنمية المهنية التي يمكن تسويقها في أكثر من جهة (كالمدارس الخاصةة, والمراكز التعليمية, والجمعيات الأهلية التي لها نشاطات تعليمية وغيرها), مما يساعد في التوسئ في في خدمات وجهود الأكاديمية المهنية للمعلمين من ناحية, ويوفر لها مصدر إضافي للتمويل من ناحية أخري.

13- تضمين برامج التنمية المهنية للمعلم مواقف تدرببية نموذجية يمارس من خلالها المعلم: التطبيقـات العمليـة, وورش العمل, والـــروس والتجـارب المعمليـة, والجلسـات النقاشـية.

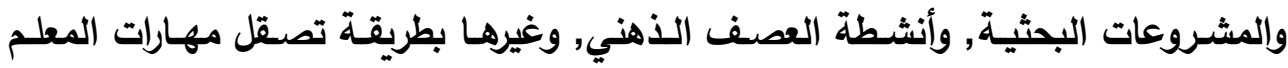
العملية وتفيدة في مجال التدريس.

14- التركيز علي جودة البناء والإخراج الفني والطباعة والتسلسل المنطقي والتكامل لبرامج

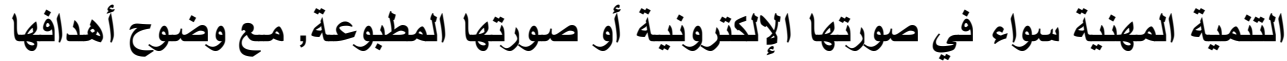

والغزض منها.

15- التركيز في برامج التنمية المهنية علي الموضوعات التي تهم المعلم ويحتاجها في مجال

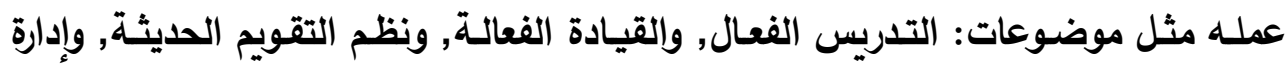

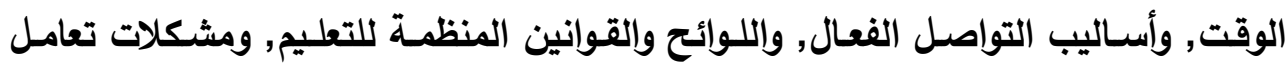

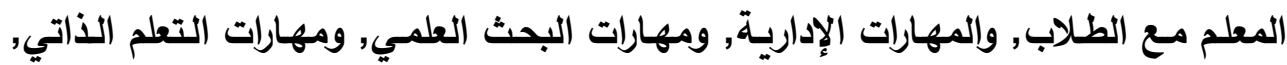
والإبداع في التدريس.

وبصفة عامـة فاهتمـام الأكاديميـة المهنيـة للمعلمين بالاختيـار الجيــ لبـرامج التنميـة

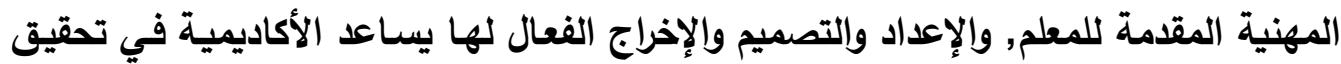

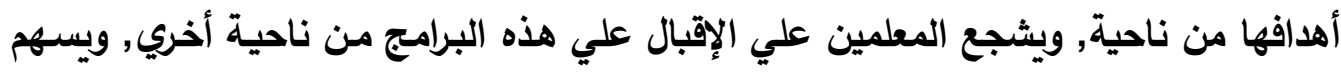
في حل كثير من مشكلات التنمية المهنية للمعلم من ناحية الثالثة الثئ. المحور السادي: تطوير الكوادر التدريبية والمدربين داخل الأكاديمية المهنية للمعلمين: 
يمثل الكوادر التدريبية والمدربون (أو مدربي المعلمين كما يطلق عليهم) عنصراً رئيساً من عناصر العمل داخل الأكاديمية المهنية للمعلمين, بل هم عصب ولمبل عملية تدريب المعلمين

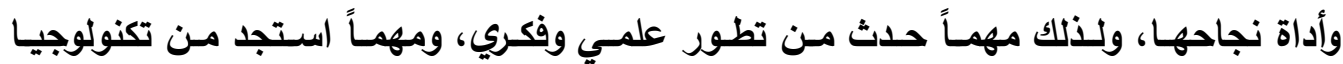

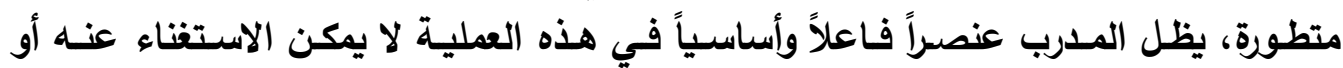

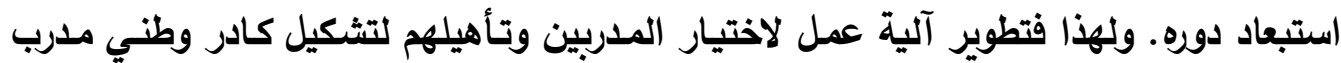

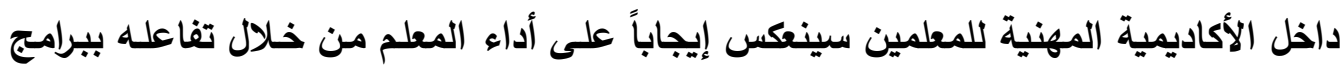

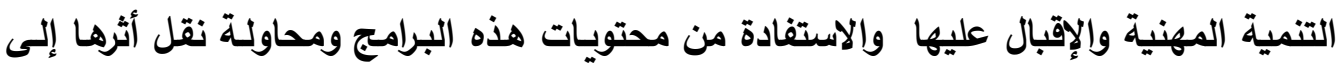
داخل الفصل.

وتتبني الدراسة الحالية بعض الآليات والجوانب المقترحة لتطوير أدوار المدرب وأسلوب

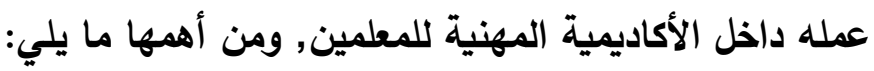
1- قيام الأكاديميـة المهنيـة للمعلمين بوضـع مجموعة معايير وآليـات علمية ومهنيـة دقيقـة لاختيار الكوادر التدربية لايها, وتأهيلهم وفق الخبرات العالمية في هذا المجال. 2- تكوين هيئة دائمة من ذوي الخبرة ومسئولي وزارة التربية والتعليم ومسئولي مراكز التدريب

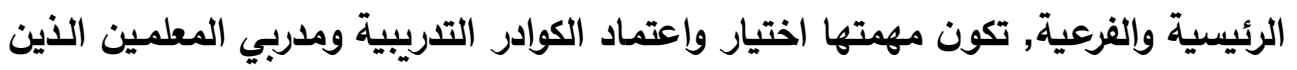

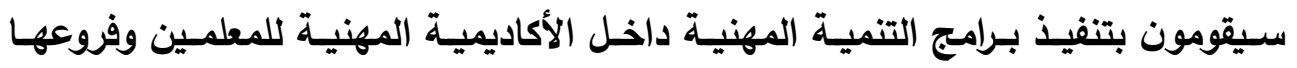
المختلفة.

3- استقطاب أساتذة وأعضاء هيئة التدريس بكليات التربية وخاصة المتخصصين منهم في طرق التدريس, وتوظيف خبراتهم في إعداد وتأهيل المدربين داخل الأكاديمية المهنية ولية وخاهية للمعلمين.

4- الإفـادة من المعلمين الذين سـافروا في بعثات تعليمية خارجية, واختيار المـاهرين منهم وتثجيعهم للحصول علي دورات إعداد المدربين للعمل بالأكاديمية.

5- وضع وتنفيذ خطة دوريـة لتحقيق التطوير المهني والأكاديمي المستمر للكوادر التدربية بالأكاديمية المهنية للمعلمين, وتشجيعهم علي المشاركات الفعالة في الندوات والمؤتمرات

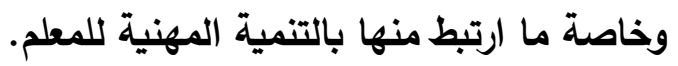

6- رصد جوائز سنوية للمتميزين من المدربين, ووضع إجراءات لتنشيط ورفع مستوي أداء

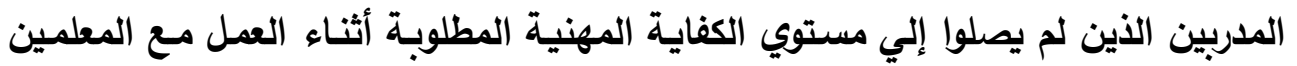
في برامج التنمية المهنية. 
7- بناء قاعدة بيانات متكاملة للكوادر التدرببية داخل الأكاديمية المهنية للمعلمين وفروعها,

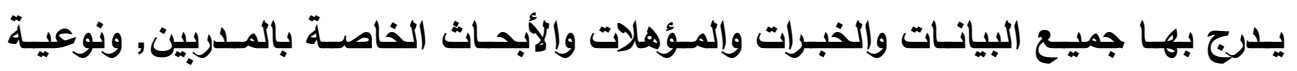

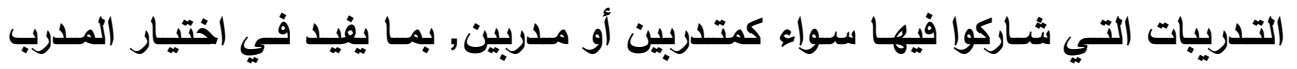
المناسب للبرنامج المناسب.

8- صـياغة وتطـوير مجموعـة مـن المؤثـرات بثـكل مقـنن لتقيـيم أداء المسـربين والكـوادر

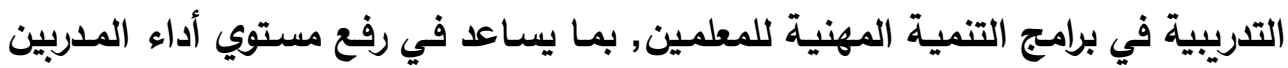
والمتدربين في هذه البرامج.

9- تبادل الخبرات التدريبية مـع الدول المتقدمـة في مجـال التنمية المهنية للمعلم, وتوفير بعض المنح للمدربين للدراسة والتدريب بهذه الدول, والإفادة من خبراتها في في مجال الكال تأهيل الكوادر التدريبية.

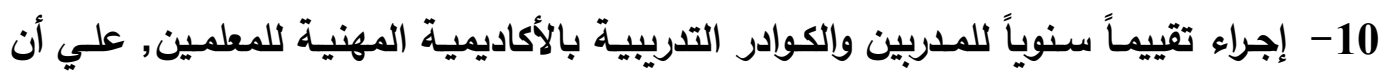

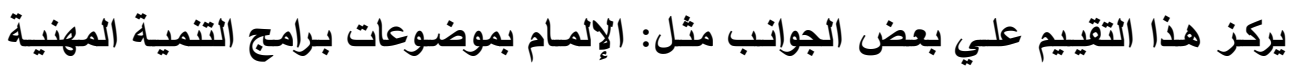

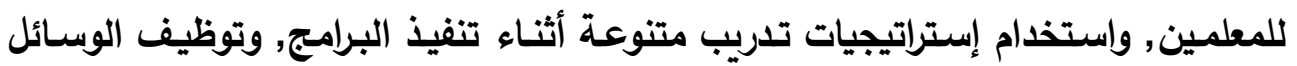

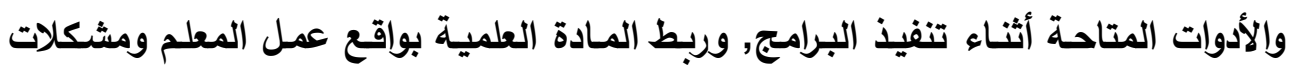

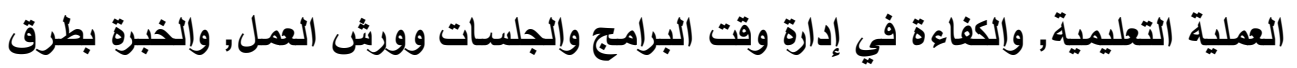

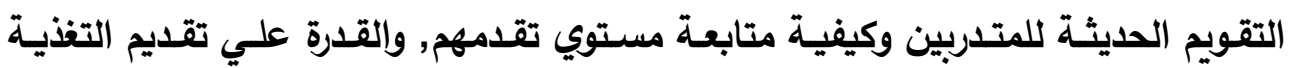
الراجعة المستمرة للمتدربين.

11- وضـع الأكاديمية المهنية للمعلمين مجموعـة ضوابط ومعايير أخلاقية (دستور أخلاقي)

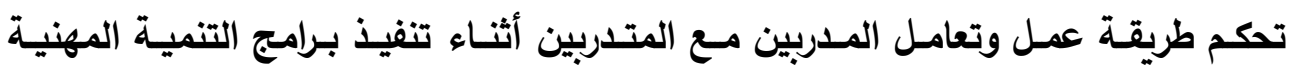
للمعلمين.

بالإضافة إلي ما سبق فإن عملية اختيار المدربين داخل الأكاديمية المهنية للمعلمين من

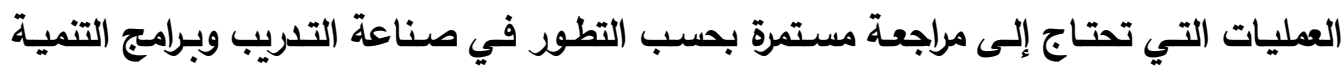

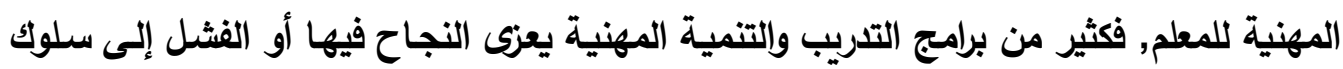

المدرب داخل قاعة التدريب وقراته وتفاعله مع المتدربين.

المحور السابع: تطوير أساليب وطر ائق التنميـة المهنيـة ووسـائلها داخل الأكاديميـة المهنيـة للمعلمين:

أن الأساليب المستخدمة في تقديم برامج التنمية المهنية للمعلمين لها أهميتها ومغزاهـا في نتائج هذه البرامج, كما أن له تأثيرها علي المعلمين أنفسهم وإقبالهم علي التدريب, فمن 
بين الأسباب التي كانت لا تشجع المعلمين للإقبال على التدريب في الماضسي هو اعتمـاد

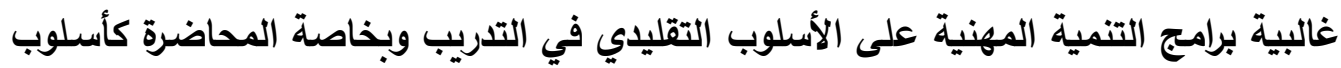

وقد أظهرت نتائج الدراسة الميدانية في الدراسة الحالية أن نمط التدربب التقليدي التلقيني هو النمط السائد في معظم برامج التنمية المهنية التي تقدمها الأكاديمية المهنية للمعلمين في مصر , الأمر الذي يتطلب التحول إلي أساليب حديثة للتدربب تقوم علي التعلم التعائ النشط والتعلم البنائي والتعلم التعاوني والتعلم عن طريق المهام وباستخدام الوسائط التدريبية المتطورة.

وتتحدد أهم الآليات والجوانب المقترحة لتطوير أسـاليب وطرائق تقديم برامج التنمية المهنية للمعلم ووسائلها داخل الأكاديمية المهنية للمعلمين فيمالئ الئي: 1- تنويع طرق وأساليب التريب بحيث لا تقتصر علي طريقة المحاضرة, وإنما تشمل بجانبها:

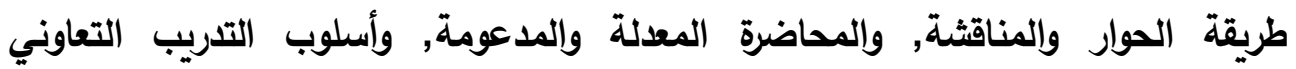

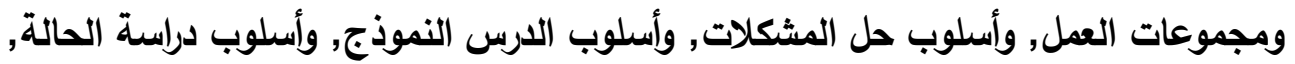

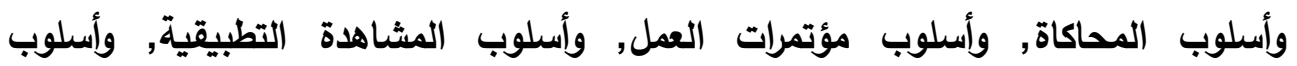

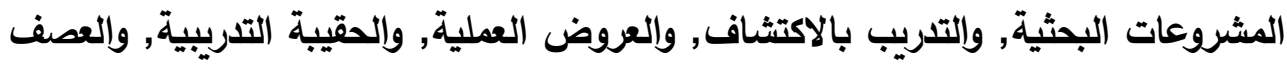

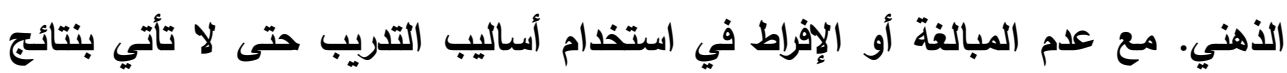
عكسية, وأن يكون أسلوب التدريب المستخدم ملائماً لموضوع التدريب ولطبيعة المتدربين.

2- استخدام أساليب عملية مستحدثة ومتطورة في مجال التنمية المهنية للمعلم, تتناسب مع

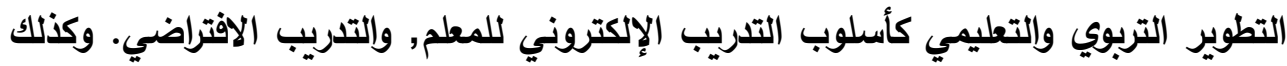
التوسع في استخدام أساليب التنمية المهنية من بُعد, وخاصة في المحافظات البعيدة

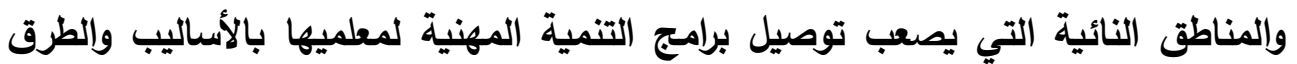
العادية.

3- الاستفادة من الاتجاهات الحديثة في مجال التنمية المهنية للمعلم وخاصة ما أرتبط منها

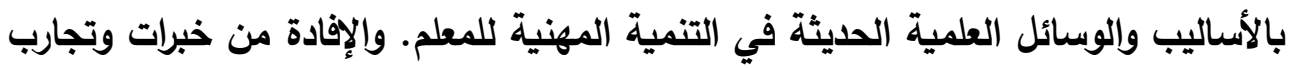

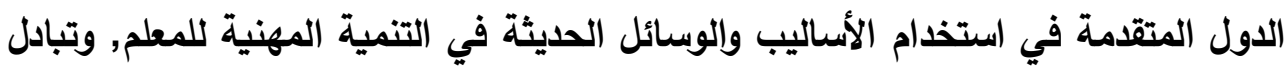
الزيارات مع الأكاديميات المهنية المناظرة في هذه الدول للتعرف علي أحدث الطرق والوسائل التي تستخدمها في تقديم خدمات وبرامج. 
4- تطوير طريقة استخدام أسلوب المحاضرة في برامج التمية المهنية للمعلم, من خلال:

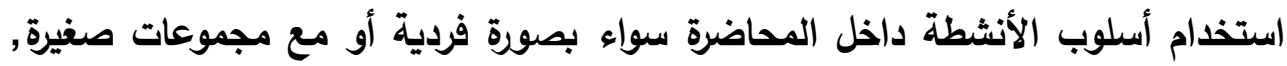

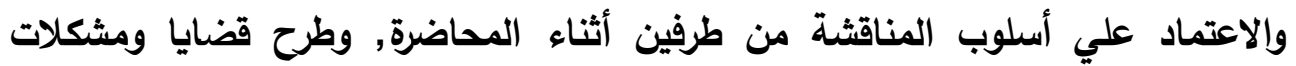
تعليمية ومهنية خلال المحاضرة بشكل يتيح أستخدام أسلوب حل المشكلات مع المتدربين. 5- المزج بين الأساليب النظرية والأساليب العملية في برامج التنمية المهنية للمعلم, وتشجيع

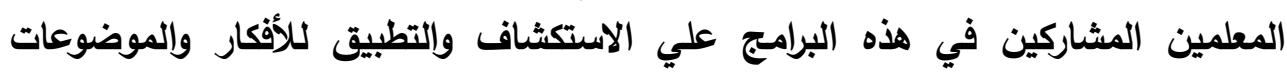
الجديدة , وإتاحة الفرصة لهم لتطبيق ما يتعلمونه.

6- تركيز أساليب التنمية المهنية المستخدمة علي تنمية مهارات التعلم الذاتي والتعليم المستمر

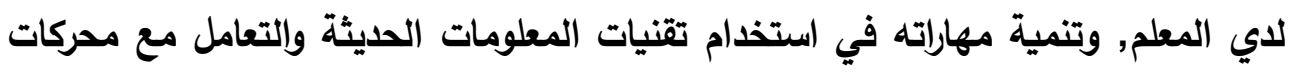

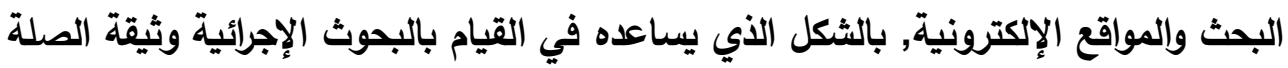
بالتدريس. 7 - تدعيم أساليب التدريب المستخدمة في برامج التنمية المهنية للمعلمين بأسلوب التدربب

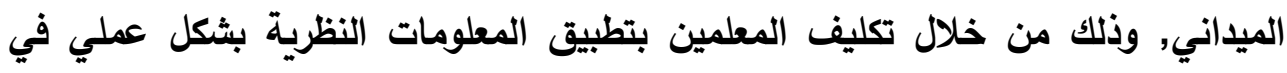
الميدان كالمدارس والفصول والمعامل وغيرها وتوضيح نتائج هذا التطبيق.

بالإضافة إلي ما سبق يمكن الاستعانة بالعديد من الوسائل الحديثة المعينة داخل البرامج

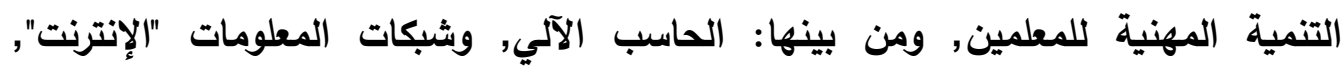

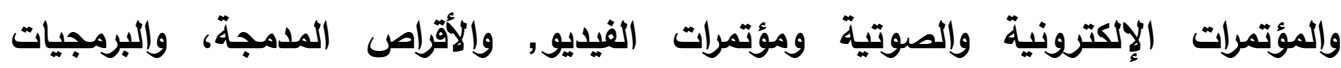
التدربية, وبعض الأشكال المطبوعة التي يمكن توفيرها للمتدربين. كما يمكن للقائمين علي الأكاديمية المهنية للمعلمين التوسع في استخدام التقنيات التدريبية الحديثة, وتدريب المعلمين علي الاستخدام المفيد لتقنية التدربب الإكتروني والتعامل

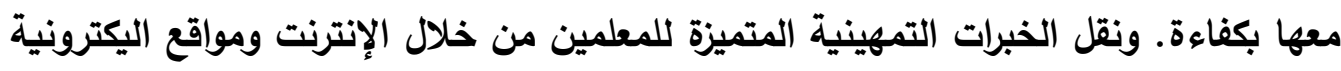

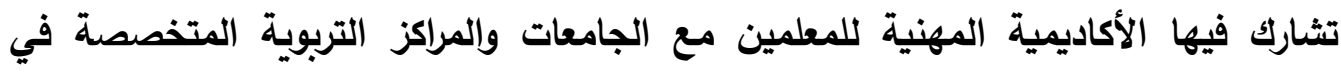
بحوث التربية والتعليم وإعداد المعلم وتنميته مهنياً.

كما يمكن للأكاديمية المهنية للمعلمين إنشاء قناة تليفزيونية بمعاونة وزارة الإعلام أو أو المات

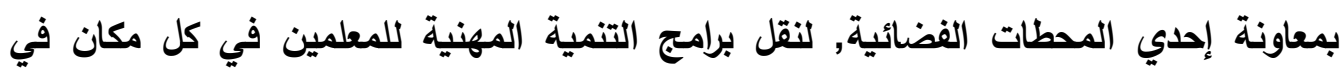
مصر , فهذا النظام مطبق الآن في عديد من الدول "كالهند وكوريا الجنوبية" وحقق فيهما نتائج ملموسة, كما ساهم في الحد من مشكلات التنمية المهنية للمعلمين. 
المحسور التـامن: تطـوير أسـاليب تقويم بـر امج التتميـة المهنيـة داخـل الأكاديميـة المهنيـة للمعلمين:

علي الرغم من أهمية التقويم في برامج التنمية المهنية للمعلم, إلا أن نتائج الدراسة الميدانية أظهرت أن هناك قصور واضح في نظم التقويم وأساليبه المتبعة في تقويم برامج التنمية المهنية بالأكاديمية المهنية للمعلمين.

وتتحدد أهم الآليات وجوانب التطوير المقترحة في نظام التقويم وأساليبه ووسائله لبرامج

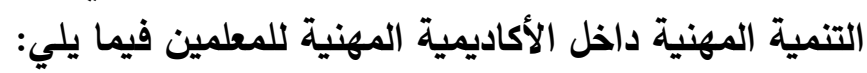

1- تركيز نظام التقويم لبرامج التنمية المهنية داخل الأكاديمية المهنية للمعلمين علي الإجابة عن عدد من التساؤلات وهي: ما الأهداف التي تسعي الأكاديمية المهنية للمعلمين

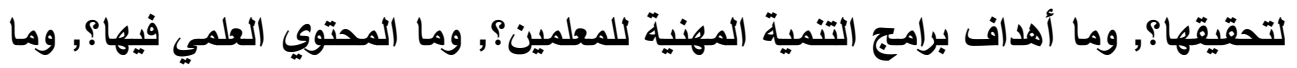
الأساليب والوسائل المستخدمة فيها؟, وما هي العقبات التي ظهرت أثناء تنفيذ برامج التنمية المهنية؟, وغيرها من التساؤلات الأخري.

2- بناء نظم تقويم قويـة وفاعلة, تتنوع أساليبها ووسائلها وفقاً لطبيعة برامج التنمية المهنية, وتثمل تقويم مرحلي قبل وأثناء تنفيذ البرنامج وتقويم نهائي بعد انتهاء البهاء البرنامج.

3- اتباع نظام لمتابعة المعلمين في مدارسهم بعد حصولههم علي برامج التنمية المهنية,

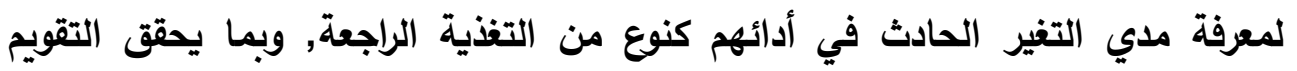
الموضوعي لبرامج التنمية المهنية للمعلمين, وإجراء التعديلات اللازمة عليها. 4- توزيع درجات التقويم للمتدبين علي عدد من البنود والمحاور مثل: الأداء العملي,

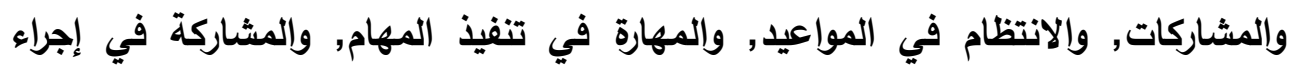

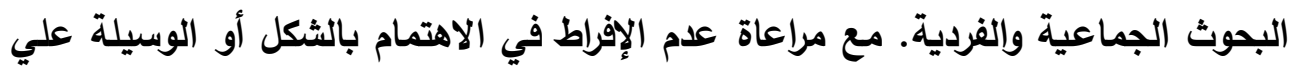
حساب المضمون في عملية التقويم لبرامج التنمية المهنية للمعلمين.

5- تحقيق شمولية التقويم بالمعني الحقيقي وليس مجرد مسمي داخل برامج التنمية المهنية للمعلم, بحيث يشمل التقويم جميع جوانب البرنامج مثل: المادة التدريبية, والمدربين, والإدارة والإثراف, وأساليب التدريب, والوسائل التقنية المستخدمة, والمكان والزمان والتسهيلات المادية وغيرها.

6- التقليل من الاعتماد علي وسائل التقويم التقليدية كالاختبارات التحريرية التي تركز فقط علي ما استوعبه المتدربون من معلومات نظرية من خلال برامج التنمية المهنية, 


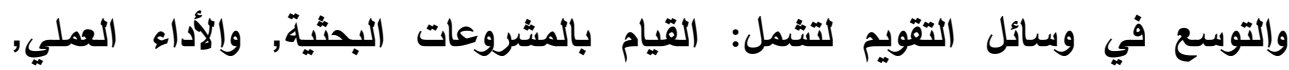

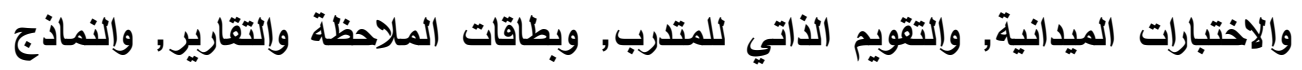

$$
\text { التطبيقية, وغيرها. }
$$

7- إنشاء وحدة تقويم بكل فرع من فروع الأكاديمية المهنية للمعلمين, تتولي تقويم برامج

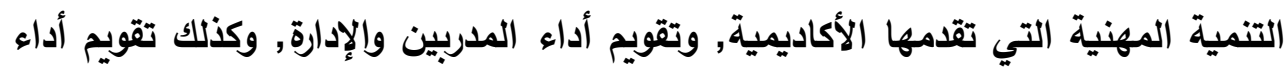

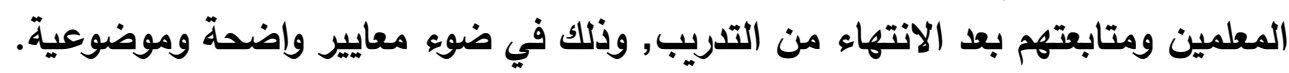
8- اهتمام الأكاديمية المهنية للمعلمين بإثرالك المسئولين في المديريات والإدارات التعليمية

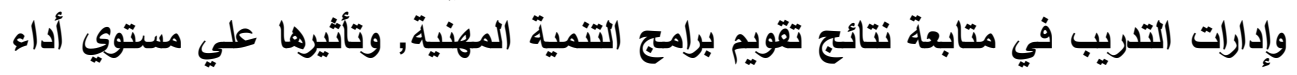
المعلمين داخل مدارسهم, وتقديم مقترحات تطويرها في المستقبل.

9- بناء مجموعة معايير دقيقة يتم في ضوئها تقويم جميع العناصر المشاركة في تقديم برامج

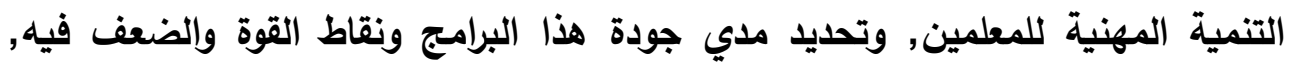
ويمكن الاسترشاد في ذلك بما وضعته الهيئة القومية لضمان جودة التعليم والاعتماد في مصر من معايير خاصة بالتنمية المهنية للمعلم. 10- تدريب العاملين داخل الأكاديمية المهنية للمعلمين علي نظم التقويم المتطورة لبرامج

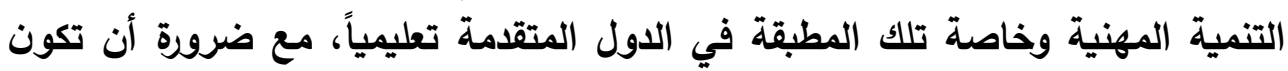
هناك خططزمنية لتطبيق هذه النظم المتطورة التي تم التدريب عليها. 11- الإفادة من الخبرات العالمية الناجحة في مجال تقويم برامج التنمية المهنية للمعلم, وكذلك الكادئ

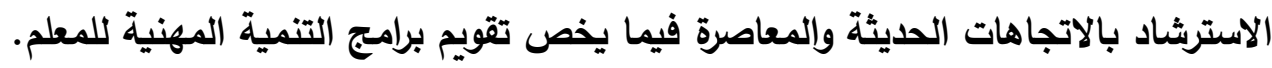

12- استخدام نتائج التقويم في تحسين الأداء في برامج التنمية المهنية التي تقدمها الأكاديمية المهنية للمعلمين, وفي تقديم تغذية راجعة مستمرة للمسئولين عنها, بما يسهم في تطوير

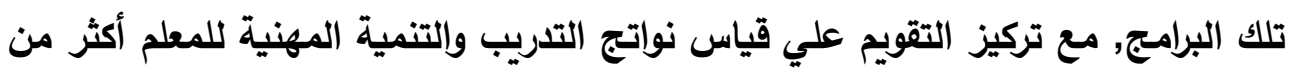
التركيز علي عملية التدربب ذاتها. المحور التاسع: فاعلية نظم ضبط الجودة لبر امج التنميـة المهنيـة داخل الأكاديميـة المهنيـة للمعلمين: فلة نطئ

إن تحقيق نظم الجودة والاعتماد أصبحت من الأمور الضرورية في أي مؤسسة أو

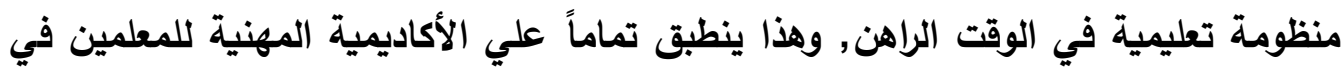

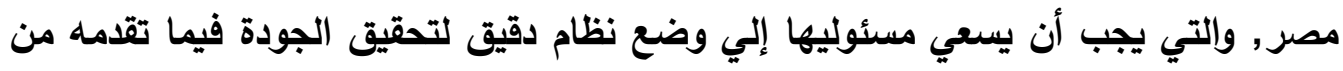


برامج للتنمية المهنية للمعلمين, وذلك من منطلق أن تحقيق الجودة في تلك البرامج إنما يسهم في تحقيق الجودة لاي عنصر مهم من عناصر العملية التعليمية بأكملها وهو المعلم. ويمكن للأكاديمية المهنية للمعلمين أن تحقق الجودة وتصل للاعتماد الأكاديمي

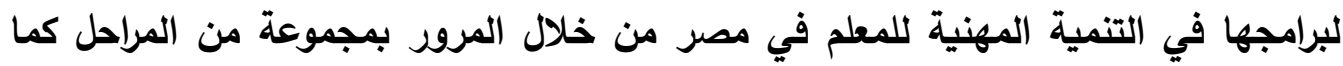

1- مرحلة الإعداد والتحضير لتطبيق نظم الجودة والاعتماد: ويتم في هذه المرحلة تشكيل

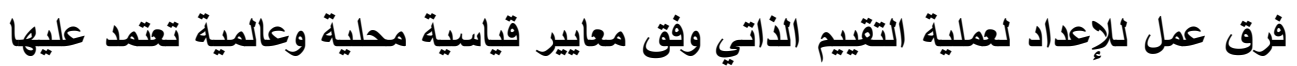

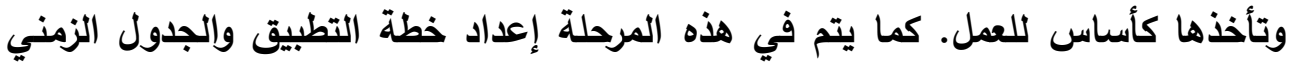
لكل مرحلة من مراحل التطبيق. 2- مرحلة تطوير الرؤية و الرسالة الخاصة بالأكاديمية المهنية للمعلمين: بحيث تتضمن هذه الرؤية وتلك الرسالة ما تسعي الأكاديمية المهنية للمعلمين إلي تحقيقه لاي المعلم

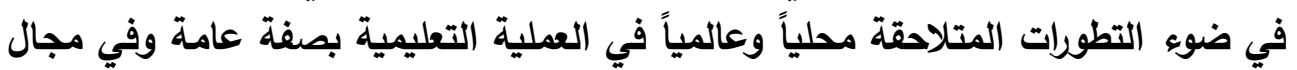
التنمية المهنية للمعلم بصفة خاصة, وبحيث ترتبط بالواقع وتستشرف المستقبل. ويمكن

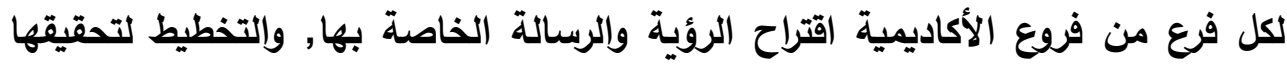
ووضعها موضع التطبيق والممارسة.

3- درحلة التقييم الذاتي داخل الأكاديمية المهنية للمعلمين: ويتم في هذه المرحلة تحليل نظام الجودة الحالي داخل الأكاديمية, وتحديد مدي تطابقه مع المعايير القياسية للجودة, فئه

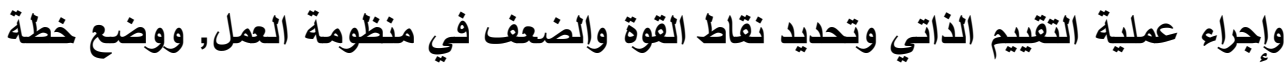

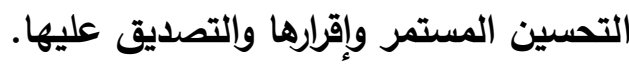
4- درحلة التوثيق لأعمال الجودة: وفيها يتم توثيق جميع الأعمال والإجراءات التي تتخذ

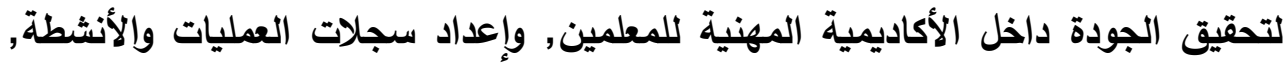

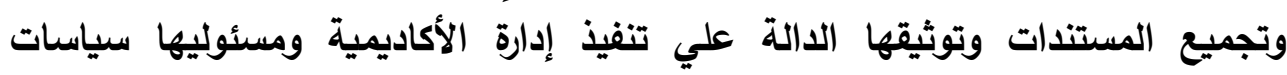
وإجراءات الجودة.

5- مرحلة التطبيق لمعايير الجودة من خلال جميع أنشطة الأكاديمية المهنية للمعلمين: وفي هذه المرحلة يتم تطبيق إجراءات وخطط الجودة لاكتثاف مجالات القصور وتحسينها, ويشرف علي هذه المرحلة فريق تم إعداده للقيام بمهمة مراجعة نظام الجودة 
6- مرحلة التدقيق والمر اجعة: وفي هذه المرحلة يتم فحص وتوثيق والتأكد من أن عناصر

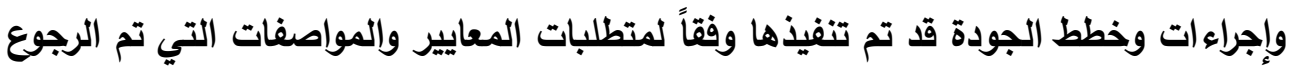
إليها, كما يتم مراجعة مدي كفاية إجراءات وسجلات الجودة المطبقة, ومدي وائمات التزام العاملين بالأكاديمية المهنية بتطبيق إجراءات الجودة, وفحص ملاءية خطط المراجعات والتقييمات الاخلية من قبل الأكاديمية المهنية نفسها. 7- مرحلة تسجيل الأكاديمية المهنية للمعلمين للحصول علي شهادة الاعتماد: وفي هذه

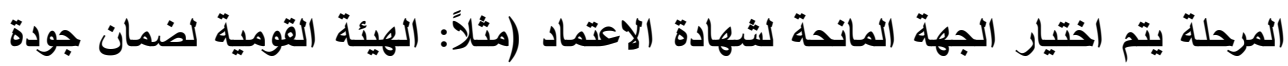

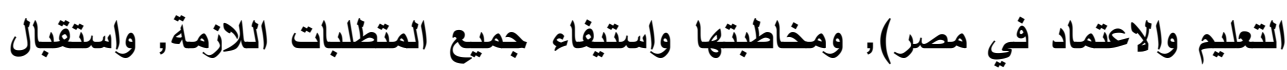

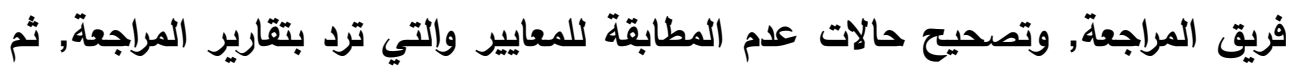
الحصول علي شهادة الاعتماد.

8- مرحلة الاستمرار في تطبيق معايير الجودة: وفي هذه المرحلة يتم عمل مراجعات

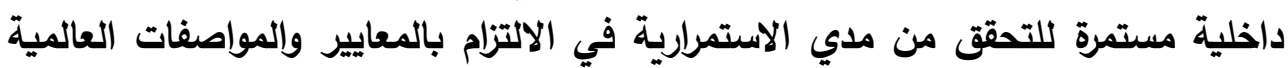

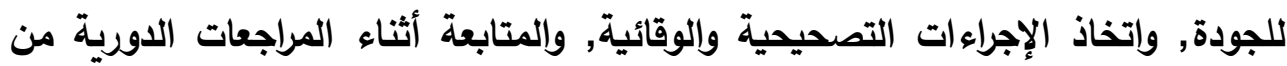
قبل الجهة المانحة.

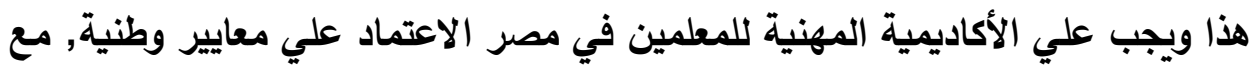

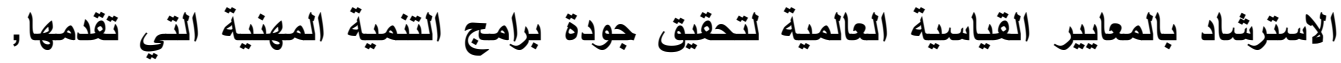
وبحيث تمثل تلك المعايير الحد الأدني الواجب تحقيقه, وبعد الوصول إليه تعديه الكداد الأكاديمية

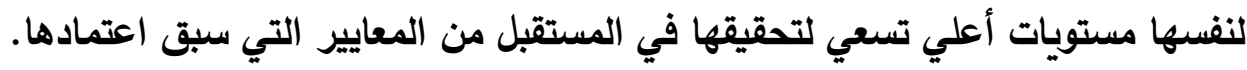


المحور العاشر: نظام مفترح لمنح الترخيص بمز اولة المهنة للمعلم من خلال الأكاديمية المهنية للمعلمين:

تقترح الدراسة بعض الخطوات والآليات التي يمكن الاسترشاد بها من قبل المسئولين

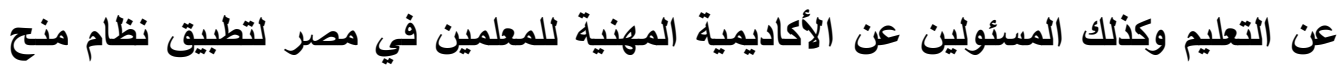
المعلم ترخيص بمزاولة المهنة, وهذه الخطوات هي: المينولين عن الاكادية المغنية

الحديد الجهـة المسئولة عن منح الترخيص بمز اولـة المهنـة: يقترح الباحث أن تتولي

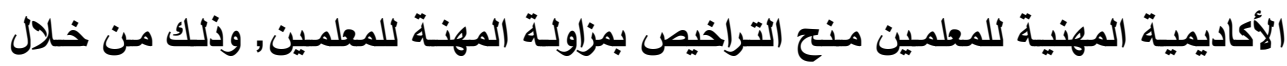

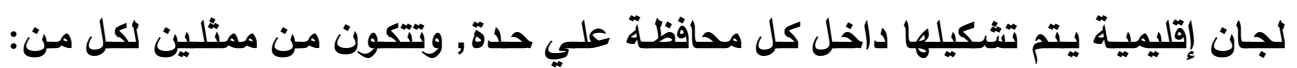

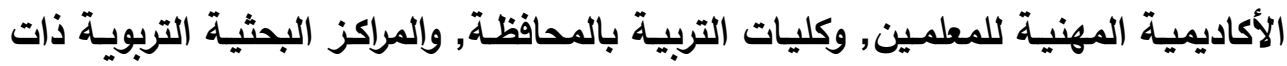

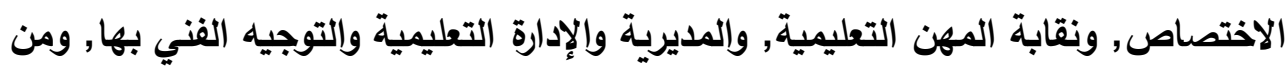

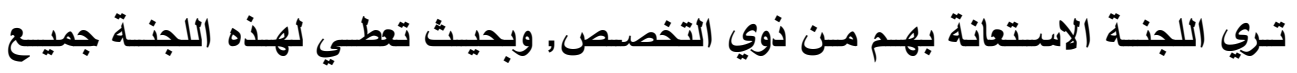
الصلاحيات لمنح التراخيص بمزاولة مهنـة التدريس أو تجديدها أو إلغائها وذلك بـانه بالنطاق الجغرافي التابع لها.

تحديد الثروط و المو اصفات و المعايير المطلوبـة لمنح الترخيص بمزاولة المهنة: بعد تثكيل اللجان الإقليمية داخل كل محافظة وتحديد اختصاصـاتها, تقوم هذه اللجان بوضع

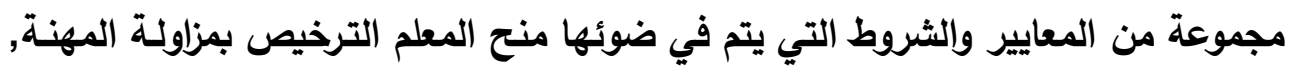

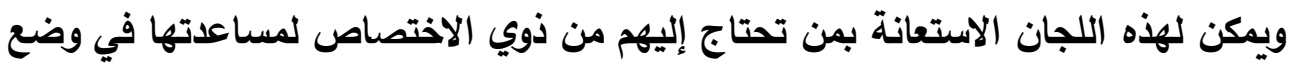

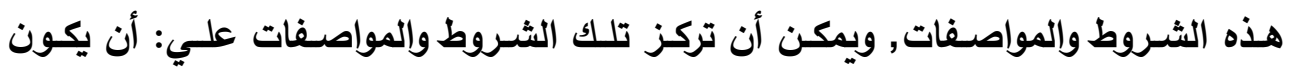

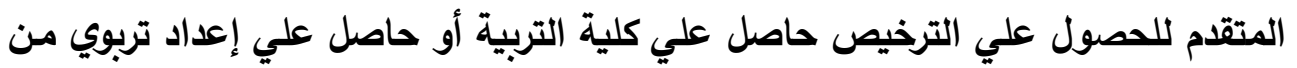

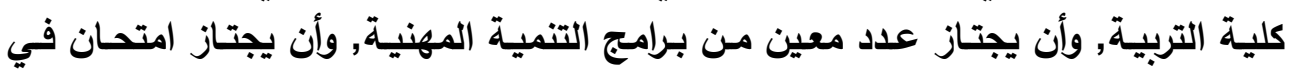
الكفاءات التربوية والتخصصية المطلوبة للتربس, وغيرها من الثروط الأخري التي تراهـا اللجنة مناسبة.

منح الترخيص بمز اولة المهنة للمعلمين: بعد اجتياز المتقدم للحصول علي الترخيص

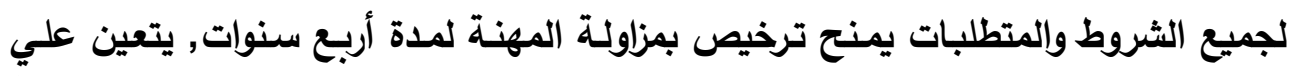
صاحبة تجديده خلال الستة شهور الأخيرة من فترة الترخيص, ويكون الترخيص مخصصاً

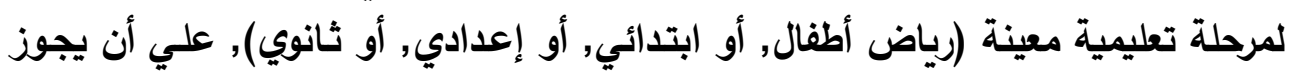

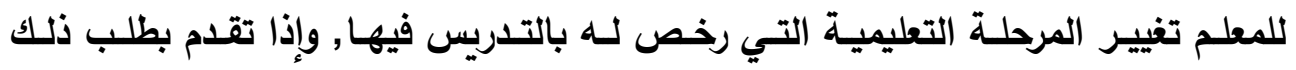
وتوفرت فيه من جديد شروط التدريس في المرحلة التعليمية التي يرغب التدريس فيها. 
وبعد منح المعلم الترخيص بمزاولة المهنية يؤدي القسم للمهنة, الذي يتعهد فيه بمراعاة الله وضميره المهني, والولاء للوطن وعدم الإخلال بأخلاقيات المهنة ومبادئها.

تجديد الترخيص للمعلم بمز اولـة المهنـة: يقترح أن يتم التجديد للمعلم بمزاولـة المهنـة

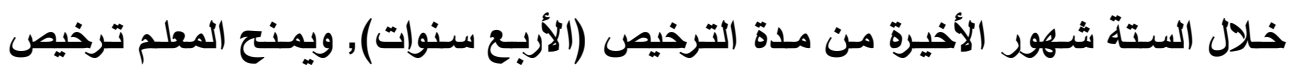

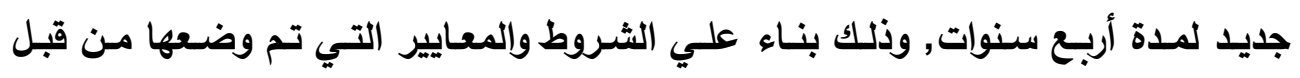

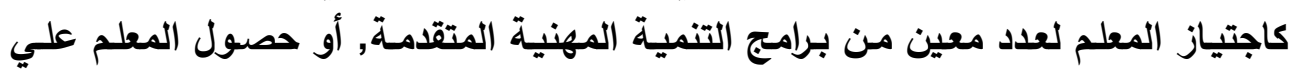

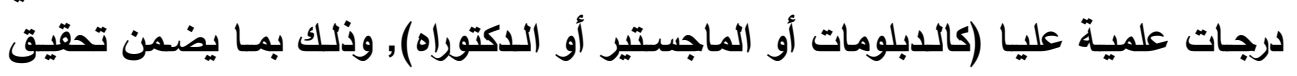

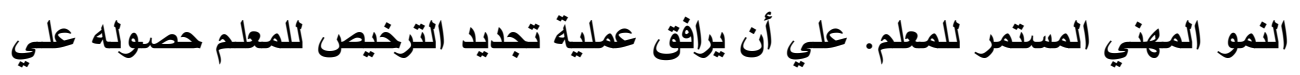
زيادة في الراتب وترقية للوظيفة الأعلي.

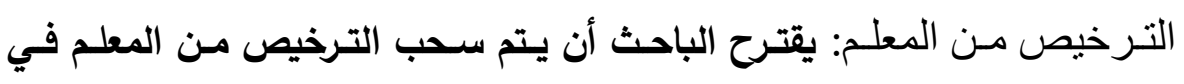

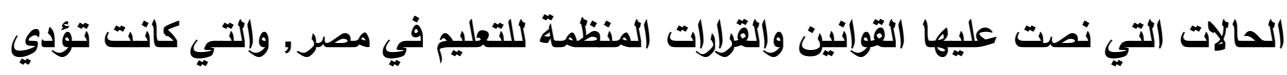

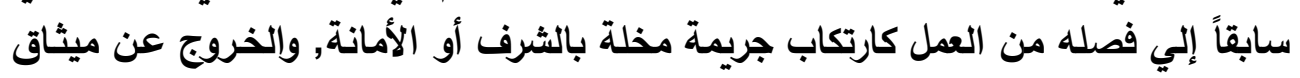

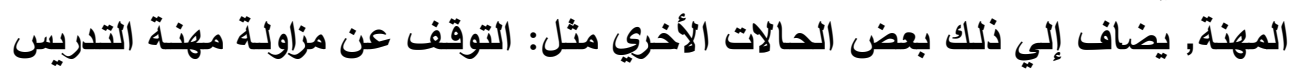

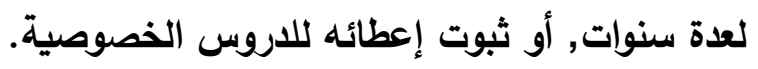

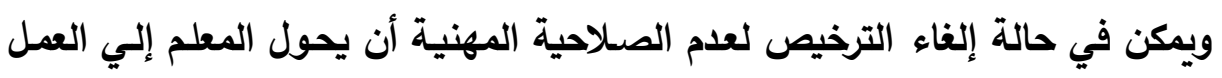

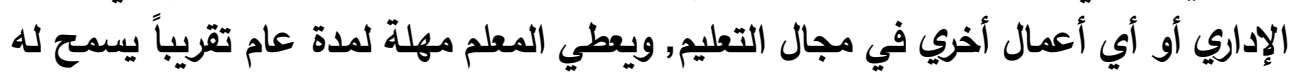

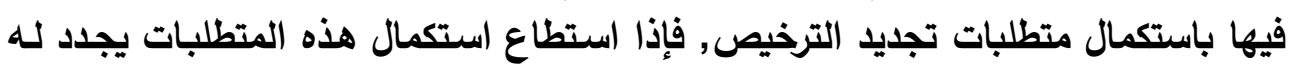

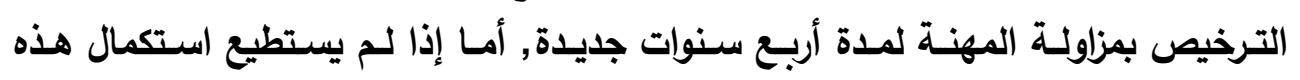

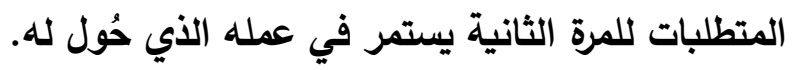

وهناك مجموعة من العوامل والضوابط التي يجب مراعاتها لضمان نجاح هذا النظام

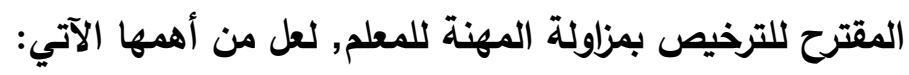

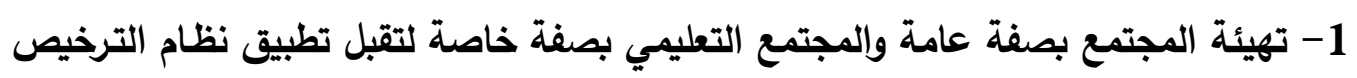

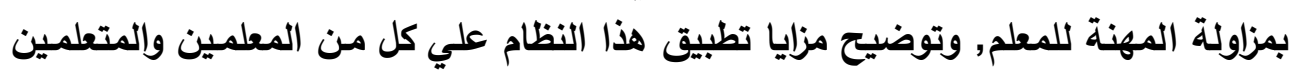

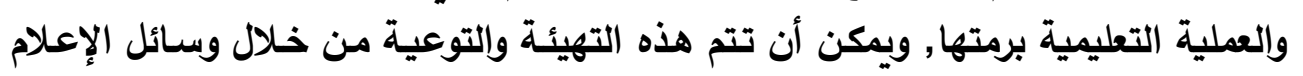
المتخصصة.

2- صدور تشريعات ولوائح تنفيذية توضح كافة تفصيلات نظام منح الترخيص بمزاولة المهنة للمعلم, وكافة الاحتمالات المستقبلية لتطبيقه. 
3- البدء في تنفيذ نظام منح الترخيص بمزاولـة المهنـة للمعلم منذ التحاق الطلاب بكليات التربيةة, وتهيئتهم لتطبيق هذا النظام عليهم, حتي يكون لدئهم الدافع لزيـادة خبراتهم المهنية والتمكن من مهارات التدريس.

4- أن تكون جميع الثـروط والمعـيير المرتبطة بالحصـول علـي الترخيص بمزاولـة المهنـة معلومة وواضحة لجميع المتقدمين من المعلمين. 5- تجنب الإجراءات الإداريـة الطويلـة والخطوات الروتينية المعقدة , والابتعاد عن السلوكيات التي تشوبها المجاملات والمحسوبيات.

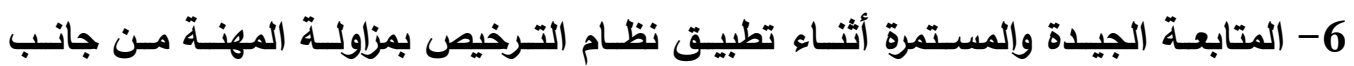

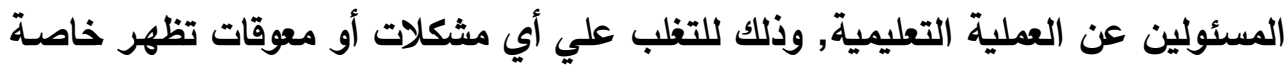
في باية تطبيقه علي المعلمين في مصر. المحور الحادي عشر: دور الأكاديمية المهنية للمعلمين في دعم وحدات التدريب والجودة داخل المدارس و المؤسسات التعليمية:

يقع علي عاتق الأكاديمية المهنية للمعلمين الآن دور بارز في مجال التنمية المهنية

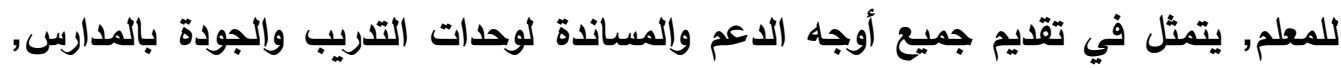

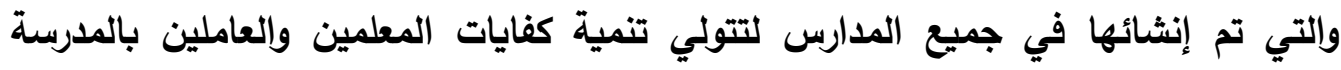
ومساعدتهم في أداء أدوارهم بفاعلية, وذلك من من منطلق أن تصبح المدرسة هي المركز

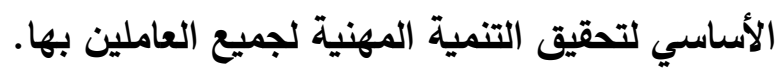

وتقترح الاراسة الحالية بعض الآليات والجوانب التي يمكن من خلالها قيام الأكاديمية

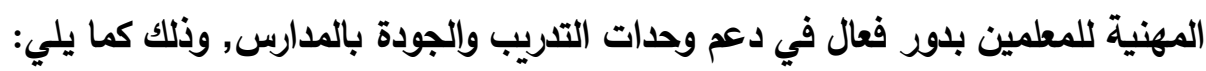
1- مشاركة الأكاديمية المهنية للمعلمين في تقديم الدعم المادي والمعنوي لوحدات التدربب والجودة بالمدارس للارتقاء بالأداء المهنى للمعلمين. 2- تعاون الأكاديمية المهنية للمعلمين مع وحدات التدريب والجودة بالمدارس في إجراء تقيييم دوري ومستمر للمعلمين (شهري, ونصف سنوي, وسنوي), وذلك للتأكيد علي نقاط القوة لاي المعلمين وتدعيمها, ومعالجة نقاط الضعف والسلبيات لاي المعلمين من خلال برامج ولهين التنمية المهنية.

3- تعاون الأكاديمية المهنية للمعلمين مع وحدات التدريب والجودة بالمدارس في إنشاء ملف إنجاز (بورتفيليو) لكل معلم بالمدرسة, علي أن يتم تقييم المعلم من خلال هذا الملف كل ولف 
فترة زمنية محدة (ولتكن ثلاث سنوات), للتعرف علي ما تم تنفيذه من إنجازات, واقتراح برامج التنمية المهنية اللازمة.

4- مشاركة الأكاديمية المهنية للمعلمين مع إدارات المدارس ومسئولي وحدات التدريب والجودة

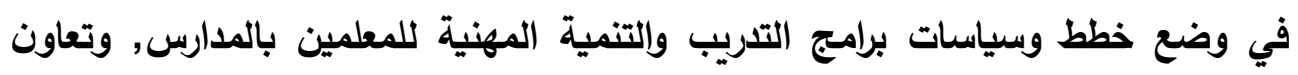
الأكاديمية في تصميم برامج متميزة للتنمية المهنية للمعلمين.

5- دخول الأكاديمية المهنية للمعلمين في شراكة فاعلة مع المؤسسات والجمعيات الأهلية ذات

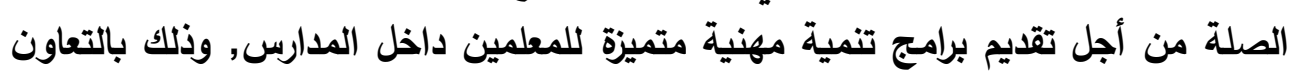

$$
\text { مع وحدات التدريب والجودة بالمدارس. }
$$

6- مشاركة الأكاديمية المهنية للمعلمين مع هيئة ضمان جودة التعليم والاعتماد في متابعة

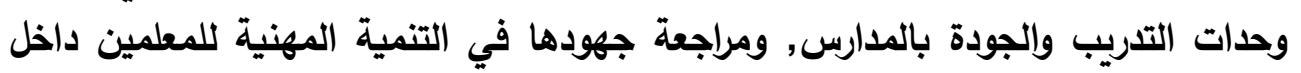

$$
\text { المدارس. }
$$

7 عقد الأكاديمية المهنية للمعلمين اجتماعات متواصلة مع إدارات التدريب بالمديريات

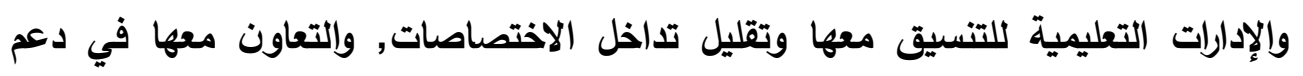

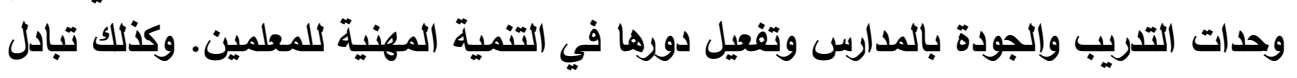

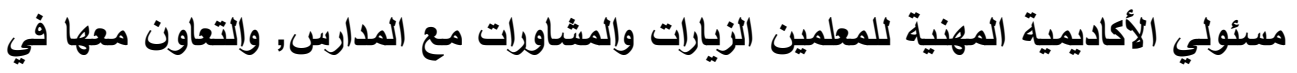
وضع خطط التحسين والتطوير للمدرسة وإلعاملين بها.

8- مشاركة الأكاديمية المهنية للمعلمين مع المسئولين في المديريات والإدارات التعليمية في

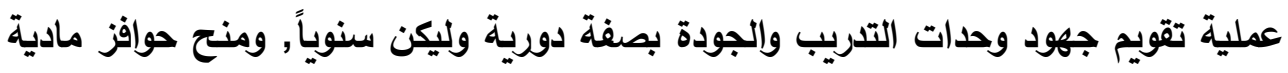
ومعنوية للوحدات المتميزة منها في مجال التنمية المهنية للمعلم. 
وبصفة عامة يمكن تلخيص جميع محاور التصور المقترح لتطوير أدوار الأكاديمية المهنية فئية

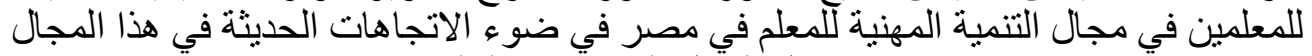
من خلال الثنكل التوضيحي التالي:

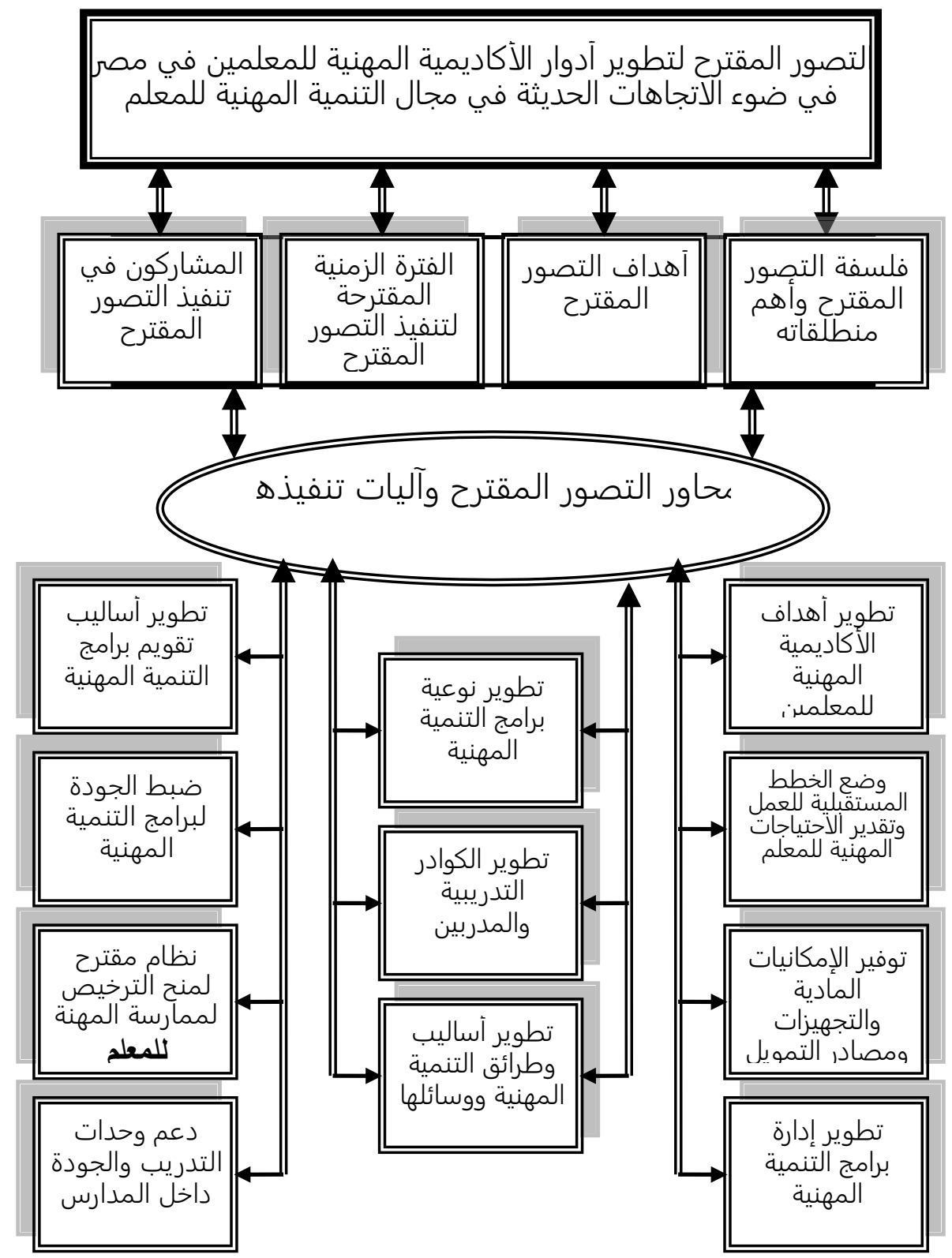

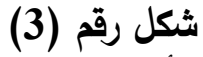

رسم تخطيطي للتصور المقتر ح لتطوير أدوار الأكاديمية المهنية للمعلمين في مصر في ضوء الاتجاهات الحيثة في مجال التنمية المهنية للمعلم المعلمين 
الضو ابطو التوصيات اللازمة لنجاح تطبيق التصور المقترح:

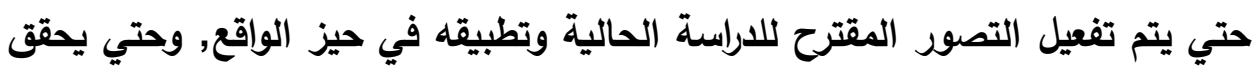

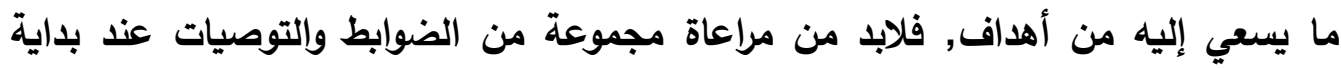

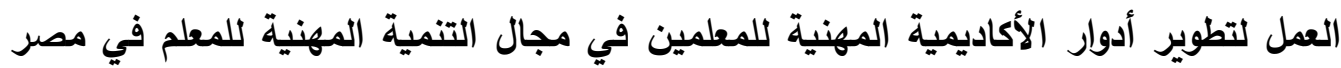

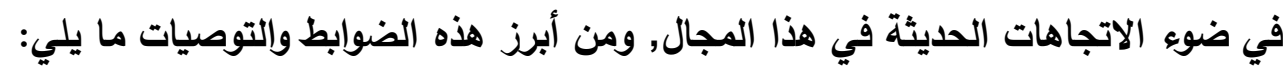

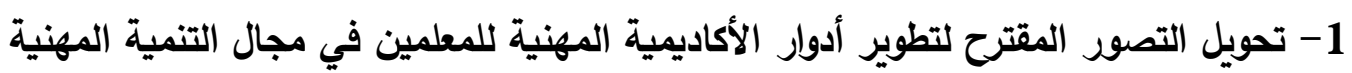

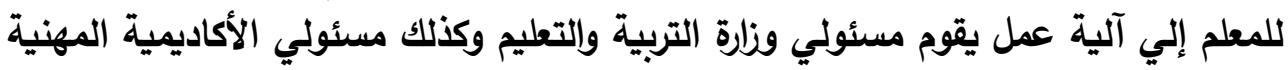

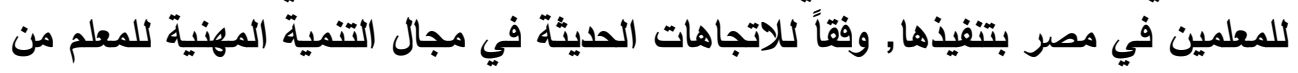
ناحية, ووفقاً للإمكانيات المجتمعية والاحتياجات المهنية الحالية للمعلمين من ناحية أخري. 2-2 اقتناع جميع العاملين بالأكاديمية المهنية للمعلمين, وكنلك الجهات التعليمية والتربوية المختلفة والمسئولين فيها, بأهمية تطوير منظومة العمل الحالية داخل الأكاديمية المهنية العية العيدية لمعلمين.

3- وجود خطة إستراتيجية مستقبلية للاستمرار في تطوير البنية التحتية والتكنولوجية, وتوفير

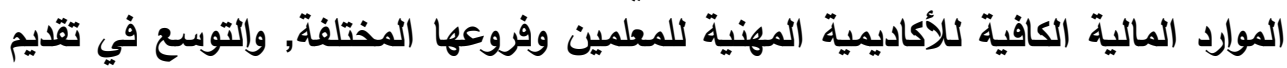

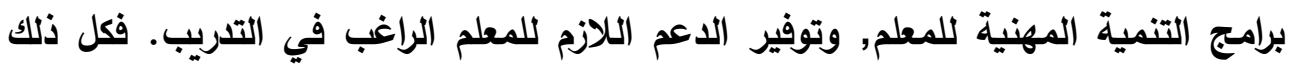
يساعد في التظلب علي العوائق التي تظهر أثناء تطوير نظام العمل داخل الأكاديمية المهنية لترية للمعلمين.

4- مراعاة المرحلية في تطوير منظومة العمل داخل الأكاديمية المهنية للمعلمين وأدوارها في

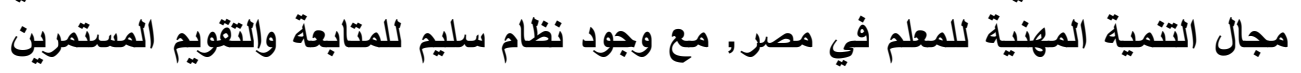
لمراحل التطوير وخاصة في بايتها.

5- التوسع في ربط نظام ترقية المعلمين باستمرارهم في الدارسة والبحث والتتمية المهنية, مما فالعادية

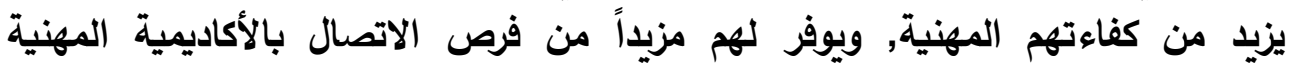

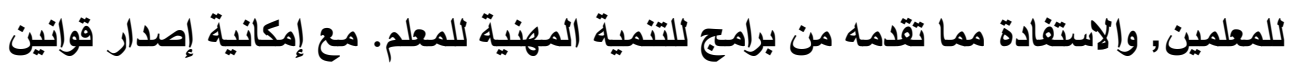
وتثريعات تلزم المعلمين بمواصلة النمو المهني.

6- إعطاء إدارة الأكاديمية المهنية للمعلمين وفروعها المختلفة مزيداً من الاستقلالية الإدارية والمالية التي تمكنهم من حسن استخدام الموارد والإمكانيات المتاحة.

7- مراجعة النظم والتجارب الدولية الناجحة في مجال تطوير أدوار الأكاديمية المهنية للمعلمين

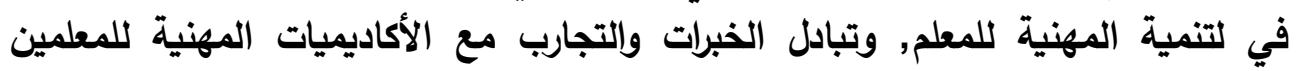


بالدول المتقدمة وكذلك بالدول التي تتشابه ظروفها ومقوماتها مع الظروف والمقومات

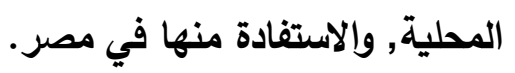

8- إجراء الأكاديمية المهنية للمعلمين دراسات ميدانية حديثة وتطبيق أدوات دقيقة لرصد الاحتياجات المهنية للمعلمين, فهذه الاحتياجات في حالة تغير مستمر , وتظهر بادية داستمرار

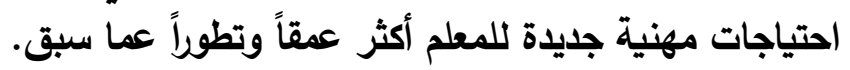

9- التأكيد علي دور الثراكة المجتمعية والتنسيق والتعاون مع بعض الهيئات والمؤسسات مثل:

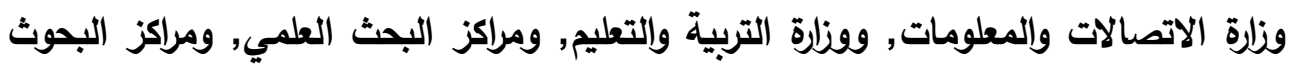

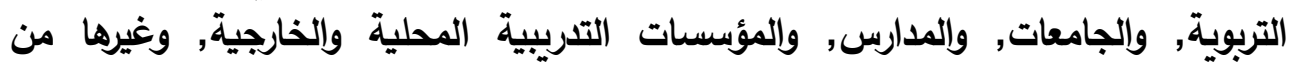
المؤسسات التي يمكن أن تقدم المساعدة للأكاديمية المهنية للمعلمين في تطوير أدوارها والتوسع في خدماتها في مجال التنمية المهنية للمعلم.

10- دعوة نقابة المهن التعليمية والنقابات الفرعية التابعة لها لتدعيم جهود الأكاديمية المهنية

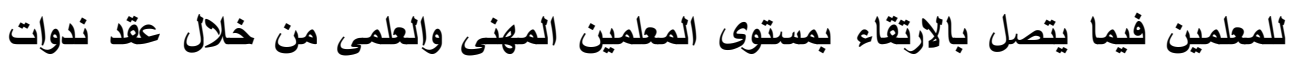
ولقاء ات عامة بالاشتراك مع الأكاديمية المهنية للمعلمين.

11- توجه الأكاديمية المهنية للمعلمين إلي استخدام نظم وآليات جديدة في التنمية المهنية

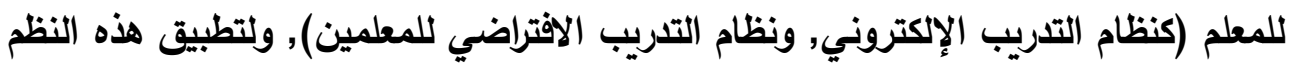

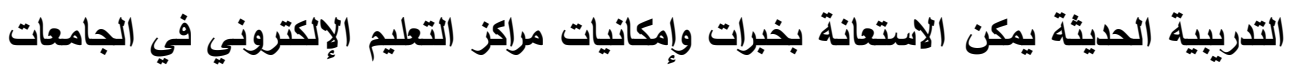
والمراكز العلمية.

12- تطبيق نظام يسمح للمعلمين بالاختيار بين برامج التنمية المهنية التي يرغبون في الحصول

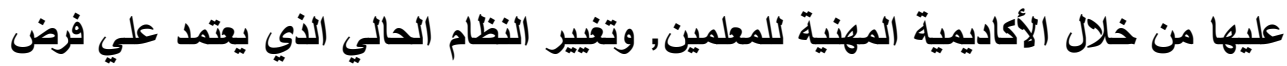

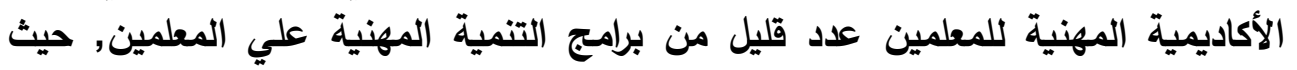

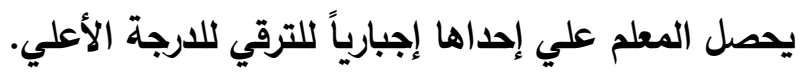
13- توحيد الجهود في مجال التنمية المهنية للمعلم بين كل من الأكاديمية المهنية للمعلمين

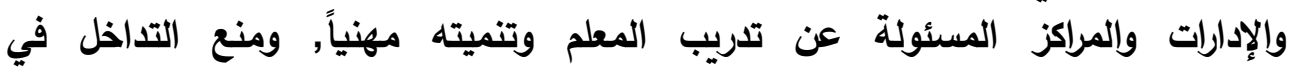
الاختصاصات والمهام فيما بينها.

14- وضع خطة مستقبلية (لمدة خمس سنوات علي الأكثر) تقوم من خلالها الأكاديمية المهنية

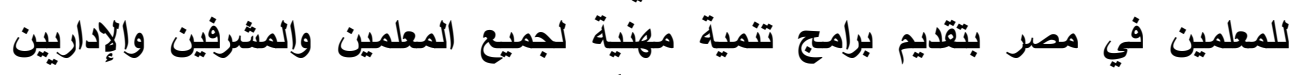

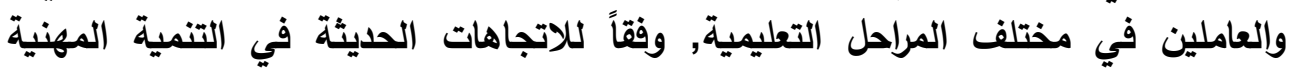
للمعلمين عالمياً. 
15- اتخاذ خطوات جادة في تطبيق نظام منح المعلم ترخيص بمزاولة المهنة, ووضع آليات

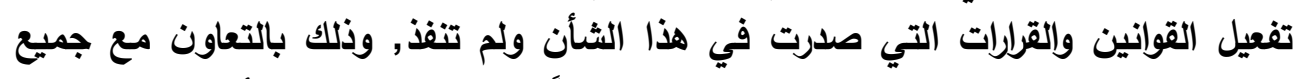
الجهات المسئولة عن إعداد المعلم وتنميته مهنياً (ككليات التربية والأكاديمية المئية المهنية

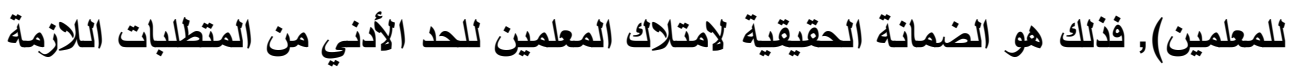

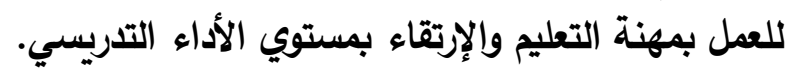

16- تحقيق معايير وآليات الجودة في منظومة العمل داخل الأكاديمية المهنية للمعلمين,

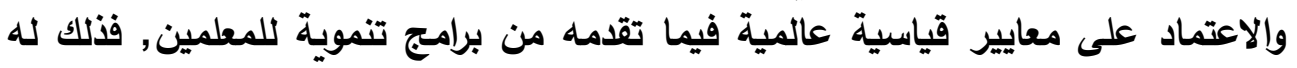

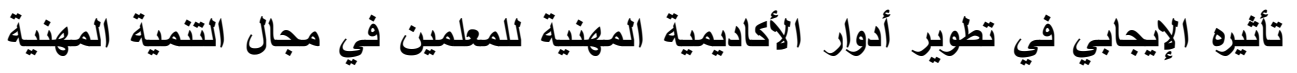
للمعلم. تاتبره

17- إدراك المسئولين بالأكاديمية المهنية للمعلمين أنه ليس بالتجهيزات المادية والتقنية وحدها

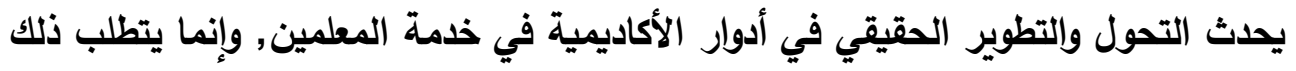
حدوث تغيير جوهري في الكيفية التي يتم بها تقديم برامج التنمية المهنية للمعلمين في ضوء الاتجاهات الحديثة في هذا المجال.

18- إجراء المزيـ من الاراسات حول الأكاديمية المهنية للمعلمين والمؤسسات المعنية بالتنمية المهنية للمعلم. وتتاولها في جوانب أخري لم تتناولها الدراسة الحانية الحالية.

وفي النهاية وبعد عرض التأصيل النظري في الدراسة الحالية, وما تبعه من دراسة

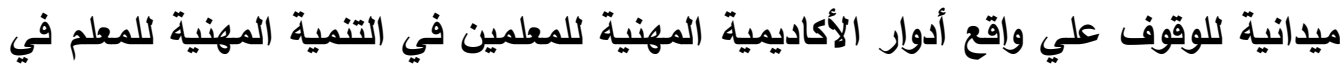

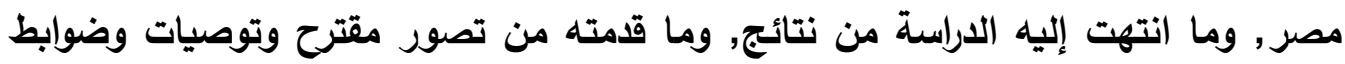
للتطبيق, تأمل الدراسة أن يكون ذلك التصور وتلك التوصيات والضوابط بمثابة حافز وموجه نتأه

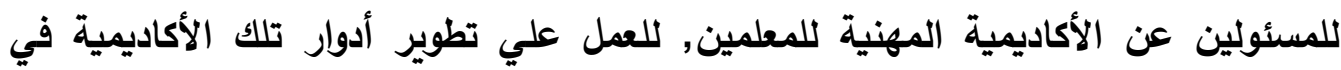

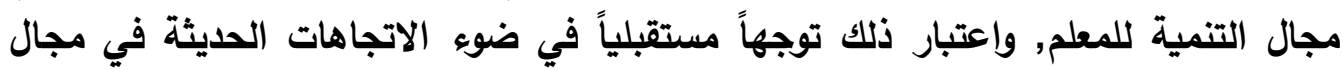
التنمية المهنية للمعلم. 
العدد (33) يناير 2013م

$$
\text { مر اجع الدراسة }
$$

$$
\text { أولاً: المر اجع العربية: }
$$

1- أسامة محمد سيد علي (2009م), التخطيط الإستراتيجي وجودة التعليم واعتماده, كفر الثيخ: دار العلم والإيمان للنشر والتوزيع.

2- أفراح محمد علي (2009)), "تطوير برامج التتمية المهنية للمعلمين علي ضواء معايير الجودة الثاملة", رسالة ماجستير , كلية التربية, جامعة عين شمس.

3- الأكاديمية المهنية للمعلمين (2012م), أهداف الأكاديمية المهنية للمعلمين, ورؤيتها ورئيل ورالتها, القاهرة: الأكاديمية المهنية للمعلمين. http://academy.moe.gov.eg/start.aspx. 4- الأكاديمية المهنية للمعلمين (2012م), اختصاصات الأكاديمية المهنية للمعلمين, القاهرة: الأكاديمية المهنية للمعلمين. http://academy.moe.gov.eg/start.aspx). 5- الأكاديمية المهنية للمعلمين (2012م), عناوين فروع الأكاديمية المهنية للمعلمين بالمحافظات,

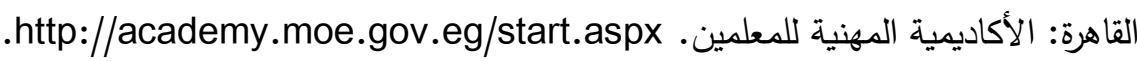

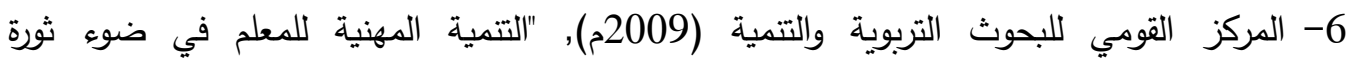
المعلومات", النشرة الدورية للمركز القومي للبحوث التربوية والتنمية, العدد (16), أكتوبر لتربة 2009 7- الهيئة القومية لضمان جودة التعليم والاعتماد (2008م), وثيقة معايير ضمان الجودة والاعتماد

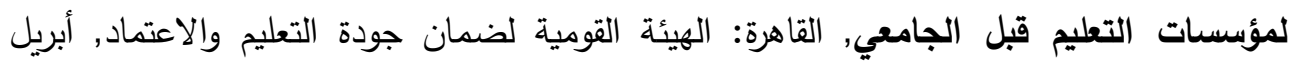
2008 8- آمال العرباوي وعبد السلام الثبراوي (2009م), "التتمية المهنية لمعلم التعليم الابتدائي في مصر

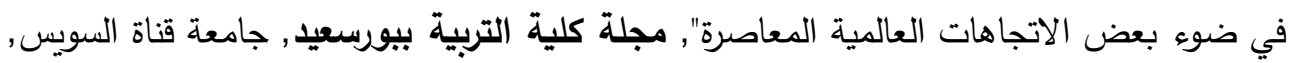
العدد (15), يناير 2009م. إيمان محمد أبو الفتوح (2006م) "مستحدثات مؤتمرات الفيديو التفاعلية وتخطيط الإفادة منها في $-9$ تدريب المعلمين أثناء الخدمة", رسالة ماجستير , كلية التربية, جامعة حلوان.

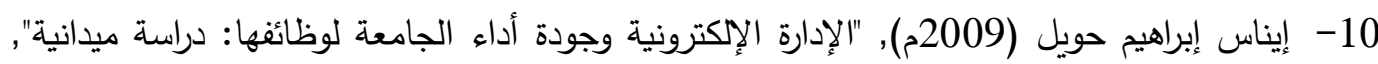

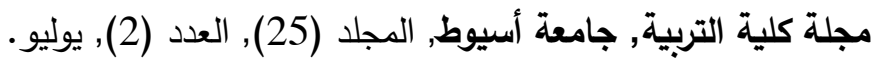
11- إيهاب مصطفي محمد (2007)), "إستراتيجية مقترحة لتطوير برامج التدريب بمراكز التطوير

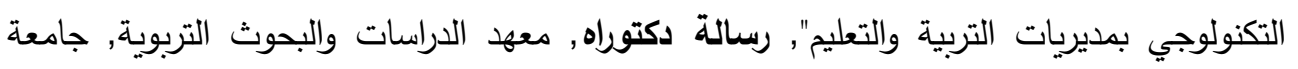
القاهرة.

12- بيومي محمد ضحاوي وسلامة عبد العظيم حسين (2009م), التنمية المهنية للمعلمين, القاهرة: دار الفكر العربي. 
13- ج· م. ع (2007)), القانون رقم (155) لسنة 2007م بتعديل بصض أحكام قانون التعليم

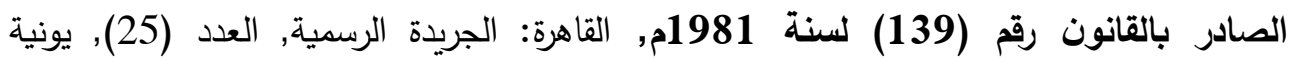
2007.

14- ج· م. ع (2008)), القرار الجمهوري رقم (129) لسنة 2008م بتنظيم الأكاديمية المهنية للمعلمين وتحديد اختصاصاتها, القاهرة: وزارة التربية والتعليم. 15- ج. ملتون سميث، الاليل إلي الإحصاء في التربية وعلم النفس، ترجمة: إبراهيم بسيوني عميرة،

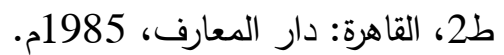
16- حسين يحيي وعبد الحميد الخطابي (2003)), "الاتجاهات الحديثة في إعداد المعلم في مراحل

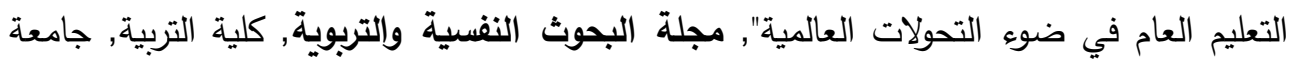
المنوفية, العدد (2), السنة (18). 17- خالد بن محمد العصيمي (2006), المتغيرات العالمية المعاصرة وأثرها في تكوين المعلم, اللقاء

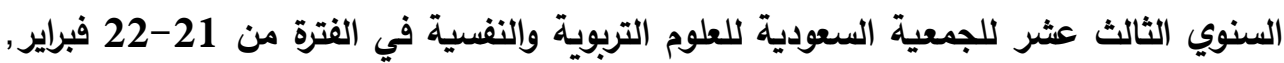
كلية التربية, جامعة الملك سعود. 18- خالد طه الأحمد (2005م), تكوين المعلمين من الإعداد إلي التدريب, الأمارات, العين: دار الكتاب

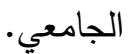
19- خالد محمد الزواوي (2008م), الجودة الثاملة في التعليم وأسواق العمل في الوطن العربي, القاهرة: مجموعة النيل العربية.

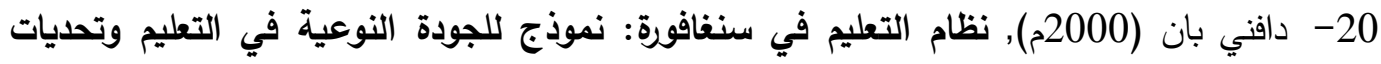
الألفية الثالثة, الإمارات: مركز الدراسات والبحوث الإستراتيجية. 21- دوجلاس ماكنتوش، الإحصاء للمعلمين، ترجمة: إبراهيم بسيوني عميرة، ط4، القاهرة: دار المعارف، الإستيرس، 1986 22- دينا علي أحمد (2007م), الاعتماد المهني للمعلم في ضوء خبرات بعض الدول المتقدمة, الإسكندرية: دار الجامعة الجديدة. 23- ديوبولد. ب. فان دالين، مناهج البحث في التربية وعلم النفس، ترجمة: محمد نبيل نوفل وآخرون،

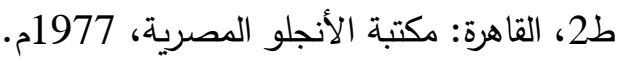
24- رجب علي عبيد العويسي (2007م), "القراءة عنصر أساسي في التتمية المهنية للمعلمين", مجلة

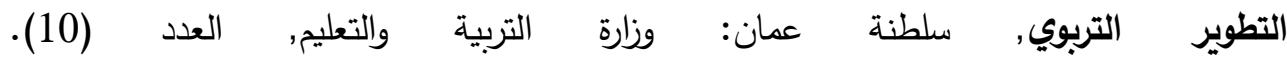
.http://www.moe.gov.com/moe/edif/ 25- رضا أحمد حافظ الأدغم (2003م), تظوير برنامج إعداد معلمي اللغة العربية في ضوء متطلبات العصر ومتغيراته, كلية التربية بدمياط, جامعة المنصورة. 
26- رفعت عمر عزوز (2007)), "تصور مقترح لتطوير كلية التربية بالعري في ضوء ضمان الجودة

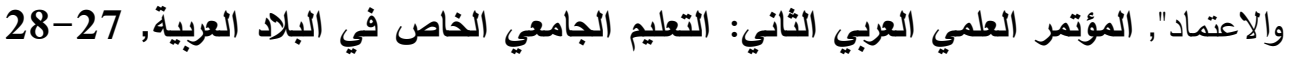
مارس 2007م, أكاديمية البحث العمي والتكنولوجيا بالمشاركة مع جمعية الثقافة من أجل التتمية. 27- روث. ج. كين (2002م), معلموا القرن الحادي والعشرين, مجلة مستقبليات, العدد (123),

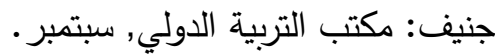

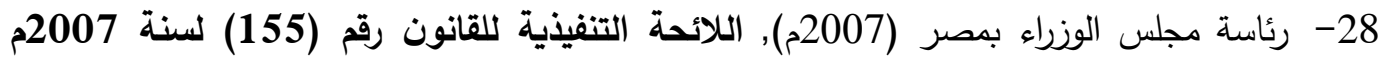
بقرار رئيس مجلس الوزراء رقم (2840) لسنة 2007م, القاهرة: رئاسة مجلس الوزراء .http://academy.moe.gov.eg/directors.aspx 29- رئاسة مجلس الوزراء بمصر (2008م), قرار رئيس مجلس الوزراء رقم (1322) لسنة 2008م

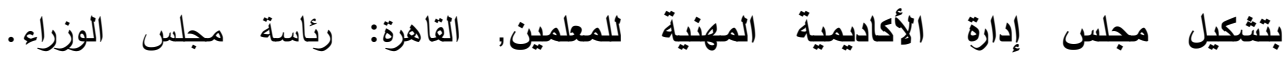
.http://academy.moe.gov.eg/directors.aspx 30- ريشارد برسون وكمبرلي براون (2005م), المعلم: ممارس متأمل وباحث إجرائي, ترجمة: علي رشيد

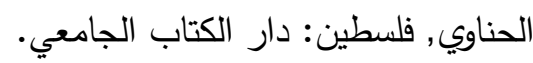
31- سكينة علي (2008م), أساليب التنمية المهنية للمعلم, الكويت: وزارة التربية. 32- سميحة مخلوف (2007م), "الإرشاد الأكاديمي كمخل من مداخل التتمية المهنية للمعلم المبتدئ",

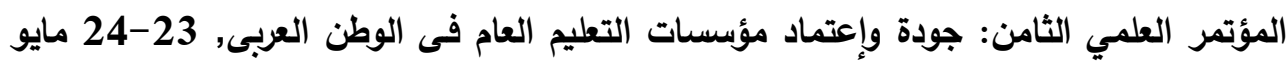
2007م , كلية التربية, جامعة الفيوم. 33- سوزان ك. سكلافاني (2011), ثقافات للأداء المتميز في مدارس سنغافورة وفنلندا. .http://www.al-khut.com/forum/showthread.php?t=722 34- شيماء محمد ربيع (2010م) "واقع برامج التتمية المهنية عن بُعد لمعلمي الحلقة الثانية من التعليم الأساسي بمحافظة المنيا", رسالة ماجستير , كلية التربية, جامعة المنيا. 35- صلاح عبد السميع عبد الرازق (2002م), "تصور مقترح لتطوير برامج إعداد معلم التاريخ بكليات

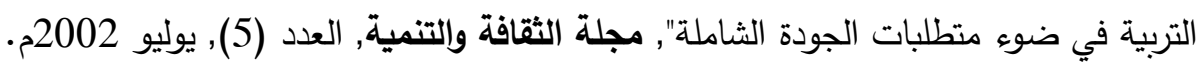
36- طارق حسن عبد الحليم (2008م), التنمية المهنية للمعلمين في مصر علي ضوه فاء الخبرة اليابانية

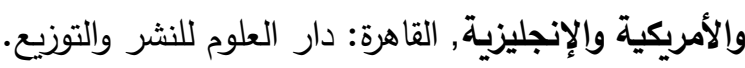
37- طارق عبد الرؤوف عامر (2008م), إعداد معلم المستقبل, القاهرة: الدار العالمية للنشر والتوزيع.

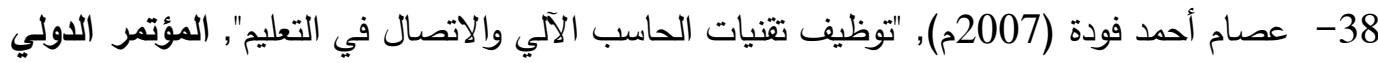
الأول لاستخدام تكنولوجيا المعلومات والاتصال لتطوير التعليم الجامعي, أبريل 2007 2007م, القاهرة:

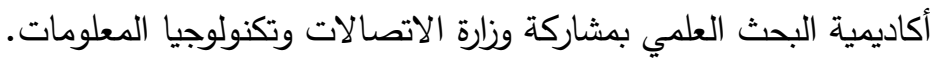


العدد (33) يناير 2013م

39- عطا أبو جبين (2008م), "دور البحث الإجرائي في تتمية مهارات التدريس", مجلة التطوير

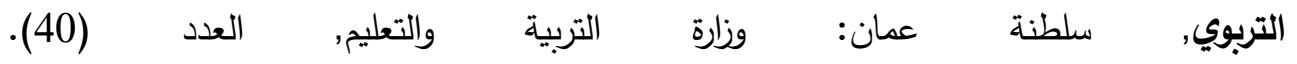
.http://www.moe.gov.com/moe/edif/

40- عقيل محمود عقيل (2003م), "متطلبات المدرسة الفعالة كمدخل لتطوير التعليم العام في مصر",

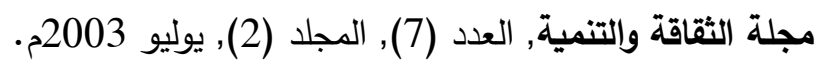

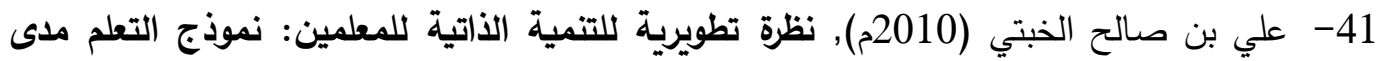
www.abhatoo.net.ma, للمعلمين.

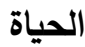
http://www.google.com.eg/search?hl=ar\&site=\&source 42- علي راشد (2002م), خصائص المعلم العصري وأدواره والإثراف عليه وتدريبه, القاهرة: دار الفكر

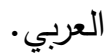

43- عماد محمد عطية (2006م), "تطوير منظومة تكوين المعلم في ضوء أدواره المستقبلية", مجلة كلية التربية بأسوان, جامعة جنوب الوادي, العدد (20), ديسمبر 2006 2006.

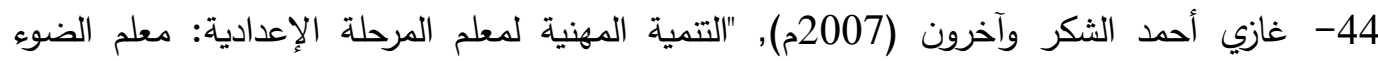
نموذجاً", المؤتمر التربوي الحادي والعشرون: التعليم الإعدادي تطوير وطموح من أجل المستقبل 24-24 يناير 2007م, مملكة البحرين: وزارة التربية والتعليم.

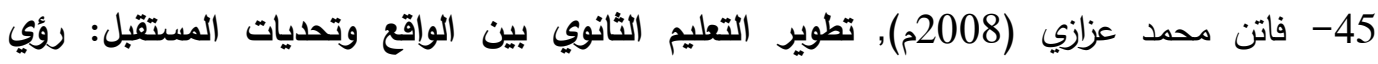
وتوجهات إستراتيجية, القاهرة: المجموعة العربية للتدريب والنشر . 46- فؤاد البهي السيد، علم النفس الإحصائي وقياس العقل البشري، ط3، القاهرة: دار الفكر العربي، 1979م 47- فوزي الثربيني وعزت الطناوي (2001م), مداخل عالمية في تطوير المناهج التعليمية في ضوي الماءي تحديات القرن الحادي والعشرون, القاهرة: مكتبة الأنجلو المصرية.

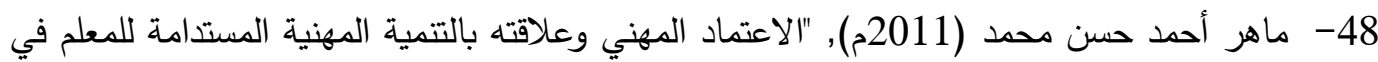
عصر التدفق المعرفي", مجلة كلية التربية, جامعة أسيوط, المجلد (27), العدد (2), الجزء (2),

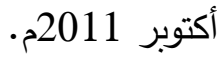
49- ماهر أحمد محمود (2005م), "تطوير سياسة وبرامج تدريب معلمي التعليم الأساسي أثناء الخدمة في

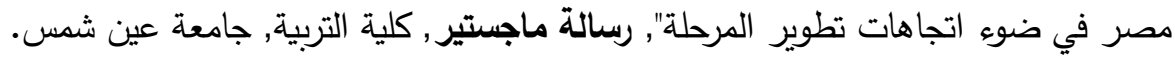
50- ماهر إسماعيل صبري (2004م), التدريس: مبادئه ومهاراته, الرياض: مكتبة الرشد.

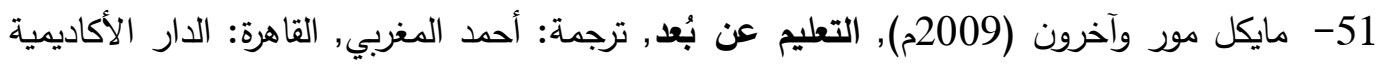

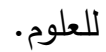


52- محمد أحمد إسماعيل (2008م), "برامج التتمية المهنية لمعلمي التعليم الثانوي في ضوء مفاهيم

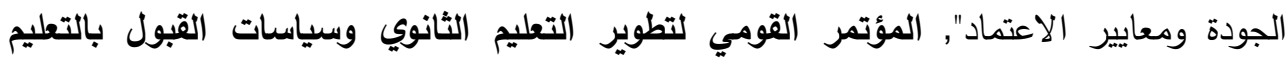

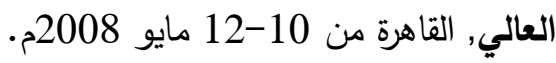
53- محمد الأصمعي محروس (2005م), الإصلاح التربوي والثراكة المجتمعية المعاصرة من المفاهيم إلي التطبيق, القاهرة: دار الفجر للنشر والتوزيع.

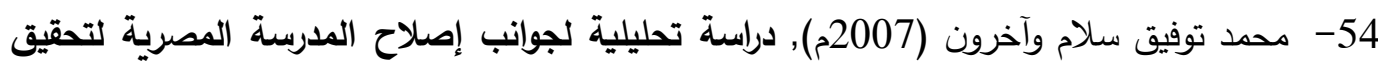
الجودة والاعتماد, القاهرة: المركز القومي للبحوث التربوية والتتمية.

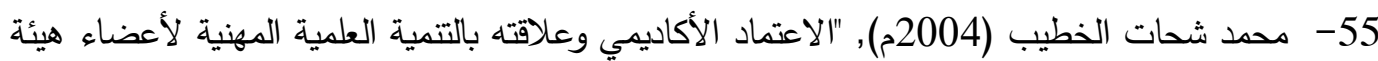

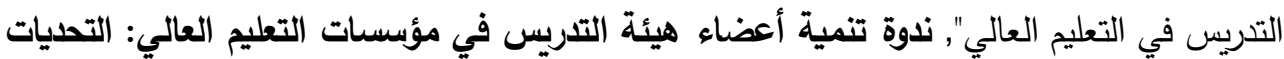

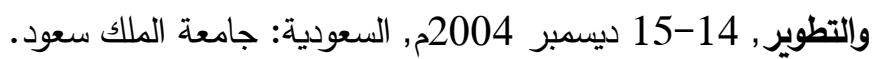

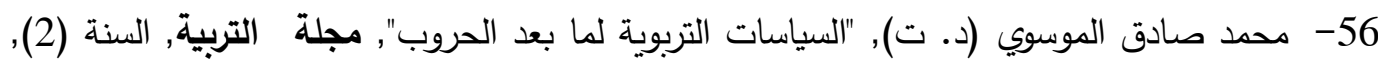
العدد (6), وزارة التربية الكويت. 57- محمد عبد الخالق مدبولي (2002م), التنمية المهنية للمعلمين: الاتجاهات المعاصرة, المداخل, الإستراتيجيات, العين: دار الكتاب الجامعي. 58- محمد عبد الرازق إبراهيم (2003م), منظومة تكوين المعلم في ضوء داءئ معايير الجودة الثاملة, الأردن: دار الفكر للطباعة والنشر والتوزيع. 59- محمد كتش (2001)), فلسفة إعداد المعلم في ضوء التحديات المعاصرة, القاهرة: مركز الكتاب للنشر 60- محمود عبد السميع أحمد وآخرون (2011)), "سيناريوهات تلبية الاحتياجات المهنية لمعلمي

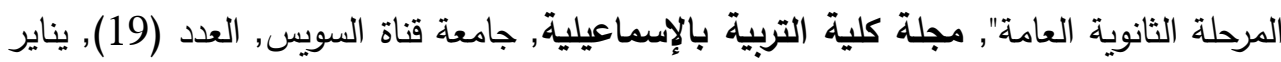
2011 61- محمود قمبر وآخرون (2004م), التعليم الابتدائي: نظمه وتطوره ومثكلاته وتجديداته, الكويت: الجامعة العربية المفتوحة. 62- مكتب التربية العربي لدول الخليج (2004)), الاتجاهات العامة للإصلاح التربوي في العالم, التربة الرياض: مكتب التربية العربي لدول الخليج.

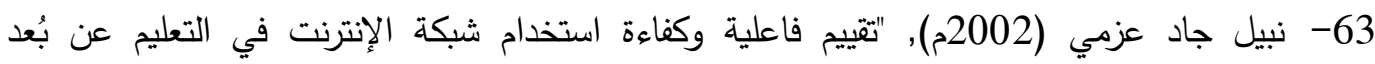

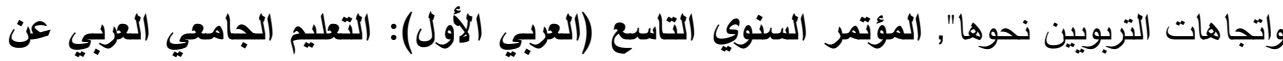

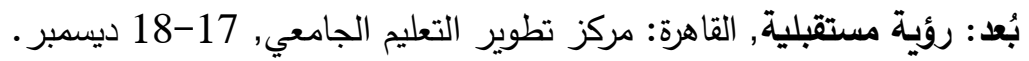

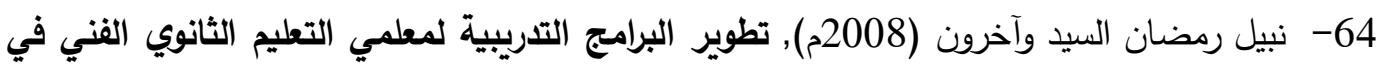
ضوء معايير الجودة, القاهرة: المركز القومي للبحوث التربوية والتنمية. 
65- نبيل سعد خليل (2005م), التعليم والتنمية: دراسة في النموذج الصيني, القاهرة: دار ومكتبة الإسراء للطبع والنشر والتوزيع.

66- نبيل سعد خليل (2009م), الإدارة المدرسية الحديثة في ضوء الفكر الإداري المعاصر, القاهرة: دار الفجر للنشر والتوزيع.

67- نبيل سعد خليل, (2008م), المنظومة التعليمية بين التقليدية والافتراضية, كلية التربية, جامعة سوهاج.

68- نجم الدين نصر أحمد (2004م), "التتمية المهنية المستدامة للمعلمين أثثاء الخدمة في مواجهة

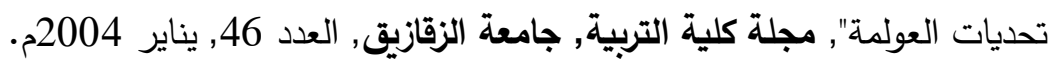
69- نشوة سعد محمد (2009م), "التدريب عن بعد لمعلمي المرحلة الابتدائية بمحافظة الإسماعيلية: دراسة تقويمية", رسالة ماجستير , كلية التربية, جامعة الزقازيق.

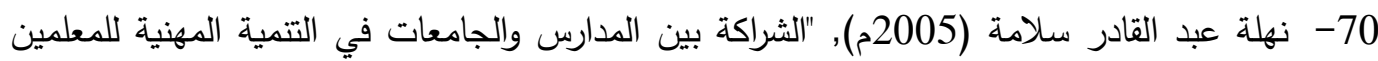

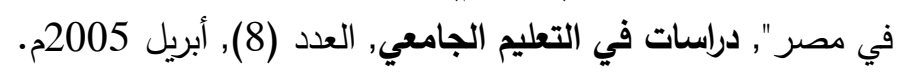
71- هادي أحمد الفراجي (2008م), "البحث التربوي", مجلة التطوير التربوي, سلطنة عمان: التعان وزارة

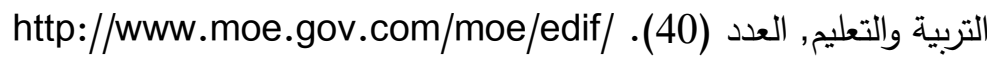
72- وزارة التربية بدولة الكويت (2007م), المؤتمر الوطني لتطوير التعليم: التنمية المهنية والتدريب أثناء الخدمة, نوفمبر 2007م بـ الكويت: وزارة التربية. 73- وزارة التربية بدولة الكويت (2008م), أساليب التنمية المهنية للمعلمين, الكويت: وزارة التربية, إدارة التوجيه الفني العام. 74- وزارة التربية والتعليم (2000م), القرار الوزاري رقم (254) لسنة 2000م بإنشاء وحدات التدريب بالمدارس, القاهرة: وزارة التربية والتعليم.

75- وزارة التربية والتعليم (2002م), القرار الوزاري رقم (48) لسنة 2002م الخاص بتعديل اسم وحدة التباد التدريب بالمدرسة, القاهرة: وزارة التربية والتعليم.

76- وزارة التربية والتعليم (2003م), "ورشة عمل حول المستويات التعليمية المعيارية القومية", مجلة التحاية التربية والتعليم, العدد (28), القاهرة: المركز القومي للبحوث التربة التربوية والتتمية.

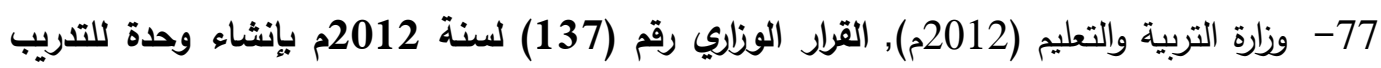
والجودة, القاهرة: وزارة التربية والتعليم.

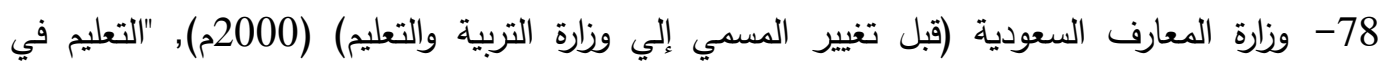

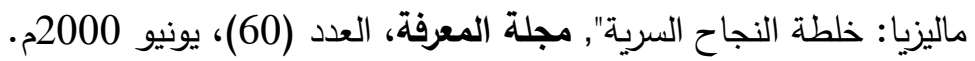
79- وزارة التربية والتعليم السعودية (2007م), تقرير عن التعليم في جمهورية كوريا الجنوبية, المملكة العربية السعودية: وزارة التربية والتعليم. http://www.moe.gov.sa/Pages/Default.aspx. 
80- يحيى مصطفى كمال الدين (2012م), نظم اعتماد برامج التنمية المهنية للمعلمين. http://elearn.shams.edu.eg/edu/elec-c/D-mehani/chapter1.htm.

81- يوسف سيد محمود (2003)), "المواجهات الفكرية لنظام إعداد المعلم ومدي توافقها مع بعض أدواره

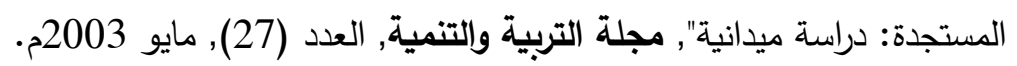

$$
\text { ثانياً: المر اجع الأجنبية: }
$$

82- Academy for Teaching and Learning Leadership (2012), Activities of Professional Development of Teachers. Indianapolis: Marian University. (http://www.marian.edu/academy/Pages/default.aspx).

83- Alan, M. V. (2009), A Changing Concept of Professional Development of Teachers, London: Rutledge.

84- American Academy of Teachers of Singing "AATS" (2012), Programmers of Training in Education. U.S.A.: American Academy of Teachers of Singing. (http://www.americanacademyofteachersofsinging.org/).

85- American Academy for Teacher Excellence (2012), Programmers of Professional Development. U. S. A.: The University of Texas at San Antonio. (https://ate.utsa.edu/about-us).

86- Anderson, K. and Others (2007), Reviewing and Refining: A Professional Education Units Journey Toward Accreditation, Teacher Education and Special Education, Vol. 30, No. 2, Spring. (http://www. Eric.ae.net.)

87- Antone, P. E. (2011), Professional Accreditation for Teachers. (www.eric.digest).

88- Australia Ministry of Education (2012), Academics of Teacher in Australia. Australia: Ministry of Education. (http://australia.gov.au/).

89- Australia, National Institute for Quality Teaching and School Leadership (NIQTSL) (2004), Implementation Strategy Report, March 2004. (http://www.allenconsult.com.au/NIQTSL).

90- Barry, B. and Others (2004), Professional Development and Leisure Time, U.S.A.: Indiana University.

91- Barth, R. S., \& Guest, L. S. (2000). Improving Schools from Within: Teachers, Parents, and Principals Can Make, How to Use Action, Research in: The Self-Renewing School, Virginia: Association for Supervision and Curriculum Development.

92- Bing, L. (2008), Current Innovation in Teacher Education in the Asia Pacific Region, China: Institute for Educational Research, Beijing Normal University. 
93- Bridges, D. (2003), Schools Based Teacher Education, In: Bridges, D., and Kerry, T. (eds), Developing Teachers Professionally, London: Rutledge.

94- Brown, J. W. and Others (2002), Administration Education Media: Instructional Technology and Library Services, 3 rd. ed., New York: McGraw- Hill Book Co.

95- Caplan, D. (2004), The Development of Online Courses, In: Anderson, T. \& Elloumi, F. (Editors), Theory and Practice of Online Learning, Canada: Athabasca University.

96- Carin, A. (2009), Teaching Modern Science, $8^{\text {th }}$ ed., New Jersey: Merrill Prentice Hall, Inc.

97- Chan, F. (2006), ICT in Malaysia Schools Policy and Strategies, Educational Technology Division, Malaysia: Ministry of Education. (htm://H:/New/folder/ ICT in Malaysian Schools Policy and Strategy).

98- Chizuko, M. (2010), A comparative Study of Teacher Education in Japan, Korea and Australia, Australia: The University of Queensland. (http://www.paaljapan.org/resources/proceeding/ PAAL8/pdf/pdf024.pdf).

99- Chuing, M. (2011), Teacher Professional Development in Japan, Tokyo: MPNS Press. (http://www.schooler.google.com).

100- Creyner, N. T. (2010), Action Research for Teachers, 3rd. ed., U.S.A.: Indiana University.

101- Daun, H. (2002), Education Restructuring in The Context of Globalization and National Policy, New York: Rutledge Flamer.

102- Deana, H. N. (2011), Accreditation Vacating in South Africa, International Development in Assuring Quality in Higher Education, Edited by: Alma Craft, London: The Flamer Press.

103- Department of Education (2010), Excellence and Accountability in Teaching, U.S.A., Washington: Department of Education.

104- Garrison, B. and Others (2004), Student Role Adjustment in Online Communities of Inquiry: Model and Instrument Validation, Journal of Asynchronous Learning Network, Vol. 8, No. 2.

105- Grevile, R. (2002), The Management of Distance Learning Systems, Paris: International Institute for Educational Planning, UNESCO.

106- Haqq, I. A. (2008), The Nature of Professional Development Schools, Eric Clearing House on Teacher Education, Washington, 2008. (http//www.eric.ed.gov).

107- Harrison, M. E. (2010), Professional Accreditation in Education, New York: MGH Book Company. 
108- Helman, L. R. and Others (2012), Professional Development of Teachers in Australian, Australian: Department of Employment and Training in Ministry of Education. (www.googleschooler).

109- Henery, N. J. and Others (2010), Professional Development and Teachers, New York: Harvard University.

110- Hung, C. C. (2012), Professional Development Programmers and Courses, Singapore: The National Institute of Education (NIE). (http://www.nie.edu.sg/studynie/professional-development-programmesand-courses).

111- Idris, N. and Others (2007), The Professional Preparation of Malaysian Teachers, Eurasia Journal of Mathematics, Science and Technology Education, Vol. 3, No. 2. (http://www.ejmest.com/v3n2/).

112- James, H. D. (2008)), Maryland Teacher Professional Development Planning Guide, U.S.A.: The Maryland State Department of Education. www.marylandpublicschools.org.

113- Jamil, H. and Others (2010), Teacher Professional Development in Malaysian, Issues and Challenges, Malaysia: Universities Sains. (http//:home.hiroshima-u.ac.jp/cice/publications/sosho4_2-08.pdf).

114- Janet, K. \& Grik, F. (2004), Philosophy and Purposes of Distance Education, U.S.A: American Distance Education Consortium (ADEC). (http://www.google.com.eg/\#hl=ar\&source= hp\&q=Janet).

115- Japan Ministry of Education (2010), Professional Development of Teachers, Tokyo: Japan Ministry of Education. (http://www.mext.go.jp/english/).

116- Johnson, B. (2002), Teacher as Researcher, Eric Digest, Washington: Eric Clearing House on Teacher Education, ED 355203. (http://www.eric.ed.gov/).

117- Jose, S. (2001), Building a Typology for the Comparing Analysis of Virtual Universities Worldwide, Paris: UNESCO.

118- Kalolema, M. R. (2010), Professional Development and Teachers of Secondary Schools, New York: Clark Press, Inc.

119- The Korean Federation of Teachers' Associations (KFTA) (2012), Good Education Good Teachers, Korea: The Korean Federation of Teachers' Associations. (http://eng.kfta.or.kr/).

120- Loucks, S. and Others (2001), Choose Effective Approaches to Staff Development, Washington: The Association for Supervision and Curriculum Development.

121- Maikel, S., L. (2011), E-Learning and Professional Development of Teachers, U.S.A.: Center of ETRC. (http//:www.eulc.edu.org) 
122- Malaysian Qualification Agency "MQA" (2011), Teachers and professional Development, Malaysia: Malaysian Qualification Agency. (http://www.mqa.gov.my/).

123- Mandes, G. N. (2011), A Professional Development Context, Paper Presented at the Annual Meeting of the American Educational Research Association. (http://oro.open.ac.uk/view/research.html).

124- Marke, H. K. (2010), Professional Development Schools, New York: McGraw- Hill Book Co.

125- Marten, B. K. (2010), Professional Teachers Development and the Accreditation, Washington: Brookings Institution Press.

126- Middleton, A. (2009), Good Practice in School Based Training for Governing Bodies, London: George's R.C. (http://www.docstoc.com/docs/26293225/Good-Practice-in-SchoolBased-Training-for-Governing-Bodies).

127- Ministry of Education in Korea, Science and Technology (2011), Educational Development of Teachers, Korea: Ministry of Education, Science and Technology. (http://english.mest.go.kr/enMain.do).

128- Ministry of Education in Malaysia (2011), Aims of Professional Development of Teachers, Malaysia: Ministry of Education. (http://www.moe.gov.my/?lang=en).

129- Minnick, C. (2009), Professional Development Schools, New York: Florida Office of Clinical Partnerships. (http//www.coe.fsu.edu/student_teaching/pds.htm).

130- Morrison, B. J. (2005), Teacher Training in China and the Role of Teaching Practice, China: Beijing, Tsing Hua University.

131- NACTE, Nevada Association for Career and Technical Education (2011), Professional Development of Teachers. http://www.nacteonline.org.

132- Palmer, S. (2003), Professional Development Schools. (http//www.wsap.uwyo.edu/PDS/).

133- Peterman, T. (2000), "Elements of Success at Traditional- Virtual University", Journal of Academic Librarianship, Vol. 26, Jan.

134- Prean, L. D. (2010), The Impact of Professional Development Actives on Teachers, Detroit: DCPGU.

135- Ptisher R. \& Wideen, F. (2006), Research in Teacher Education International Perspectives, U.S.A: The Flamer press.

136- Republic of Singapore (2009), Annual Survey On Infocomm Industry For 2008, Infocomm Development Authority of Singapore, June. (http://www.ida.gov.sg/doc/Publications/ Publications_Level2.pdf). 


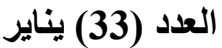

137- Richard, I. and Others (2007), Comparative Study of Teacher Preparation and Qualifications in Six Nations. Graduate School of Education Publications, University of Pennsylvania. (http://www.cpre.org/images/stories/cpre_pdfs/RB47.pdf).

138- Sebba, J. (2008), What Work in Innovation in Education: Case Study, Australia, Queensland. (http//: www.oecd.org.dataoecd).

139- Sentea, D. Y. (2007), Teachers Professional Development in Schools, New Jersey: Department of Education.

140- Shane, A. \& Docherty, P. (2003), Learning By Design Building Sustainable Organization, Oxford: Blackwell Publishing Ltd.

141- Smith, R. A. (2011), Patterns and Models of Professional Development of Teachers, Illinois: Skylight Publishing Inc.

142- Stefen, F., A. (2010), Collaboration in Professional Development of Teacher in America, U.S.A.: Michigan University.

143- Stella, V. (2012), Accreditation of Professional Development Programs, London: George Allen and Lin Win in Service.

144- Sullivan, P. \& Mosley, J. (2001), Promoting Professional Qualities of Teachers. (http://www.accrediting.com).

145- Suzuke, N. (2008), Professional Development and Teaching, Construction Education in Japan. (http://www.schooler.google.com).

146- Teacher Training Agency (2005), The Use of Information and Communication Technology, London: Teacher Training Agency. (http://www.legislation.gov.uk/uksi/2003/2564/contents/made).

147- Teacher Training Agency (2012), Types of Professional Development Programs, London: Teacher Training Agency. (http://www.legislation.gov.uk/uksi/2003/2564/contents/made).

148- Tebbano, R. S. (2011), The Effect of Online and Distance Professional Development of Teachers, European Center for the Development of Vocational Training. (http//:www.eulc.edu.org).

149- The Academy of Singapore Teachers "AST" (2012), Professional Development programmers, Singapore: The Academy of Singapore Teachers. (http://www.academyofsingaporeteachers.moe.gov.?).

150- The American Federation of Teachers (2010), American Teacher. U. S. A.: The American Federation of Teachers. (http://www.aft.org/newspubs/periodicals/at/index.cfm).

151- The Holmes Group (2008), Tomorrow's Teachers, A Report of the Holmes Group, U.S.A.: The Holmes Group Inc. 
152- The Holmes Partnership (2008), History and Work, Penn State's: College of Education. (http//www.holmespartnership.org.history.html).

153- The National Center for Teachers Development "NCTD" (2012), Functions and Training Data, Japan: NCTD. (http://www.nctd.go.jp/X_sosiki/index).

154- Timperley, H. (2008), Teacher Professional Learning and Development, U.S.A.: The International Academy of Education.

155- Training and Development Agency for Schools "TDA" (2009), Timescale and Process, England: Training and Development Agency for Schools, June. (http://tda.gov.uk/partners/funding).

156- Vasumathi, T. (2009), "Challengers for Professional Development of Mother Teacher Educators in Information Communication Technologies, Online Submission", Paper Presented at the Annual Meeting of the Indian Association of Teacher Educators (IATE), Dec 2009. (www.Eric, Ed508358.)

157- Walachia, T. F. (2010), Knowledge Base for Professional Development of Teacher Educator, New York: Plenum Press.

158- Wen, D. \& Hiltz, S. (2004), Predicting from Asynchronous Online Discussions, Journal of Asynchronous Learning Network, Vol. 4, No. 2.

159- Wendy, S. (2002), The Impact of Professional Development on the Education of Urban Student, New York: U.S. Development of Education. (http/www.ericfacility.net/databases/eric_digest/ed).

160- Zheng, L. \& Smaldino, S. (2003), "Key Instructional Design Elements For Distance Education", Quarterly Review of Distance Education, An Official Journal of the Association for Educational Communications and Technology, Nova South-Eastern University, Vol. 4, No. 2. 